National Library

of Canada

Acquisitions and

Bibliographic Services Branch

395 Wellington Street

Ottawa. Ontano

KIAONA
Bibliothèque nationale

du Canada

Direction des acquisitions ef

des services bibliographiques

395, rue Weilington

Ollawa (Ontario)

KIAON4

NOTICE

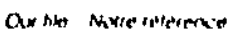

AVIS

The quality of this microform is heavily dependent upon the quality of the original thesis submitted for microfilming. Every effort has been made to ensure the highest quality of reproduction possible.

If pages are missing, contact the university which granted the degree.

Some pages may have indistinct print especially if the original pages were typed with a poor typewriter ribbon or if the university sent us an inferior photocopy.
La qualité de cette microforme dépend grandement de la qualité de la thèse soumise au microfilmage. Nous avons tout fait pour assurer une qualité supérieure de reproduction.

S'il manque des pages, veuillez communiquer avec l'université qui a conféré le grade.

La qualité d'impression de certaines pages peut laisser à désirer, surtout si les pages originales ont été dactylographiées à l'aide d'un ruban usé ou si l'université nous a fait parvenir une photocopie de qualité inférieure.

La reproduction, même partielle, de cette microforme est soumise à la Loi canadienne sur le droit d'auteur, SRC 1970, c. C-30, et ses amendements subséquents.
Reproduction in full or in part of this microform is governed by the Canadian Copyright Act, R.S.C. 1970, C. C-30, and subsequent amendments. 


\title{
Measurement of Residence Time Distribution by Laser Absorption Spectroscopy
}

\author{
Written \\ by \\ Patrice Nadeau \\ Department of Chemical Engineering \\ McGill University, Montreal
}

\begin{abstract}
May 1995
A thesis submitted to the Faculty of Graduate Studies and Research in partial fulfillment of the requirements of the degree of Masters of Engineering
\end{abstract}

$1995^{\circ}$ Patrice Nadeau 
. National Library

of Canada

Acquisitions and

Bibliographic Services Branch

395 Wellington Street

Ottawa, Ontario

KIA ONA

\section{Bibliotheque nationale}

du Canada

Direction des acquisitions et

des services bibliographiques

395, rue Weilinglon

Oltawa (Ontatio)
THE AUTHOR HAS GRANTED AN IRREVOCABLE NON-EXCLUSIVE LICENCE ALLOWING THE NATIONAL LIBRARY OF CANADA TO REPRODUCE, LOAN, DISTRIBUTE OR SELL COPIES OF HIS/HER THESIS BY ANY MEANS AND IN ANY FORM OR FORMAT, MAKING THIS THESIS AVAILABLE TO INTERESTED PERSONS.
L'AUTEUR A ACCORDE UNE LICENCE IRREVOCABLE ET NON EXCLUSIVE PERMETTANT A LA BIBLIOTHEQUE NATIONALE DU CANADA DE REPRODUIRE, PRETER, DISTRIBUER OU VENDRE DES COPIES DE SA THESE DE QUELQUE MANIERE ET SOUS QUELQUE FORME QUE CE SOIT POUR METTRE DES EXEMPLAIRES DE CETTE THESE A LA DISPOSITION DES PERSONNE INTERESSEES.
THE AUTHOR RETAINS OWNERSHIP OF THE COPYRIGHT IN HIS/HER THESIS. NEITHER THE THESIS NOR SUBSTANTIAL EXTRACTS FROM IT MAY BE PRINTED OR OTHERWISE REPRODUCED WITHOUT HIS/HER PERMISSION.
L'AUTEUR CONSERVE LA PROPRIETE DU DROIT D'AUTEUR QUI PROTEGE SA THESE. NI LA THESE NI DES EXTRAITS SUBSTANTIELS DE CELLECI NE DOIVENT ETRE IMPRIMES OU AUTREMENT REPRODUITS SANS SON AUTORISATION. 


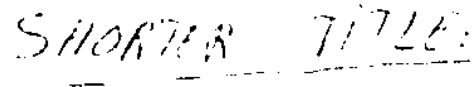

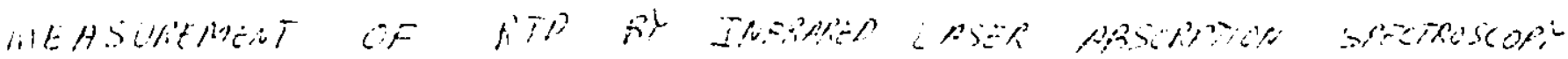




\begin{abstract}
The residence time distribution was measured at ambient temperature and pressure in a tubular reactor with radial injection at very short space times (0.04-0.7 s). A technique using infrared laser absorption spectroscopy was developed and used to provide the required rapid response for concentration measurements. The equipment comprised an infrared He-Ne laser emitting at a wavelength of $3.39 \mu \mathrm{m}$ and a lead selenide detector. Methane, which absorbs strongly at the laser wavelength, was used as the tracer. The absorption of the laser light was related to the tracer concentration by Beer-Lambert law. The laser beam passed through the diameter of the reactor at different axial locations. The residence time distributions were obtained from the response to quasi-step inputs. An axial dispersion model was used to describe the reactor.
\end{abstract}




\section{Résumé}

La distribution du temps de résidence a été mesurée à température et pression ambiante dans un réacteur tubulaire à injection radiale pour des temps de résidence moyens très coutts (0.04$0.7 \mathrm{~s}$ ). Une technique utilisant la spectroscopie infrarouge par absorption laser a été utilisée pour développer un instrument capable de détecter avec un temps de réponse très court la concentration d'un traceur. Cet instrument était composé d'un laser He-Ne infrarouge émettant à une longueur d'onde de $3.39 \mu \mathrm{m}$ et d'un détecteır au sélénure de plomb. Le traceur utilisé était le méthane, un gaz qui absorbe fortement la lumière du laser infrarouge. L'absorption du rayon laser était associée à la concentration du traceur par la loi de BeerLambert. Le rayon laser traversait le réacteur par son diamètre à différentes positions axiales. La distribution du temps de résidence a été obtenue à partir de la réponse du système à un stimuli en forme de quasi marche ("quasi-step"). Un modèle à dispersion axiale a été utilisé pour décrire le réacteur. 


\section{Acknowledgments}

This Master's research would not have been possible without the contribution of many people. First, the precious help from my two supervisors. Dr. Berk and Dr. Munz, need to be recognized. Their support and suggestions made this work realizable. I particularly recognize their availability; a quality not easily found in a competitive domain such as engineering research.

Special thanks also to all the technicians and professors who helped me in some form or another during my research: Lou Cusmich, Charles Dolan, Jean Dumont, Alain Gagnon, Dr. Meunier, Dr. Patterson, Dr. Rey and Frank Szabo. Their help was simply invaluable.

Research equipment was borrowed from many different sources. Some sincere thanks go to Mr. François Dallaire of the McGill Metallurgical Engineering Department, to Alcan and to Professor Maher Boulos at the Université de Sherbrooke for their laser Doppler anemometer equipment.

Many of my research colleagues share also a part in the accomplishment of this thesis. I hope that they all feel my gratitude in recognition of their support. Sometimes too, a good chat is all what you need! Thanks also to all the people on the Internet who answered my numerous questions.

Je ne pourrais passer outre le support de ma famille: mon frère Luc pour son intérêt envers mon travail, ma mère pour ses bons petits plats et ses soins attentionnés, mon père pour toute la fierté qu'il a manifesté (discrètement) envers mes études. Évidemment, leurs contributions sont bien loin de s'arrêter là.

Finalement, un immense me:ci à Jine, ma bien-aimée, pour m'avoir supporté pendant tout ces longs mois de travail. Son désir constant (mais vain) de vouloir comprendre mon travail m'a fait chaud au coeur plus d'une fois. 


\section{Table of Contents}

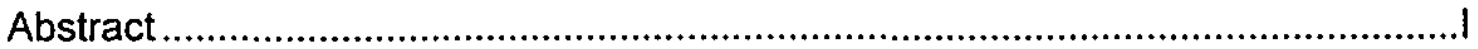

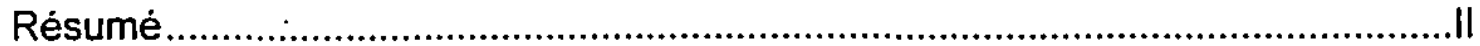

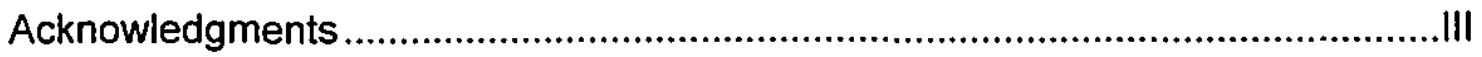

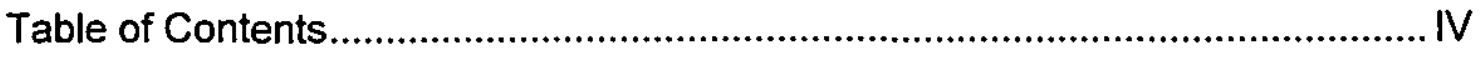

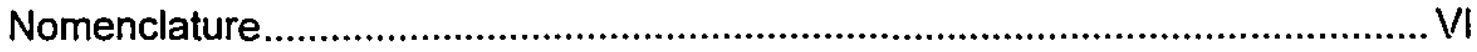

Chapter 1: Introduction ......................................................................................

1.1 Residence Time Distribution for Reactor Characterization.............................1

1.2 Experimental Conditions Overview .............................................................2

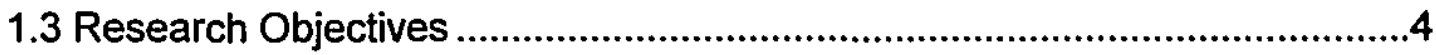

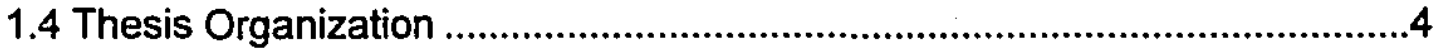

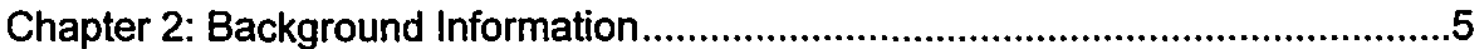

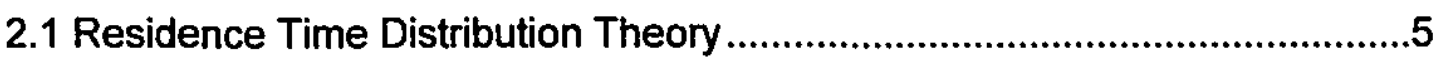

2.2 Infrared Molecular Absorption Spectroscopy .......................................... 10

2.3 Infrared Measuring instruments ................................................................ 13

Chapter 3: Experimental Techniques ................................................................. 15

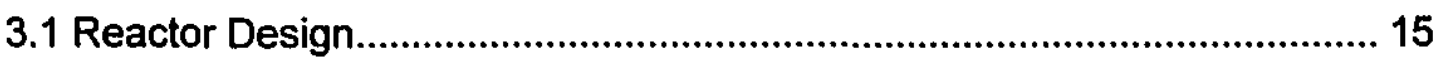

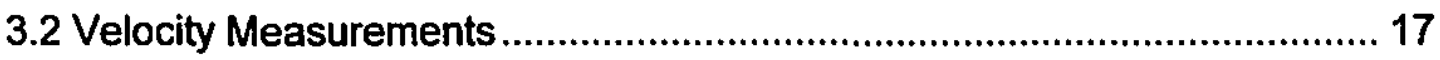

3.3 Concentration Measurements ................................................................... 23

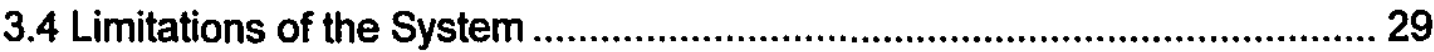

3.5 Residence Time Distribution Measurements ............................................ 33

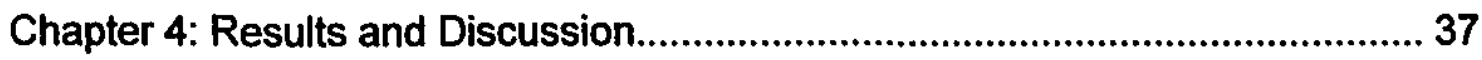

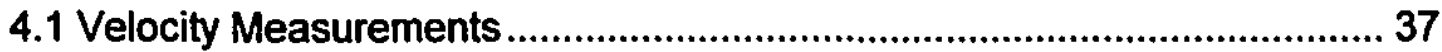

4.1.1 Gas Flow without Radial Injection .......................................................................37

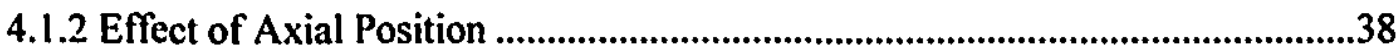

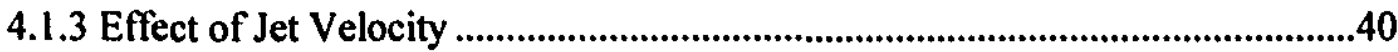

4.1.4 Behavior of the Radial Injector..............................................................................42

4.1.5 Turbulence Intensity .......................................................................................46

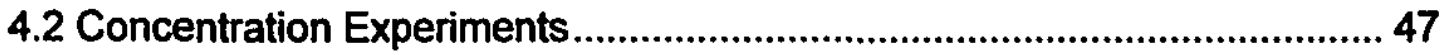


4.2.1 Effect of the Angle of Measurement.............................................................47

4.2.2 Effect of the Jet Velocity and Axial Position...................................................50

4.2.3 Steady State Concentrations .................................................................5

4.3 Residence Time Distribution Results ................................................. 56

4.3.1 Selection of Experiments for RTD Aralysis .............................................56

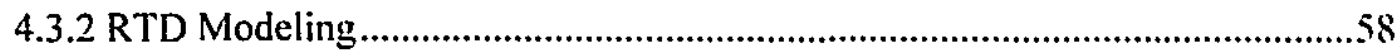

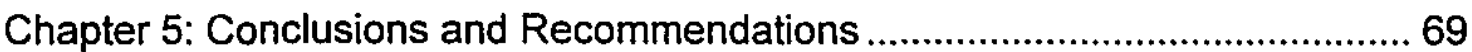

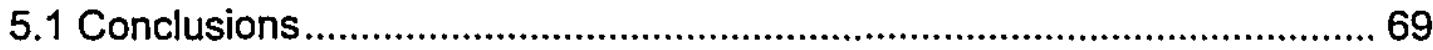

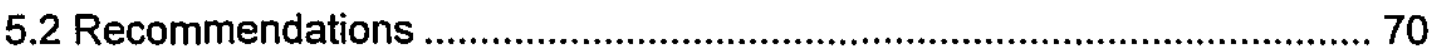

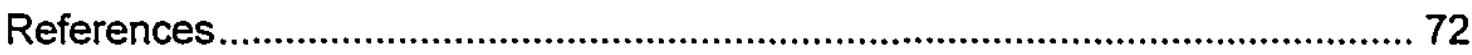

Appendix A: Additional Velocity Measurements ........................................... 74

Appendix B: Additional Concentration Measurements .................................... 76

Appendix C: Additional Residence Time Distribution Results .......................... 82 


\section{Nomenclature}

$$
\begin{aligned}
& \text { c } \quad \text { speed of light in vacuum } \\
& \text { d }=\text { reactor diameter } \\
& \mathrm{d}_{\mathrm{f}} \quad=\text { fringe spacing } \\
& f(t)=\text { residence time distribution density function } \\
& \mathrm{f}_{\mathrm{d}}=\text { frequency of the Doppler signal } \\
& \text { h }=\text { Planck's constant } \\
& \text { in = as a subscript, refer to the entrance of the reactor } \\
& \text { m = total amount of tracer injected for a pulse input } \\
& \text { out = as a subscript, refer to the reactor exit } \\
& r \quad=\text { radial location } \\
& r_{0} \quad=\text { reactor radius } \\
& \text { t }=\text { time } \\
& \mathrm{t}^{\prime}=\text { dimensionless time } \\
& \mathrm{x} \quad=\text { path length (thickness) of the absorbing media } \\
& v \quad=\text { gas velocity in the reactor } \\
& v_{\text {jet }}=\text { injector jet velocity } \\
& \mathrm{z}=\text { axial position in the reactor, measured from the radial injector location } \\
& \text { A = spectroscopic constant } \\
& \text { B }=\text { spectroscopic constant } \\
& \mathrm{C}=\text { tracer concentration } \\
& \mathrm{C}_{0}=\text { tracer steady state concentration } \\
& \mathrm{D}_{\mathrm{Z}}=\text { axial dispersion coefficient } \\
& D_{\mathrm{r}}=\text { radial dispersion coefficient } \\
& E_{v+r}=\text { energy of a vibrational-rotational level } \\
& \mathrm{E}_{\mathrm{p}} \quad=\text { energy of photon } \\
& \mathrm{F}=\text { residence time distribution function } \\
& \text { I = laser beam intensity } \\
& \mathbf{l}_{0} \quad=\text { incident laser beam intensity }
\end{aligned}
$$




$$
\begin{array}{ll}
\mathrm{J} & =\text { rotational energy level } \\
\mathrm{L} & =\text { axial location of measurement } \\
\mathrm{P} & =\text { reactor pressure } \\
\mathrm{Pe} & =\text { Peclet number (axial) } \\
\mathrm{Pe}_{\mathrm{r}} & =\text { radial Peclet number } \\
\mathrm{Q} & =\text { total flow rate in the reactor } \\
\mathrm{Re} & =\text { Reynolds number (=vdp/ } \eta \\
\mathrm{S}(\mathrm{t}) & =\text { unit step function } \\
\mathrm{T} & =\text { temperature } \\
\alpha & =\text { absorptivity } \\
\phi & =\text { half angle between the laser beams of a laser Doppler anemometer } \\
\eta & =\text { gas viscosity } \\
\lambda & =\text { wavelength of light } \\
\mu & =\text { mean value of the residence time distribution } \\
\mu_{\mathrm{v}} & =\text { mean value of a laser Doppler velocity measurement } \\
v & =\text { frequency of light } \\
\theta & =\text { angle formed between the pipe connector of the radial injector and the laser beam } \\
\rho & =\text { gas density } \\
\sigma_{\mathrm{v}} & =\text { standard deviation of a laser Doppler velocity measurement } \\
\sigma^{2} & =\text { variance of the residence time distribution } \\
\tau & =\text { space time of a reactor } \\
\tau_{\mathrm{LFR}} & =\text { space time of the laminar flow portion of a reactor } \\
\tau_{\mathrm{pFR}} & =\text { space time of the plug flow portion of a reactor } \\
v & =\text { vibrational energy level } \\
\Delta & =\text { denotes the difference between two values } \\
&
\end{array}
$$




\section{Chapter 1}

\section{Introduction}

\subsection{Residence Time Distribution for Reactor Characterization}

A great deal of attention has recently been devoted to the production of ultrafine ceramic and metal powders for the development of high technology materials. It is believed that materials made from ultrafine ceramic powders would require lower sintering temperatures as well as exhibit better properties because of their finer microstructure. In the past decade, many researchers investigated the use of thermal plasma reactors to produce such ultrafine ceramics. This technology possesses many distinct advantages such as the high temperatures required to vaporize the solid raw materials, a controlled atmosphere and the possibility of using cheap raw materials.

According to Young and Pfender ${ }^{(1)}$, ultrafine powders represent one of the most important applications for thermal plasma processing. Although many different types of ultrafine materials have been successfully produced by thermal plasma processing, there is a lack of information on reactor characterization. This is an important tool for the optimization and scale-up of the current processes. One aspect of characterization, mentioned by Vogt and Newkirk ${ }^{(2)}$, is the lack of control on the size distribution of the produced particles.

It is believed that a knowledge of the residence time distribution (RTD) would help to characterize the flow patterns of the reactor. This residence time distribution could then be used in combination with other information to control better the particle size 
distribution. The residence time of a given molecule or particle is the time it spent in the reactor. The exit consists of fluid elements having a distribution of residence times.

To obtain the RTD of a reactor, one must perform a stimulus-response type of experiment. To do so, one injects a known amount of tracer at the inlet of a reactor. The tracer concentration at the reactor outlet is then measured as a function of time. An appropriate tracer should not disturb the flow patterns and its concentration must be measurable in some way. Common input functions (inlet concentration vs time) are pulse and step inputs, but theoretically any function may be used as long as it is known. An old but still excellent review of the measurement of residence time distribution is given by Levenspiel and Bischoff ${ }^{(3)}$.

Measuring the RTD is usually much simpler than characterizing the complete flow field in a reactor. While the former needs only measurements at the inlet and outlet of a reactor, the latter requires different measurements at a large number of locations. As a consequence, however, a knowledge of the RTD does not give a complete solution of the

flow patterns inside a reactor. As explained by Shinnar ${ }^{(4)}$, the RTD is a linear solution to a nonlinear problem, which means that there can be a large number of different flow patterns that will produce the same RTD. Nevertheless, the residence time distribution is a useful technique to obtain some important flow properties.

\subsection{Experimental Conditions Overview}

At the Plasma Technology Research Center of McGill University, Moura ${ }^{(5)}$ developed a transferred arc process for the production of ultrafine aluminum nitride (see Figure 1.1). His reactor system was composed of a transferred arc chamber in which the anode was a molten bath of aluminum. The vaporized metal was carried with the hot gas flow (argon) into a tubular reactor where the second reactant, ammonia, was injected radially through a multiplicity of small holes. The hot fluid containing ceramic particles was then quenched 
using a cold nitrogen flow. For such a system, the reactor portion is approximately delimited by the ammonia injection point and the quenching location: no ceramic production is assumed to occur outside that region. Mixing studies of similar reactors have been performed by Njah, Mostaghimi and Boulos ${ }^{(6)}$ and by Soucy, Jurewicz and Boulos $^{(7)}$. The former used a mathematical model while the latter presented experimental data for complete radial mixing in the reactor. However, none used an experimental determination of the RTD for reactor characterization.

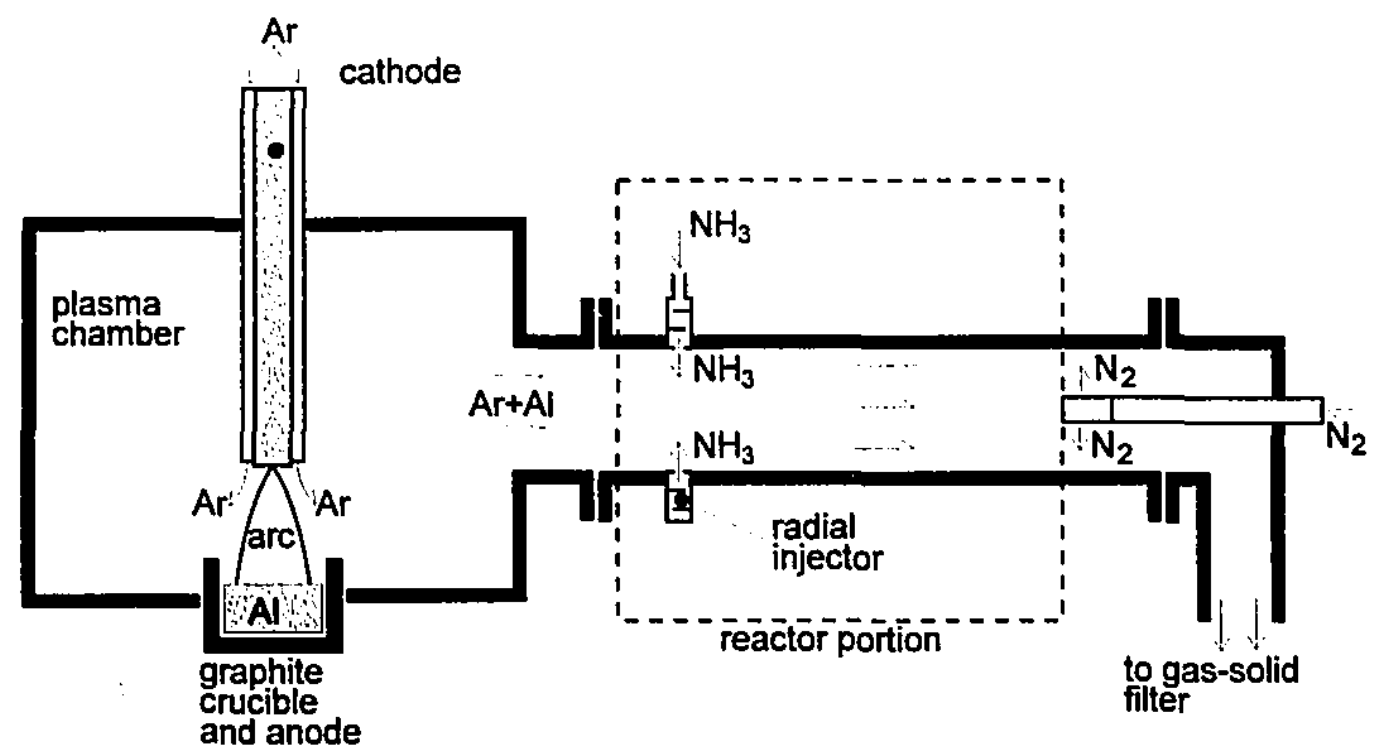

Figure 1.1 Transferred arc process used for the production of aluminum nitride ceramic used at the Plasma Technology Research Center of McGill University (Moura ${ }^{(5)}$ ).

As mentioned previously, obtaining the RTD in a reactor implies detecting the exit concentration of a tracer species. For the reactor described above, the method of measurement should fulfill the following requirements.

- Because the reactor has a very short average residence time, in the order of a few hundred milliseconds, very short time resolution is required: about 1 millisecond at most between measurements.

- The flow inside the reactor must not be disturbed significantly by the measuring system. 
- The detection system should have a low cost.

Laser absorption spectroscopy was the technique chosen for measuring the RTD. It uses an infrared laser as the ligint source, in this case a He-Ne laser tuned to a wavelength of $3.391 \mu \mathrm{m}$. The $\mathrm{C}-\mathrm{H}$ bond of most hydrocarbons absorbs strongly the light at that laser wavelength. The tracer selected was methane $\left(\mathrm{CH}_{4}\right)$. The technique was successfully applied to a room temperature system.

\subsection{Research Objectives}

The objective of this Master's research work was to design, construct and implement a very fast response detection method for the measurement of the residence time distribution (RTD) in a tubular reactor and to model the reactor from the measurements obtained. Ultimately, the objective would be to obtain a good flow characterization of the reactor used for ultrafine ceramic production.

\subsection{Thesis Organization}

In chapter 2, additional background information is given pertaining to RTD measurement and modeling. Some notion of molecular absorption spectroscopy and a brief review of detection devices similar to the one used are explained as well. The following chapter describes in detail the experimental method used. It contains information on the tubular reactor studied and on laser Doppler anemometry. The RTD detection device used is detailed along with its calibration, operation and limitations. Chapter 4 is concerned with the results obtained and their analysis. Conclusions and recommendations are given in Chapter 5. 


\section{Chapter 2}

\section{Background Information}

It is not the intent in this chapter to give a complete overview of the theory behind residence time distribution and infrared absorption spectroscopy. Only the basic information directly related to this master's research work is given.

\subsection{Residence Time Distribution Theory}

The residence time distribution function $F(t)$ is defined as the fraction of the exit stream that has a residence time less than time $t$. From its nature, $F(t)$ has values between 0 and 1 inclusively and is a monotically increasing function. Similarly, the derivative of $F(t)$

$$
f(t)=\frac{d F(t)}{d t} \quad \text { RTD density }
$$

is the fraction of the outgoing stream that has a residence time in between $t$ and $t+d t$ and is called the density function of the RTD.

It was explained in the preceding section that tracer input functions can take any form. One usually tries to use a simple input function since the analysis of the tracer output is then simplified. The two simplest input functions are the step and the pulse input; they are illustrated in Figure 2.1. The step consists of a sudden change of concentration of the tracer. It is maintained for a time long enough to allow the output tracer concentration to reach the input concentration, $\mathrm{C}_{0}$. It can be shown that

$$
F(t)=\frac{C}{C_{0}} \quad \text { step input }
$$


where $C$ is the output tracer concentration. The pulse input function is similar to the step except that its duration should be very much less than the time required for $\mathrm{C}$ to equal $\mathrm{C}_{\mathrm{n}}$. The following relation applies for a pulse type of input:

$$
f(t)=\frac{C(t)}{\int_{0}^{a} C(t) d t}=\frac{Q \cdot C(t)}{m} \quad \text { pulse input }
$$

where $\mathrm{m}$ is the total amount of tracer injected and $\mathrm{Q}$ is the flow rate inside the test section. Since the duration of a good pulse is very short, all the tracer molecules can be assumed to enter at the same time in the reactor.
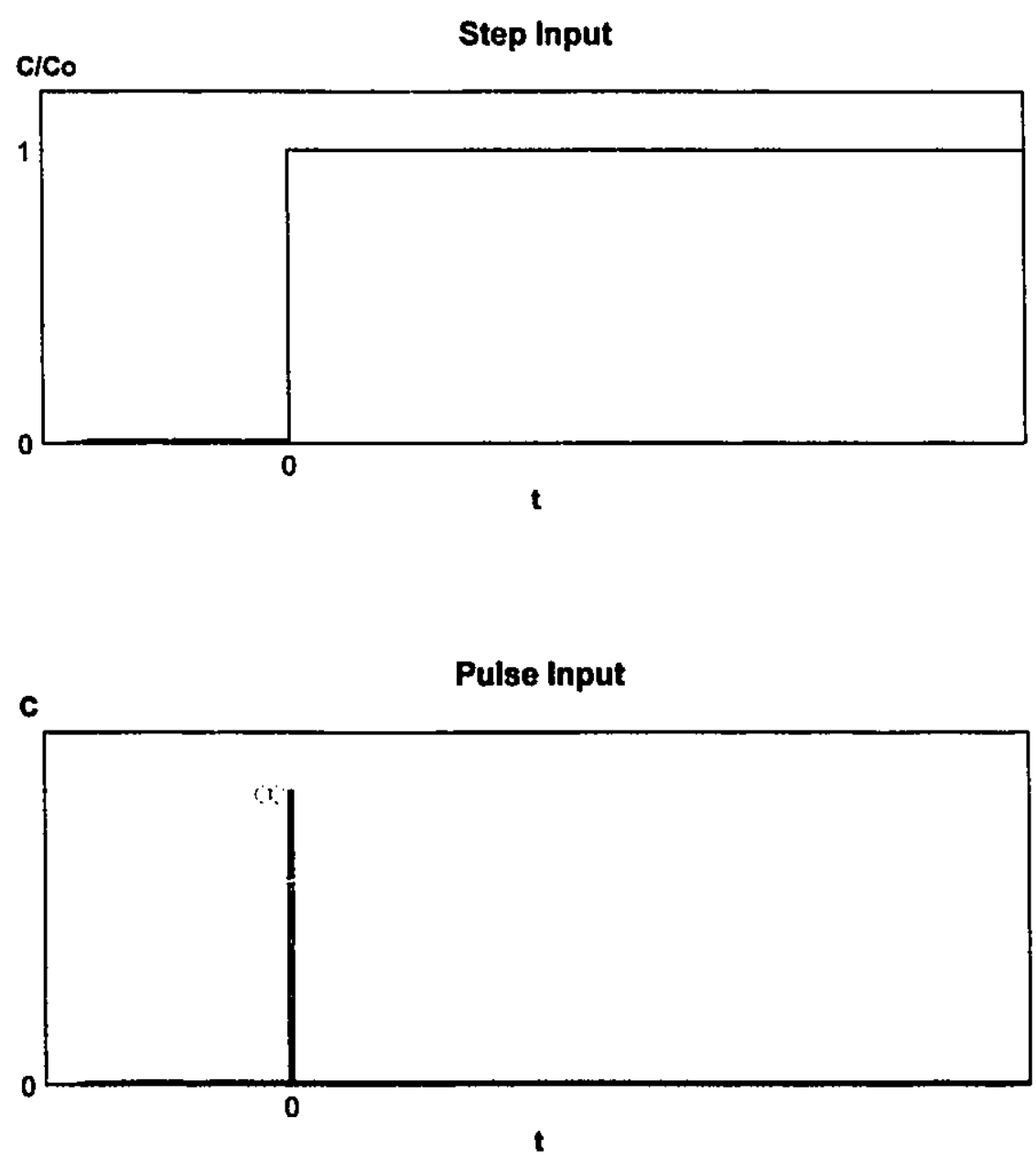

Figure 2.1 Simple input functions for RTD measurements. 
In practice, a perfect step or pulse injection is impossible. It can be well approximated in many cases, however. Obtaining the RTD or its density function is more complex for situations where the tracer input function can not be defined by a pulse or step. In particular, equations 2.2 and 2.3 do not apply for imperfect step and pulse inputs.

Statistical parameters are used to characterize a given RTD. Of particular interest are the first and second moments, namely the mean residence time and its variance (the second moment with respect to the mean). In terms of the RTD function, these parameters can be calculated as follows:

$$
\begin{array}{ll}
\mu=\int_{0}^{0}[1-F(t)] d t & \text { mean residence time } \\
\sigma^{2}=2 \int_{0}^{0}[1-F(t)] d t-\left[\int_{0}^{o r}[1-F(t)] d t\right]^{2} \ldots & \begin{array}{l}
\text { variance of the } \\
\text { residence time }
\end{array}
\end{array}
$$

An important relationship is that relating the space time to the reactor volume $\mathrm{V}$ and the flow rate $(Q)$ in a constant density reactor:

$$
\tau=\frac{V}{Q}, \quad \text { space time }
$$

In most cases, $\mu$ and $\tau$ are equal. Since they can be obtained independently, one can be compared with the other to ensure consistency of the data.

One is generally interested in modeling the obtained RTD. A good model should be representative of the overall flow pattern inside the reactor. It is thus desirable to have some knowledge of the flow pattern obtained independently of the RTD. Figure 2.2 illustrates four different flow patterns: perfect mixing, plug flow, laminar flow and axial dispersion. Their RTD functions are given below:

$$
\begin{aligned}
& F(t)=1-e^{\frac{-t}{\tau}} \\
& F(t)=S(t-\tau)
\end{aligned}
$$

perfect mixing

plug flow 


$$
\begin{aligned}
& F(t)=1-\frac{1}{4}\left(\frac{t}{\tau}\right)^{-2} \text { for } t \geq 0.5 \cdot \tau \\
& F(t)=0 \text { for } t<0.5 \cdot \tau \\
& F(t)=\frac{1}{2}\left[\operatorname{erfc}\left(\frac{\sqrt{\mathrm{Pe}}}{2} \frac{1-t / \tau}{\sqrt{\mathrm{t} / \tau}}\right)+\mathrm{e}^{\mathrm{Pe}} \cdot \operatorname{erfc}\left(\frac{\sqrt{\mathrm{Pe}}}{2} \frac{1+t / \tau}{\sqrt{\mathrm{t} / \tau}}\right)\right] \quad \begin{array}{c}
\text { closed-open } \\
\text { axial dispersion }
\end{array} \\
& \text { tubular laminar } \\
& \text { flow } \\
& \mathrm{Pe}=\frac{\mathrm{v} \cdot \mathrm{L}}{\mathrm{D}_{2}} . \quad \text { Peclet number }
\end{aligned}
$$

All four models described above require some parameter estimation. The first three require only a knowledge of the space time. Since it can be obtained independently of the RTD, these models are termed zero parameter models. The axial dispersion model is a one parameter model since the Peclet number must be evaluated from the RTD data. Statistical methods to obtain Pe from $\mu$ and $\sigma^{2}$ are detailed by Bischoff and Levenspicl ${ }^{(8)}$. In particular, for an open-open vessel,

$$
\frac{\Delta \sigma^{2}}{\Delta \mu^{2}}=\frac{\left(\sigma_{\text {out }}^{2}-\sigma_{\text {in }}^{2}\right)}{\left(\mu_{\text {out }}-\mu_{\text {in }}\right)^{2}}=\frac{2}{P e} \quad \text { Peclet calculated from the }
$$

In this equation, the delta symbol refers to the difference between the inlet and outlet measurements. This equation is thus valid for any type of input as long as $\mu_{\text {in }}$ and $\sigma_{\text {in }}$ are known. Another method is to write the governing differential equation and to solve for $\mathrm{Pe}$ either analytically or numerically. The optimal value of $\mathrm{Pe}$ is then found by comparing the goodness of fit between the actual RTD data and the one estimated from the differential equation. 


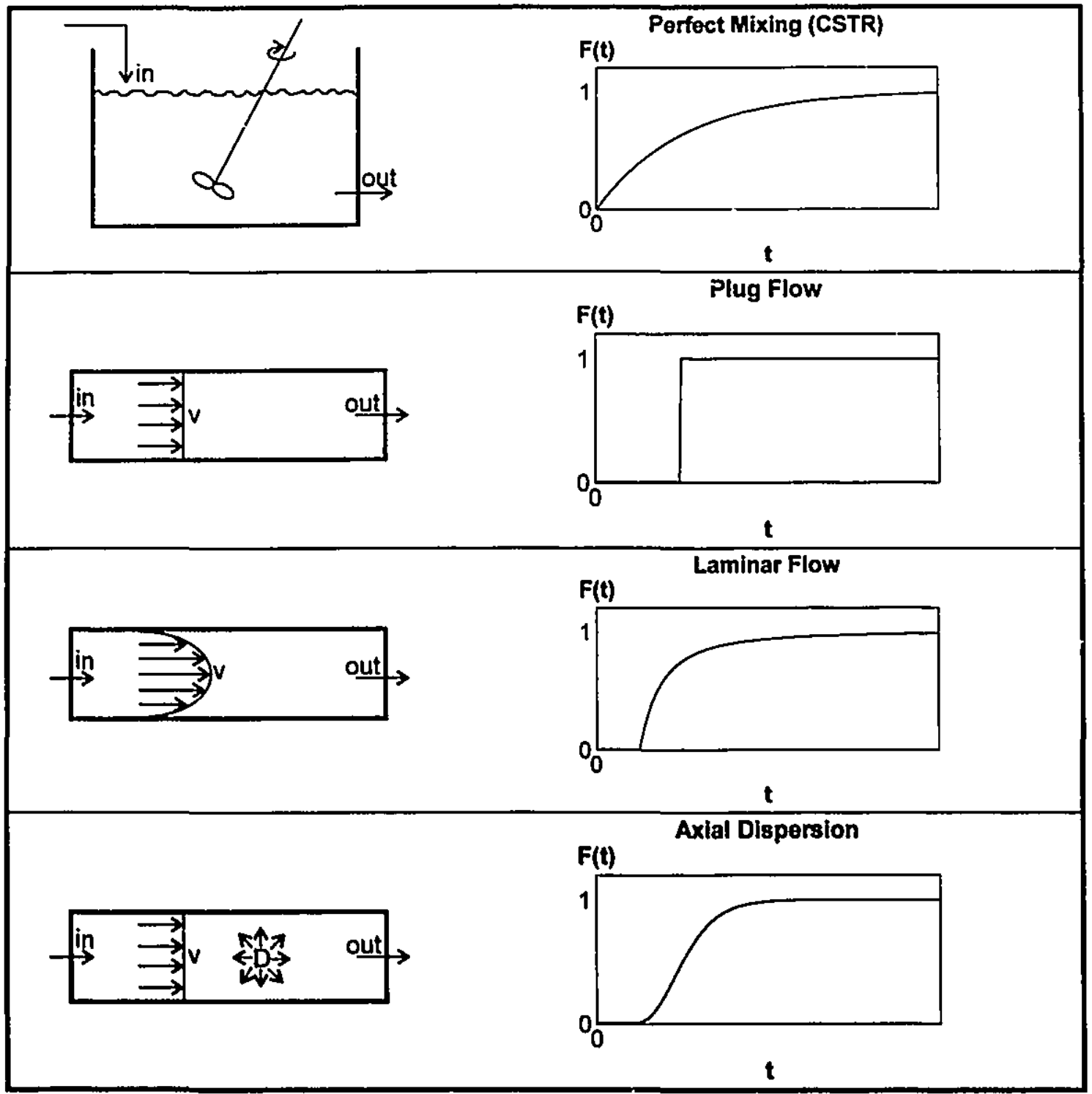

Figure 2.2 Different flow patterns in chemical reactors and their associated RTD functions. 


\subsection{Infrared Molecular Absorption Spectroscopy}

Interactions between molecules or atoms and light are well known and may take many forms. Of particular interest to this research project is the absorption of light by a molecule accompanied by a change in its rotational and/or vibrational level. This type of interaction falls in the category of infrared molecular spectroscopy. The wavelength $\lambda$ of a photon of light is proportional to its frequency $v$ according to the relation

$$
\lambda=\frac{\mathrm{c}}{v} \quad \begin{gathered}
\text { wavelength-frequency } \\
\text { relation }
\end{gathered}
$$

where $\mathrm{c}$ is the speed of light $\left(2.998 \cdot 10^{8} \mathrm{~m} / \mathrm{s}\right)$. The wave number is sometimes used instead of the wavelength: it is simply equal to $\lambda^{-1}$ and usually has the units of $\mathrm{cm}^{-1}$. The energy carried by a photon $\left(E_{p}\right)$ is expressed by

$$
E_{p}=h \cdot v \quad \text { energy of a photon }
$$

where $h$ is Planck's constant $\left(6.626 \cdot 10^{-34} \mathrm{~J} \cdot \mathrm{s}\right)$.

According to quantum theory, the energy of a molecule can not take an infinite number of values. Instead, the different levels take a finite number of discrete values. Such energy levels are characterized by the vibration and the rotation of the molecule; they are thus called vibrational-rotational levels. As a first approximation, the energy of a vibrationalrotational level is given by

$$
E_{v+r}=(v+0.5) h c A+B h c J(J+1) \text {. vibrational-rotational energy }
$$

The constants A and B can be evaluated from molecular parameters; $v$ and $J$ are the vibrational and rotational levels, respectively, and can take only positive integer values $(0,1,2, \ldots)$.

Molecular vibrations can be excited by photons provided that the photon frequency matches the vibrational frequency of the molecule. A photon of light is absorbed every time a change in the dipole moment of a molecule is caused by a molecular vibration. Such a change is a modification of the vibrational-rotational energy level of the molecule. Molecules of only one atom (like Ar and He, for example) and molecules where all atoms 
are of the same species (such as $\mathrm{N}_{2}$ and $\mathrm{O}_{2}$ ) do not have a change in dipole moment in their vibrational modes and are thus said to be infrared inactive. The energy of the photon absorbed is equal to the difference between the new and the original energy level of the molecule. Letting $v$ " and $J "$ be the quantum numbers in the original energy level and $U$ ' and $J$ ' the quantum numbers in the new level,

$$
\Delta E_{v+r}=h c\left[A\left(v^{\prime}-U^{\prime \prime}\right)+B\left[J^{\prime}\left(J^{\prime}+1\right)-J^{n}\left(J^{n}+1\right)\right]\right]=E_{p} . \quad \begin{gathered}
\text { energy difference } \\
\text { between levels }
\end{gathered} 2.16
$$

For the case where the new energy level is lower than the original one, a photon of energy $E_{p}$ is emitted by the molecule.

For this research, the molecular species of interest is methane. An infrared absorption spectrum is displayed in Figure 2.3. On can see that it is composed of a central broader band (the $Q$ branch) and several narrower ones (the $P$ and $R$ branches). The symmetry of the methane molecule imposes that the possible rotational quantum number difference $\left(\Delta \mathrm{J}=\mathrm{J}^{\prime}-\mathrm{J}\right.$ ) $)$ be either $-1,0$ or +1 . The different combinations where $\mathrm{J}^{\prime}-\mathrm{J}=-1$ form the bands of the $P$ branch and similarly, the $Q$ and $R$ branches are made of vibrationalrotational transitions where $\mathrm{J}^{\prime}-\mathrm{J} "=0$ and +1 , respectively. All the transitions of Figure 2.3 are from $v=0$ to $v=1$ since at room temperature, the molecules with $v=0$ form the dominant species. The partition of the molecules between different rotational and vibrational energy levels is given by partition functions but studying them in more detail is beyond the scope of this thesis.

In their study of laser absorption by methane, Jaynes and Beam ${ }^{(10)}$ used values of $A$ and $B$ corresponding to about $3018 \mathrm{~cm}^{-1}$ and $5.25 \mathrm{~cm}^{-1}$, respectively. The laser emission was assumed to be composed of a single, very narrow band. This is explained in more detail in reference 10. Knowing that its wavelength is $3.391 \mu \mathrm{m}$, one can see which band of the methane spectrum is used. It corresponds to the vibrational-rotational transition $v=1 \leftarrow v=0-J=6 \leftarrow J=7$ and it is situated in the $P$ branch (Figure 2.3 and 2.4). 


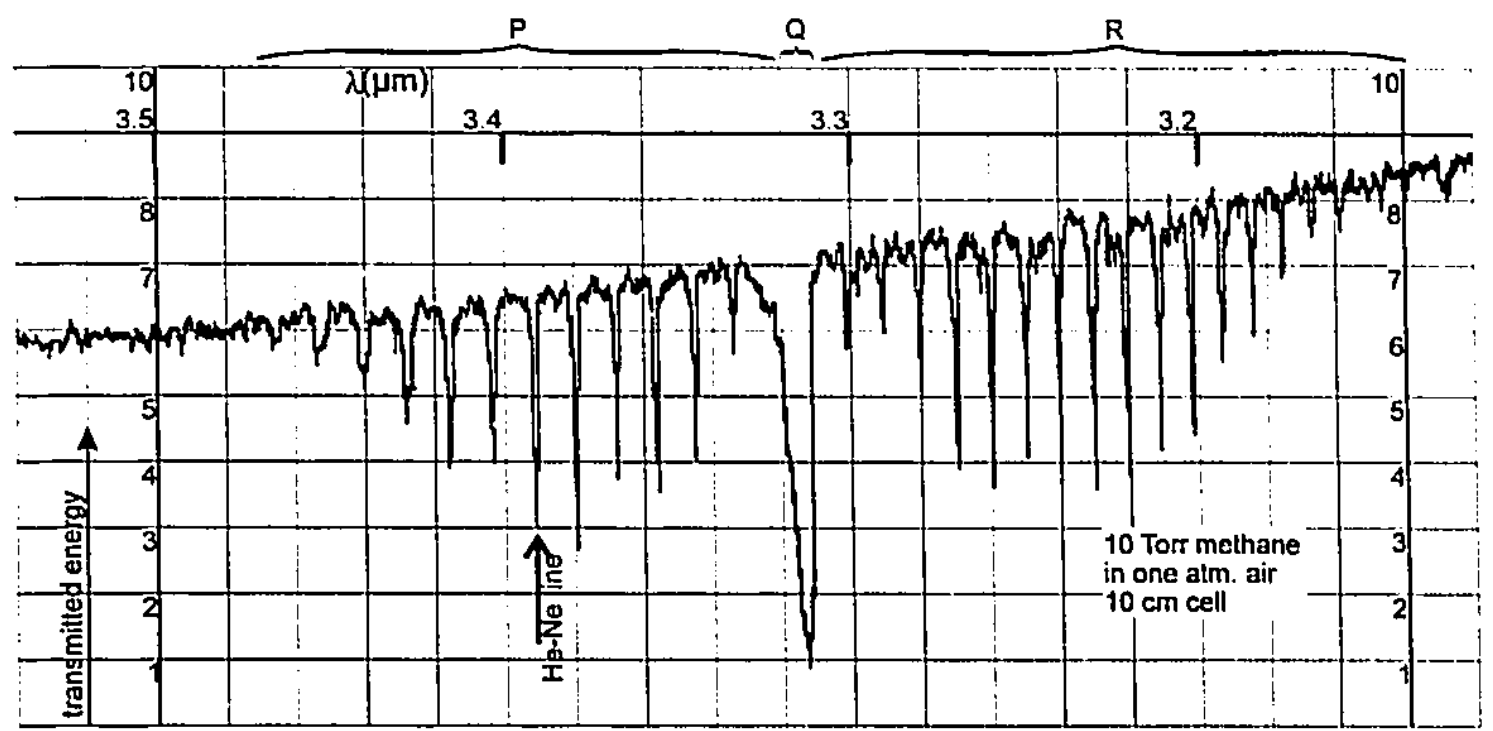

Figure 2.3 Infrared spectra of methane around $\lambda=3.33 \mu \mathrm{m}$ (taken from Hanst ${ }^{(9)}$ ).

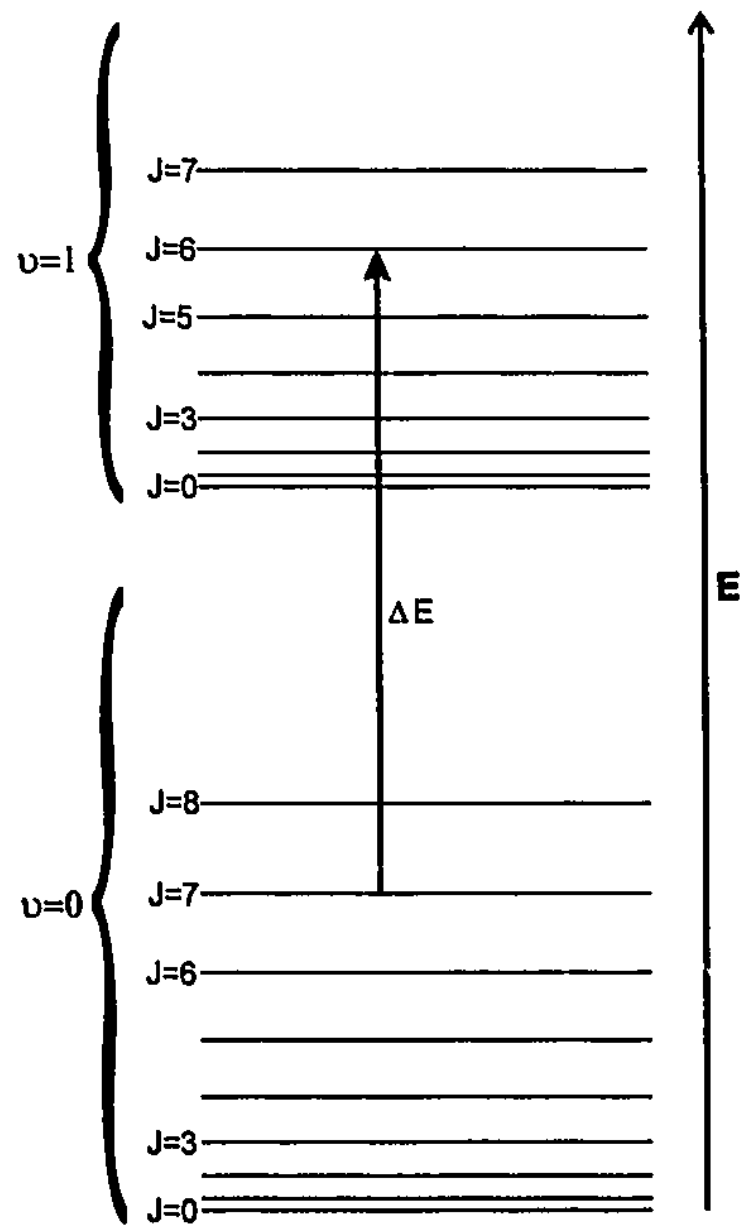

Figure 2.4 Vibrational-rotational energy transition of methane with a He-Ne laser at $\lambda=3.391 \mu \mathrm{m}$. 
Quantitative measurements of a molecular species are made by measuring the intensity of the light beam absorbed by that species. The Beer-Lambert law relates the transmittance to the concentration $\mathrm{C}$ by the following equations:

$$
\begin{array}{ll}
\frac{1}{I_{0}}=\mathrm{e}^{-\mathrm{tlCx}} & \begin{array}{c}
\text { Beer-Lambert law } \\
\text { (integrated form) }
\end{array} \\
\mathrm{dl}=-\mathrm{I} \cdot \alpha \cdot \mathrm{C} \cdot \mathrm{dx} & \begin{array}{c}
\text { Beer-Lambert law } \\
\text { (differential form) }
\end{array}
\end{array}
$$

where $\mathrm{x}$ is the path length of the absorbing medium, $\mathrm{I}_{0}$ and $\mathrm{I}$ are the intensities of the incident and absorbed light beams, respectively. The constant $\alpha$ is termed the absorptivity and is specific to the molecular species and wavelength. The absorptivity $\alpha$ can not be estimated accurately from Figure 2.3 because the spectral width of the $\mathrm{He}-\mathrm{Ne}$ laser line is much narrower than the resolution of the spectrophotometer used to obtain the spectra.

\subsection{Infrared Measuring Instruments}

Many types of spectroscopic instruments are commercially available for measuring concentration. A recent review is given by Dailey ${ }^{(11)}$. He divided the different instruments into four categories: non-dispersive infrared analyzers (NDIR), near-infrared analyzers (NIR), photoacoustic spectroscopy instruments (PAS) and Fourier transform infrared analyzers (FTIR).

NDIR and PAS are quite similar in their principle of operation. They both use an infrared light source, usually polychromatic. The light beam is focused into the media where the concentration is to be measured (normally a gas or liquid). Since absorption usually occurs in narrow bands where the vibrational-rotational transitions are, the wavelength of interest is selected by using narrow bandpass filters, as explained by Wilks ${ }^{(12)}$. Since these instruments do not use gratings, prisms or interferometers to select the wavelength of interest, they are said to be non-dispersive. Alternatively, a laser emitting at the proper wavelength can be employed, eliminating the need of filters. The difference between 
NDIR and PAS is in the way that the beam intensity is measured. While NDIR uses light detectors like Golay cells or of the pyroelectric type, PAS uses a microphone: when the species of interest absorbs infrared light, it increases its temperature and pressure thus producing a sound wave.

A Fourier transform analyzer measures the entire spectrum instead of a single wavelength. One big advantage is that it can monitor more than one infrared bands without additional equipment, but this comes at a higher cost. Near-intrared analyzers are also employed for multicomponent analysis. They use scanning spectrophotometers in the visible to near-infrared region to scan the harmonics and combination bands of the fundamental vibrational frequencies.

A difference is usually made between open and closed path instruments. In the former, the light beam is not contained in a cell: usually, it passes through atmospheric air. 'This type of application is used with atmospheric pollutant measurement. The latter type of instrument encloses the infrared beam in a measuring cell containing the gas or liquid to be measured. When on-line analysis of a stream is needed, a portion or the entire flow is deviated into the cell.

When the concentrations and/or the absorptivity of a coinpound is very low, it can be necessary to have a longer path length $(x)$ in order to have a significant transmittance $\left(I / 1_{0}<1\right)$. For open path type of measurements, increasing $x$ is normally easily achieved by increasing the distance between the source and detector. Closed path instruments use multipass cells where the light beam is reflected many times in the cell before being measured. 


\section{Chapter 3}

\section{Experimental Techniques}

Two types of measurements were made in this research project. The first one was concentration and the second type was velocity. The residence time distribution was obtained from the concentration measurements. They will each be explained in this chapter, a greater emphasis being placed on concentration measurements and RTD. Since the reactor used for both measurements was the same, it will be described first.

\subsection{Reactor Design}

The reactor used for RTD measurements was not operated under the same conditions as the one used for ceramic production. Table 2.1 displays a summary of conditions for the two reactors. The fact that the reactor for RTD measurement was operated at room conditions is of particular interest. A consequence of this is that its Reynolds number range was significantly higher since the viscosity of gases is lower at room temperature. The low value of Re with helium was due to its low density. At high temperatures, the gas temperature varied both radially and axially since the reactor wall was colder than the gas. The reactor used in this study was operated isothermally.

The gases used for RTD measurements were chosen for their different transport properties. While helium provided lower Reynolds numbers, nitrogen gave better radial mixing as it will be explained later (Section 3.4 and Chapter 4). The tracer, methane, was chosen for its spectroscopic characteristics. Neither He nor $\mathrm{N}_{2}$ supported the combustion of $\mathrm{CH}_{4}$, thus eliminating the risk of explosion. 
Table 3.1 Comparison of reactor conditions used for ceramic production and residence time distribution measurements.

\begin{tabular}{|c|c|c|}
\hline PARAMETERS & $\begin{array}{c}\text { Reactor for Ceramic } \\
\text { Production }\end{array}$ & $\begin{array}{c}\text { Reactor for RTD } \\
\text { Measurement }\end{array}$ \\
\hline \hline$T$ (temperature) & $1000-1100 \mathrm{~K}$ & $20 \mathrm{~K}$ \\
\hline $\mathrm{L}$ (reactor length) & $0.1-0.3 \mathrm{~m}$ & $0.03-0.35 \mathrm{~m}$ \\
\hline carrier gas & $\mathrm{Ar}: 50-55 \mathrm{l} / \mathrm{min}$ (reactor $\mathrm{T}$ ) & $\mathrm{N}_{2}$ or He: $\approx 50 \mathrm{l} / \mathrm{min}$. \\
\hline reacting gas & $\mathrm{NH}_{3}: 2-6 \mathrm{l} / \mathrm{min}$ (room T) & $\begin{array}{c}\mathrm{CH}_{4} \text { with possibly } \mathrm{N}_{2} \text { or } \\
\mathrm{He}: 1.6-27.2 \mathrm{l} / \mathrm{min} .\end{array}$ \\
\hline quenching gas & $\mathrm{N}_{2}: 25 \mathrm{l} / \mathrm{min}($ room $\mathrm{T})$ & none \\
\hline P (pressure) & $101.3 \mathrm{kPa}(1 \mathrm{~atm})$ & $101.3 \mathrm{kPa}(1 \mathrm{~atm})$ \\
\hline $\mathrm{d}$ (reactor diameter) & $4.5 \mathrm{~cm}$ & $4.5 \mathrm{~cm}$ \\
\hline no. of radial jets & 24 & 24 \\
\hline jet diameter & $0.79 \mathrm{~mm}(1 / 32 \mathrm{in})$ & $0.79 \mathrm{~mm}(1 / 32 \mathrm{in})$ \\
\hline$\tau$ & $0.15-0.45 \mathrm{~s}$ & $0.04-0.7 \mathrm{~s}$ \\
\hline Re & $150-200$ & $\begin{array}{c}\mathrm{N}_{2}: 1450-2200 \\
\text { He: } 200-250\end{array}$ \\
\hline
\end{tabular}

The reactor used is displayed in Figure 3.1. It was made of acrylic, a transparent polymer. Its length and diameter were of similar dimensions as the reactor for ceramic production (see Table 3.1). The carrier gas was introduced at the left end. It then flowed through a porous metallic plate creating a sufficient pressure drop to even the flow. The reacting gas, $\mathrm{CH}_{4}$ with $\mathrm{N}_{2}$ or $\mathrm{He}$ in some cases, was injected into the reactor through 24 radial jets, placed at about $10 \mathrm{~cm}$ downstream of the porous plate. Throughout this thesis, the term reacting gas will be used to designate the gas that flows through the radial injector even though no chemical reaction occurred in the reactor studied. The remaining portion of the reactor, about $40 \mathrm{~cm}$ in length, was composed of several smaller tubular sections 5 or $10 \mathrm{~cm}$ long connected one into each other. One of the sestions had sapphire windows which were transparent to infrared radiation. Another was equipped with high quality visible laser windows for measurement of the velocity by laser Doppler 
anemometry (Section 3.2). The different sections were interchangeable so that the ones with the windows could be placed at different axial locations. All the reactor sections were secured together by long screws extending from the injector to the right reactor end.

The radial injector design was similar to the one used by Moura ${ }^{(5)}$. The details are displayed in Figure 3.2. The reacting gas entered by the pipe connector on top of the injector. It then flowed through the injector chamber. A baffle was placed in the middle of the chamber to prevent the gas from the pipe connector impinging directly on the top jets. The baffle did not totally obstruct the chamber so that the gas could flow over it. A sufficient pressure drop was maintained between the chamber and the injection holes to ensure equal gas flow through each radial jet.

\subsection{Velocity Measurements}

The fluid dynamics of the reactor was investigated by performing axial velocity measurements at several positions. The results obtained were used to understand better the flow patterns inside the reactor; this was useful for RTD analysis. The exact velocity values matter little; what was important was the magnitude of the values and the trends observed. The Reynolds number values indicated that the gas flow, when fully developed, was in the laminar region $(\operatorname{Re}<2300)$. However, the flow was not expected to be fully developed because of the reactor shortness and the strong turbulence induced by the jets. The velocity profile across the reactor diameter was an indicator of the type of flow. A flat profile is usually associated with turbulent conditions while a parabolic shaped profile indicates laminar flow conditions. 


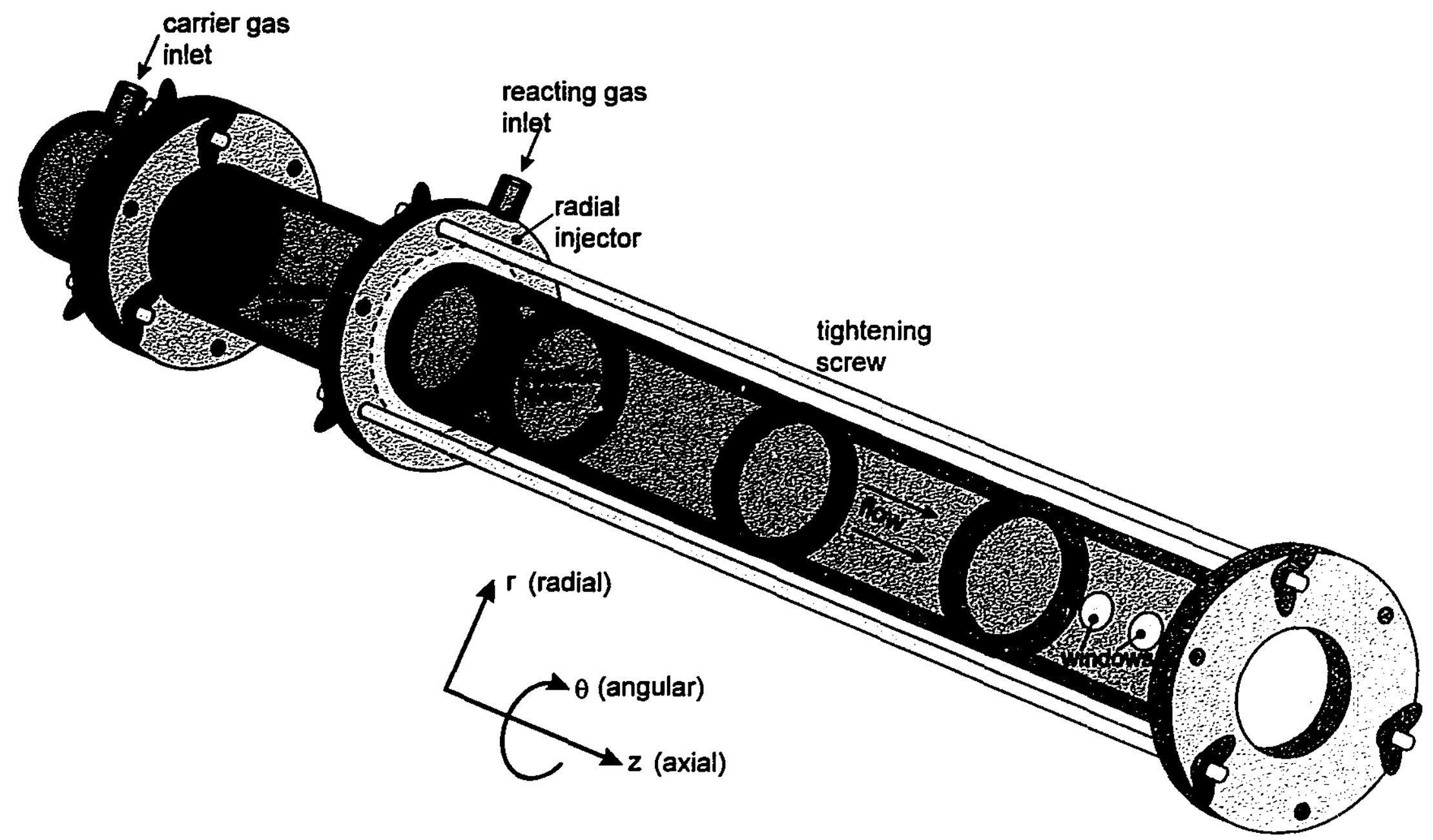

Figure 3.1 Reactor used for residence time distribution and velocity measurements. 


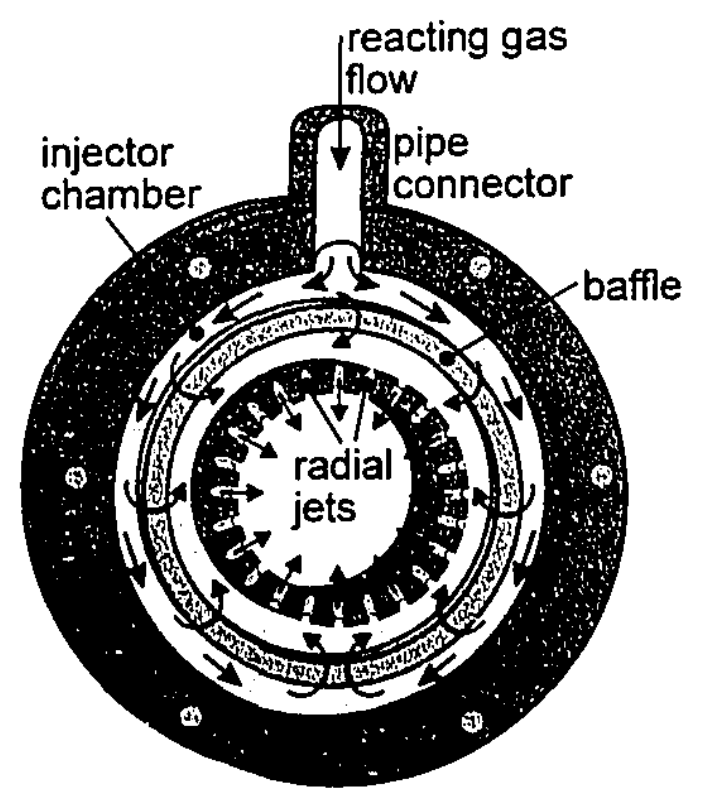

Figure 3.2 Cut view of the radial injector.

Axial gas velocities were measured by using a TSI model 900 laser Doppler anemometer (LDA). This instrument works on the principle that when two linearly polarized laser beams cross each other, they form an interference pattern due to the superposition of the light waves (Figure 3.3). The interference pattern, consisting of fringes, is described as a series of dark and bright light bands. The distance between fringes is calculated from

$$
\mathbf{d}_{\mathbf{f}}=\frac{\lambda}{2 \sin (\phi)} \quad \text { fringe spacing }
$$

where $\lambda$ is the laser wavelength and $\phi$ is the half angle between the two laser beams. A solid or liquid particle passing through the measuring volume (the beam crosspoint) will scatter light with an intensity related to its position relative to the fringe pattern (see Figure 3.4). A detector that senses the intensity of the scattered light then displays a signal similar to the one of Figure 3.5. The higher frequency component (Doppler signal) is caused by the particle going from a dark light band to a bright one and vice versa. The lower frequency component (pedestal) is due to the Gaussian radial intensity profile of the laser beams. The velocity of the particle is obtained by measuring the frequency of the Doppler signal $\left(f_{d}\right)$ and multiplying it by the fringe spacing:

$$
v=f_{d} \cdot d_{f} \text {. velocity from Doppler frequency }
$$


The velocity $\mathrm{v}$ is the component perpendicular to the fringes. To obtain the gas velocity. one must simply make sure that the particle causing the signal is small enough to faithfully follow the gas flow. A more complete explanation of laser Doppler anemometry can be found in Durst ${ }^{(13)}$.

The reactor-LDA setup is represented in Figure 3.6. The LDA used was of the backscatter type, which means that the scattered light from the particles was collected on the same side of the equipment as where the laser beams entered. A portion of the carrier gas stream was used to transport titanium dioxide particles in the $1-2 \mu \mathrm{m}$ diameter range. A dust feeder was employed to disperse the solids in the gas. The reacting gas was either methane or a mixture of methane with helium or nitrogen.

Measurements were taken at different axial (z) and radial positions. The angle formed by the laser beams of the LDA and the pipe connector of the radial injector was kept at $60^{\circ}$ for all experiments (Figure 3.7). Table 3.2 summarizes the various flow rates and axial positions that were used. For each axial location and flow rate measurements were taken at 10 to 12 radial positions. One measurement consisted of the :verage of about 128 to 512 particle velocities. Not all possible combinations of the conditions shown in the table were made. Time constraints limited the total number of experiments since part of the equipment was loaned from Alcan and had to be returned. 

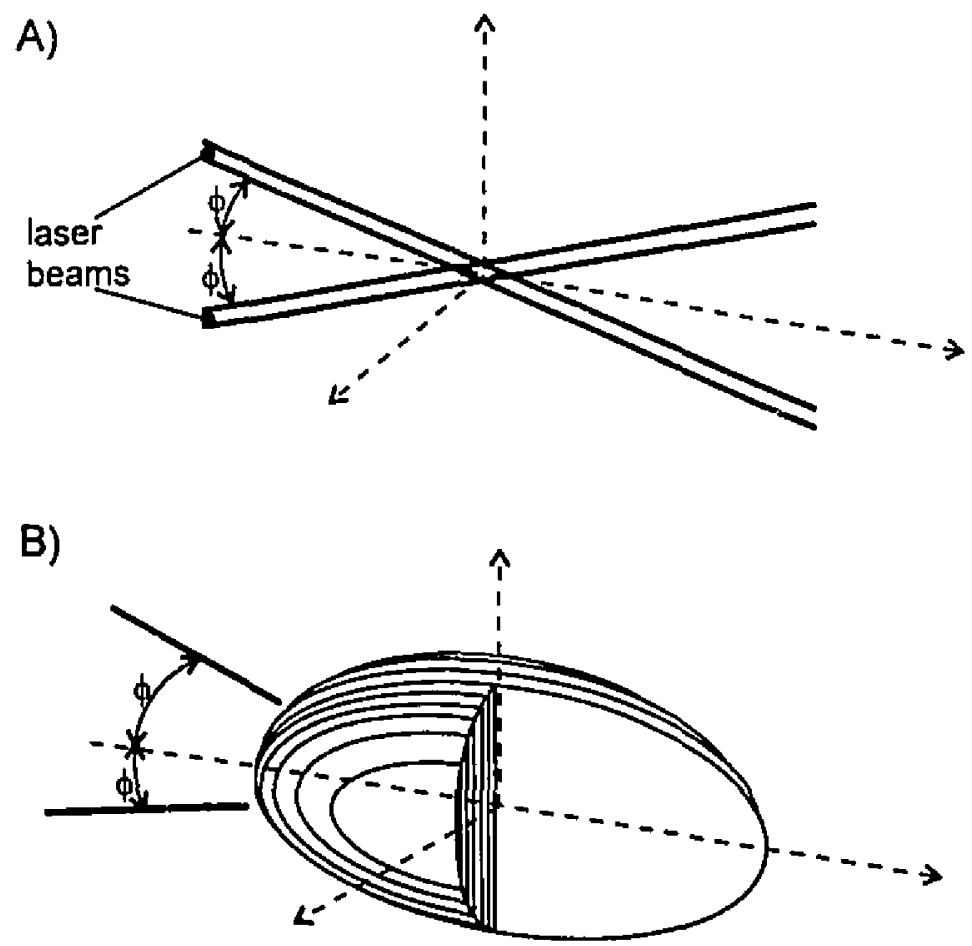

Figure 3.3 Intersection of two linearly polarized laser beams: a) laser beams crossing, b) enlargement of the measuring volume.

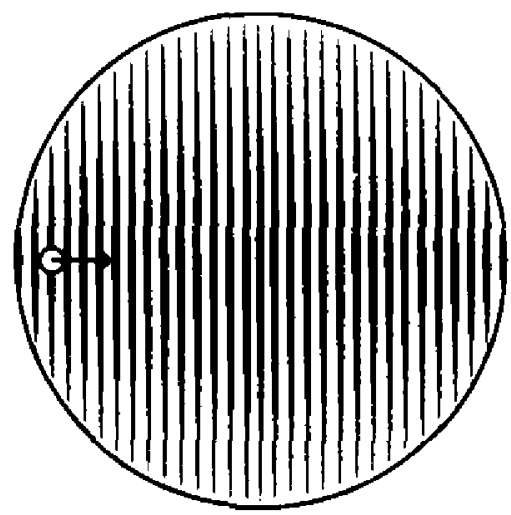

Figure 3.4 Particle passing through the fringe pattern of the measuring volume. 


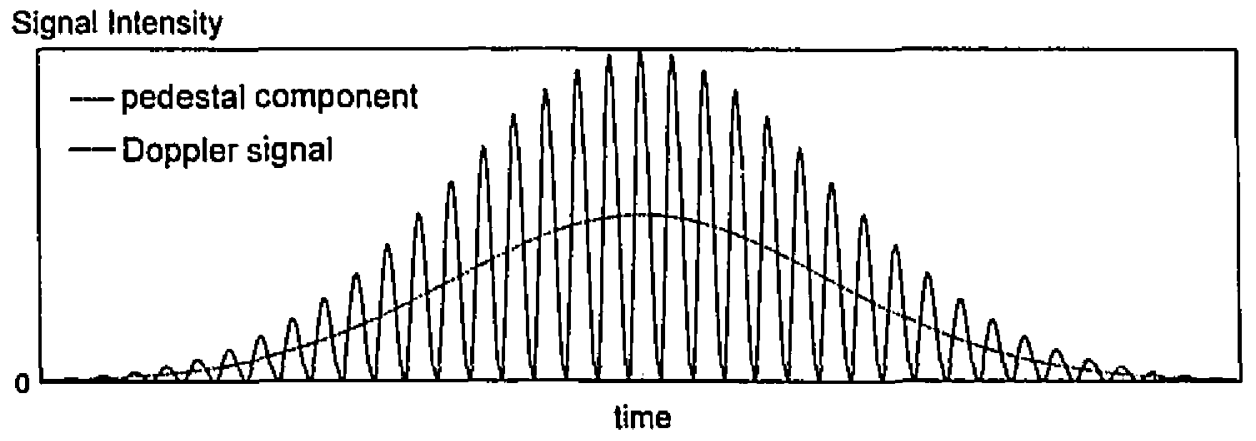

Figure 3.5 Laser Doppler anemometer signal.

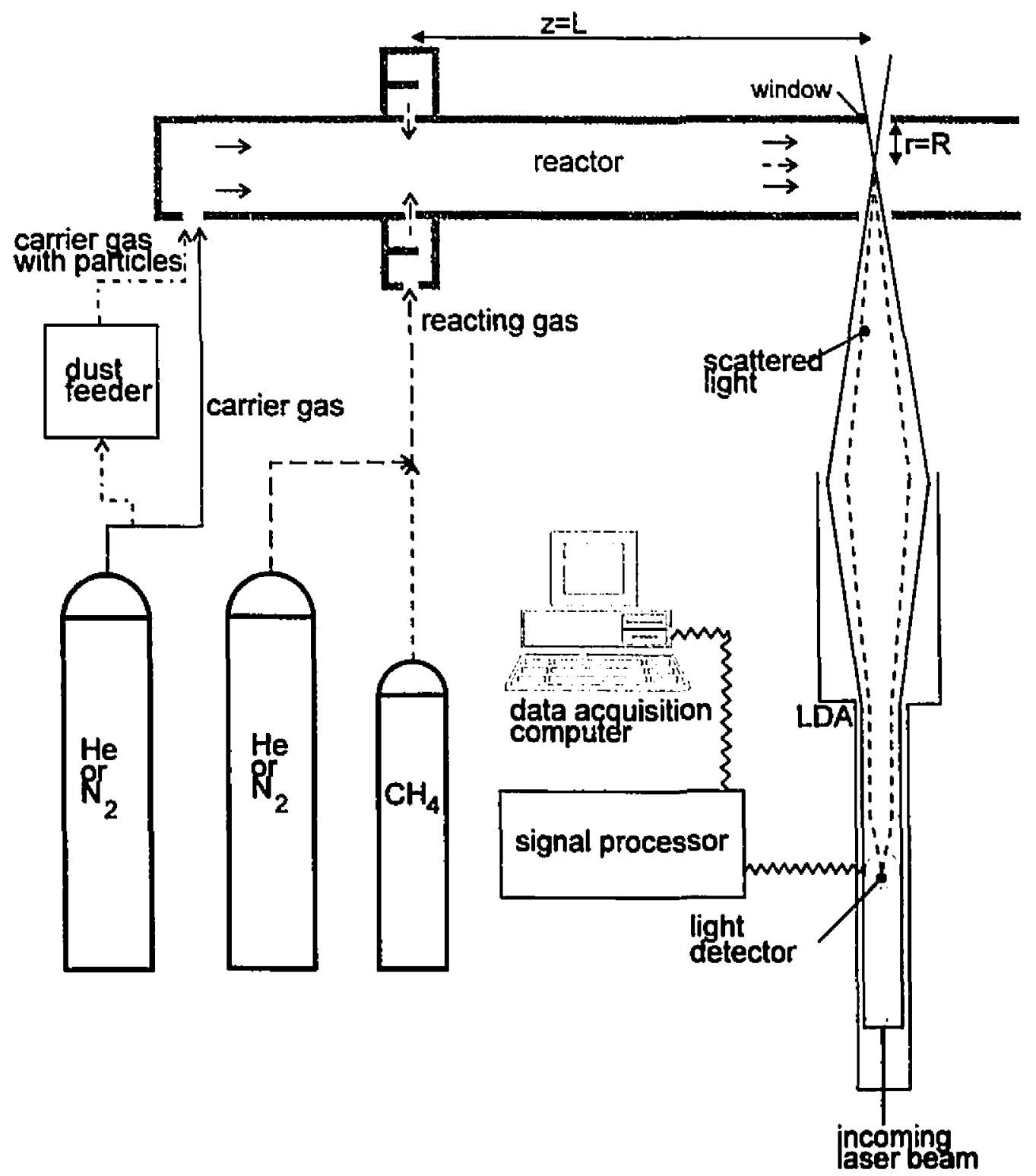

Figure 3.6 Reactor setup with the laser Doppler anemometer. 


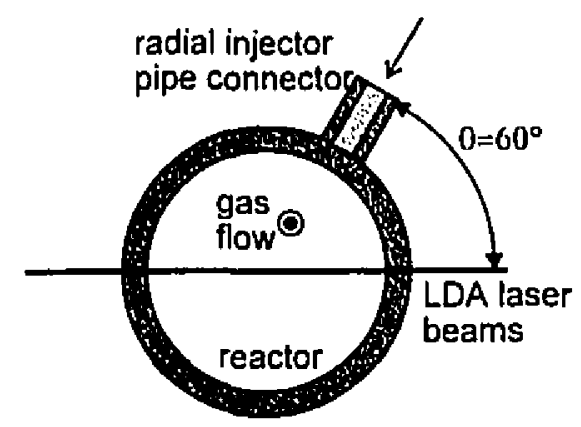

Figure 3.7 Angle between the axis of the laser beams and the pipe connector of the radial injector.

Table 3.2 Experimental conditions for the velocity measurements.

\begin{tabular}{|c|c|c|}
\hline Carrier Gas & $\begin{array}{l}\text { Reacting Gas } \\
\text { (Jet Velocity) }\end{array}$ & Axial Locations \\
\hline $\mathrm{N}_{2}: 50.5 \mathrm{l} / \mathrm{min}$ & $\begin{array}{l}\text { none }(0 \mathrm{~m} / \mathrm{s}) \\
\text { - } \mathrm{CH}_{4}: 2.2 \mathrm{l} / \mathrm{min}(3.1 \mathrm{~m} / \mathrm{s}) \\
\text { - } \mathrm{CH}_{4}: 3.9 \mathrm{l} / \mathrm{min}(5.5 \mathrm{~m} / \mathrm{s}) \\
\text { - } \mathrm{CH}_{4}: 2.7 \mathrm{l} / \mathrm{min}-\mathrm{N}_{2}: 3.7 \mathrm{l} / \mathrm{min}(8.1 \\
\mathrm{m} / \mathrm{s}) \\
\text { - } \mathrm{N}_{2}: 10.5 \mathrm{l} / \mathrm{min}(14.7 \mathrm{~m} / \mathrm{s}) \\
\text { - } \mathrm{N}_{2}: 25.4 \mathrm{l} / \mathrm{min}(35.7 \mathrm{~m} / \mathrm{s}) \\
\end{array}$ & $\begin{array}{l}\text { - } 2.7 \mathrm{~cm} \\
\text { - } 12.1 \mathrm{~cm} \\
\text { - } 21.4 \mathrm{~cm} \\
\text { - } 30.7 \mathrm{~cm}\end{array}$ \\
\hline He: $52.1 \mathrm{l} / \mathrm{min}$ & $\begin{array}{l}\text { none }(0 \mathrm{~m} / \mathrm{s}) \\
\text { - } \mathrm{CH}_{4:} 3.9 \mathrm{l} / \mathrm{min}(5.5 \mathrm{~m} / \mathrm{s}) \\
\text { - He: } 10.7 \mathrm{l} / \mathrm{min}(15.0 \mathrm{~m} / \mathrm{s})\end{array}$ & $\begin{array}{l}-2.7 \mathrm{~cm} \\
-\quad 12.1 \mathrm{~cm} \\
-\quad 30.7 \mathrm{~cm}\end{array}$ \\
\hline
\end{tabular}

\subsection{Concentration Measurements}

Infrared absorption spectroscopy was chosen to measure concentration primarily for its nearly instantaneous response time. The choice then remained to find a suitable light source-absorber-detector combination that would perform well and cost as little as possible. A He-Ne infrared laser-methane-lead selenide detector combination was finally chosen. 
The He-Ne laser is one of the cheapest sources of inirared radiation. Its main inconvenience is that it emits only at a few discrete wavelengths. However, this turned out to be an advantage since the $\mathrm{C}-\mathrm{H}$ bond of most organic molecules absorbs strongly at $3.391 \mu \mathrm{m}$, one of the laser wavelengths. Compared to conventional polychromatic (broadband) infrared sources, the laser beam is already focused and does not require bandpass filters to eliminate the undesirable wavelengths unless the background radiation is high. Using such a laser, Jaynes and Beam ${ }^{(10)}$ measured the absorptivity of several hydrocarbons and found it to be high. The laser used for this research was a Trius Engineering $2 \mathrm{~mW}$ He-Ne emitting at $3.391 \mu \mathrm{m}$.

Methane $\left(\mathrm{CH}_{4}\right)$ was selected to be the monitored chemical species (tracer). It is a readily available gas, one of the strongest absorbers at $3.391 \mu \mathrm{m}$ and its spectroscopic constants are well known. The gas used for the experiments was approximately $99 \%$ pure. Lead selenide $(\mathrm{Pb}-\mathrm{Se})$ detectors are relatively expensive compared to other infrared detectors, but they can be operated at $20^{\circ} \mathrm{C}$ rather than sub-zero temperatures and their response time is in the order of microseconds. An Oriel Pb-Se detector was employed. To improve the quality of the detector signal, the laser beam was modulated by using a rotating wheel light chopper.

Figure 3.8 is a diagram of the experimental setup for concentration measurements. The laser beam passed along a diameter of the reactor through two sapphire windows $1.27 \mathrm{~cm}$ in diameter ( $0.5 \mathrm{in})$. The detector was placed on the side of the reactor opposite to the laser. The whole system was aligned using a visible red He-Ne laser. The detector signal was sent to an oscilloscope and then to a computer for analog to digital (A/D) conversion and storage. Figure 3.9 is a picture of the setup: the laser is located in the upper part of the picture while the $\mathrm{Pb}-\mathrm{Se}$ detector is at the bottom.

Initially, there was no methane flowing in the reactor. To start an experiment, at a time $t=0$, a fraction or the total flow of the reacting gas, either nitrogen or helium, was replaced by methane. This was accomplished by using the computer to trigger solenoid valves and 
at the same time to start to record the detector signal. The total reacting gas flow rate remained constant before and after $t=0$; the carrier gas flow was unaltered. The solenoid valve on the $\mathrm{CH}_{4}$ stream was 3-way so that the methane flow was simply diverted from an exhaust stream to the injector stream upon triggering. Methane had only to be injected in small amounts to produce good measurements, about 3 to $7 \%$ of the total gas flow on a molar basis. Concentrations as low as $0.1 \%$ were easily detectable.

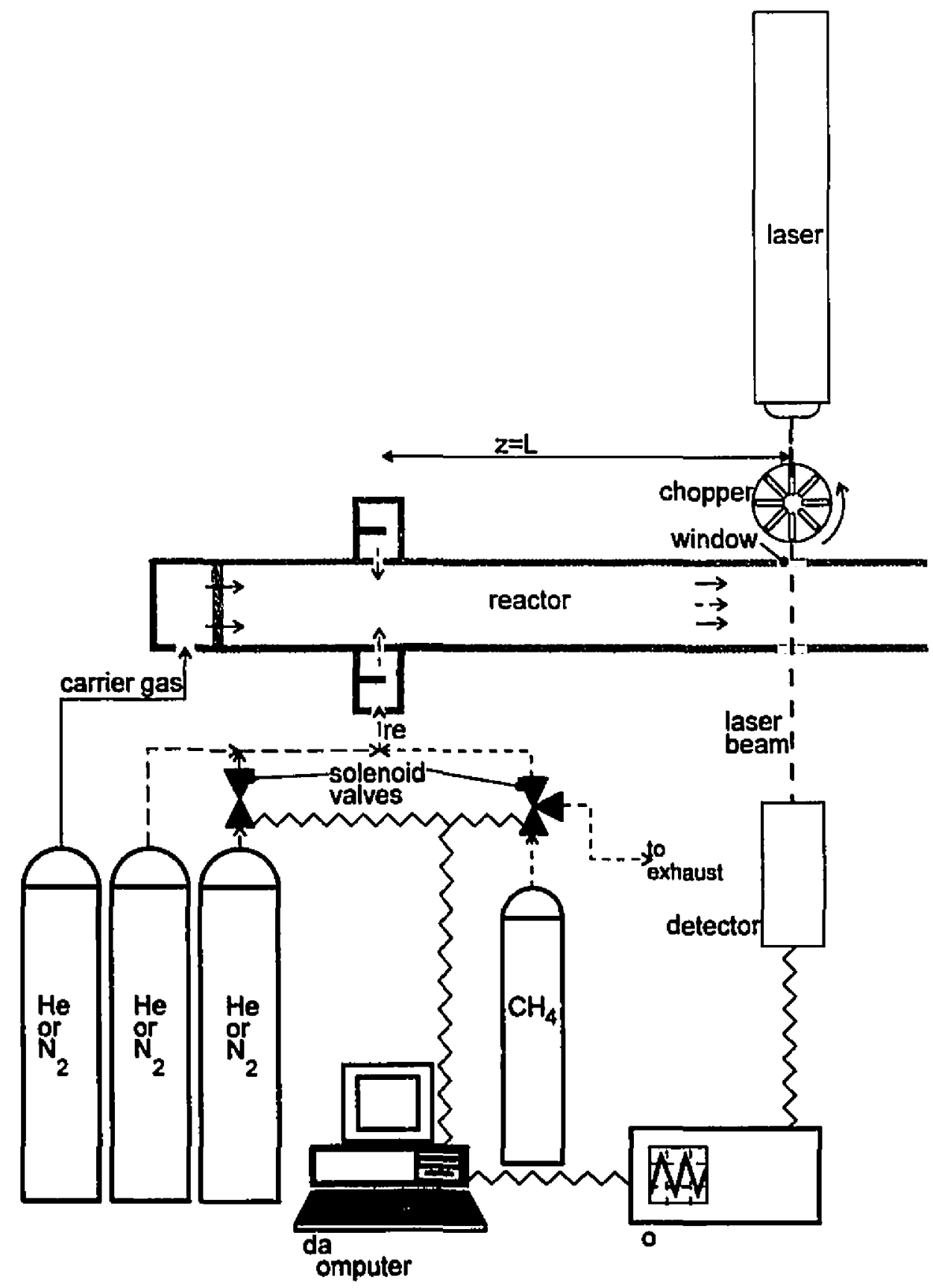

Figure 3.8 Reactor setup with the RTD measurement system. 


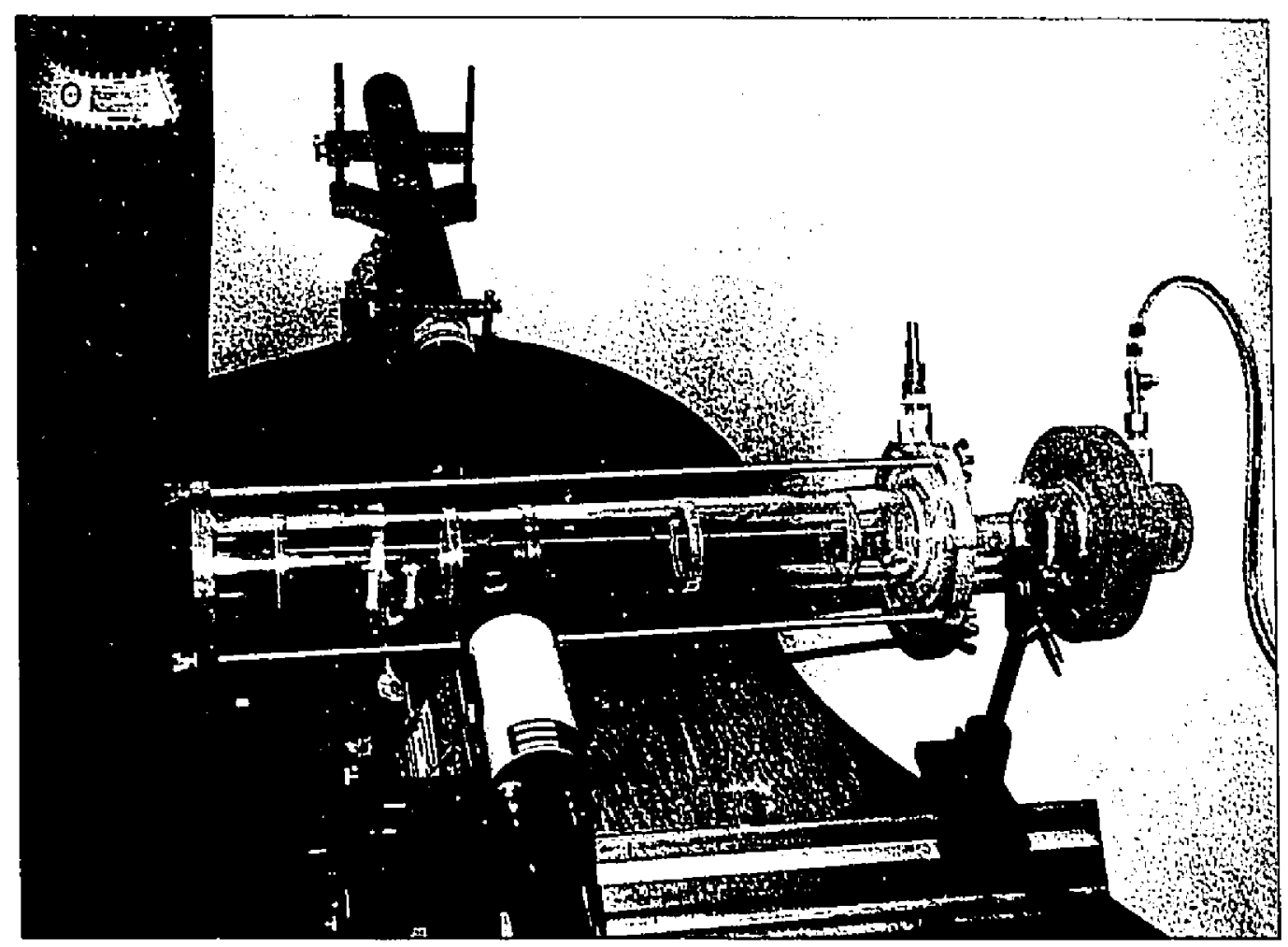

Figure 3.9 Picture of the reactor setup with the He-Ne laser, chopper and detector.

The signal obtained from the detector, as viewed on an oscilloscope, resembled the one displayed in Figure 3.10. The signal was centered at about zero Volts by the detector electronic circuitry. The high voltage peaks (portion (1) on the figure) corresponded to when the laser was unobstructed by the chopper wheel. The low regions between peaks (valleys, portion (3) were caused by the laser beam being blocked by the chopper. The slopes between the high and low regions (portion (2)) resulted from the partial obstruction of the laser beam by the chopper wheel. The computer sampled the signal for analog to digital conversion once for each peak and valley. The sampling rate varied from 2 to 8 $\mathrm{kHz}$. The voltage difference between a peak and its adjacent valley was directly proportional to the light intensity; two A/D conversions were needed to obtain one light intensity measurement. Before the measurements were converted to concentration, the digital signal was filtered using a lowpass Butterworth filter to remove the background noise. 


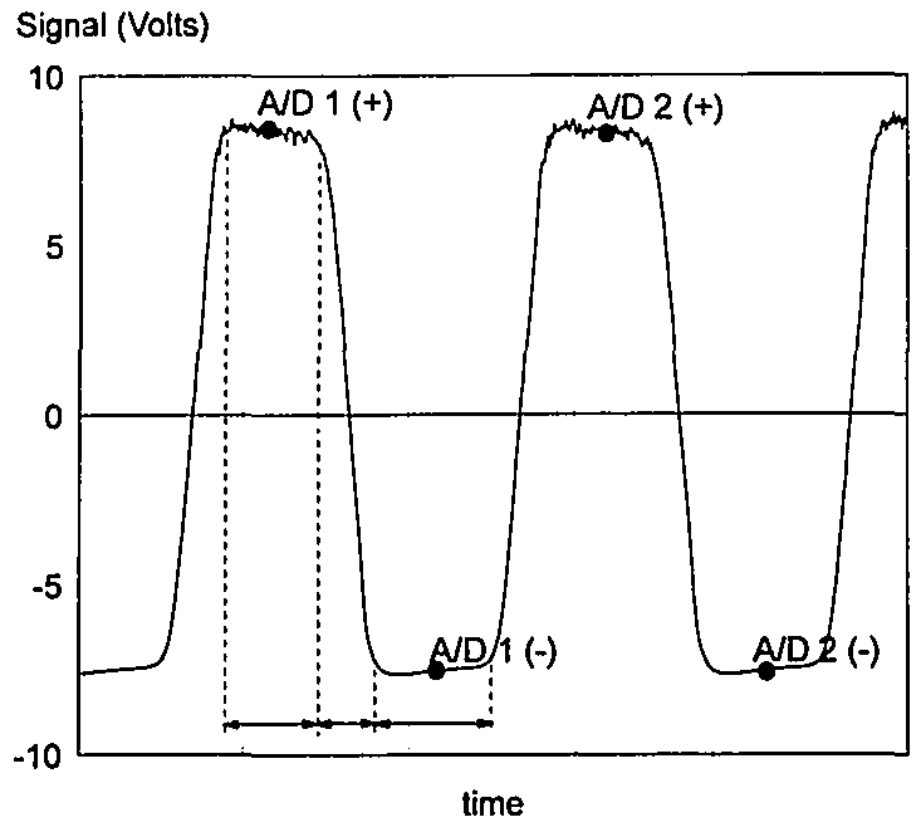

Figure 3.10 Raw signal from the lead selenide detector: the black dots are where the signal is sampled for analog to digital conversion.

To relate the intensity of the laser light (the signal from the detector) to concentration, the Beer-Lambert law (equation 2.17) was used. The incident beam intensity $I_{0}$ was taken as the signal intensity when no methane was present. The path length $x$ was equal to the reactor diameter. To determine the absorptivity $(\alpha)$, experiments were performed where the intensity of the laser beam was measured after passing through known concentrations of methane. The results are plotted in Figure 3.11. The straight line indicated that BeerLambert law was followed very accurately over the entire concentration range used for this research. A similar plot with only the lower concentration values (not shown) gave statistically identical results. The absorptivities were calculated to be 8.24 and 10.85 $\mathrm{atm}^{-1} \cdot \mathrm{cm}^{-1}$ in nitrogen and helium, respectively. When air was substituted to nitrogen, the absorptivity obtained was $8.40 \mathrm{~atm}^{-1} \cdot \mathrm{cm}^{-1}$, but this was not statistically different from the value for $\mathrm{N}_{2}$. 


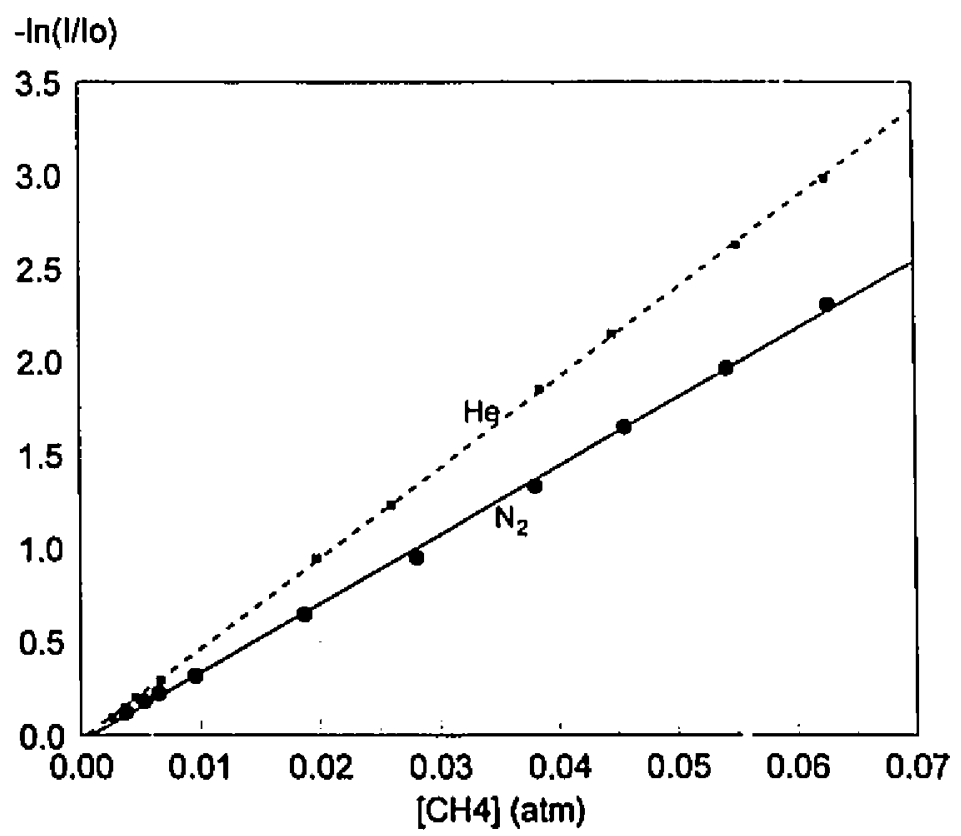

Figure 3.11 Normalized intensity of the signal versus methane concentration in two different gases: nitrogen and helium ( $T=293 \mathrm{~K}, \mathrm{P}=1 \mathrm{~atm})$.

A value of $\alpha=15 \mathrm{~atm}^{-1} \cdot \mathrm{cm}^{-1}$ has previously been published by Jaynes and Beam ${ }^{(11)}$ for $\mathrm{CH}_{4}$ in air measured under similar conditions. The difference with this research results is hard to explain. A possibility is that the methane used for this research calibration measurements (and only for the calibration measurements) was about $93 \%$ pure only (natural gas quality). However, it is believed by the author that this can only account for a part of the difference between the two values. Other hydrocarbons that may be present with natural gas have absorptivities in the same range as $\mathrm{CH}_{4}$. A more probable explanation could be the different lasers used: a very slight wavelength shift can cause large absorptivity differences. Nevertheless, the analysis of the RTD is independent of the value of $\alpha$ as will be shown in Section 3.5.

It can be seen in Table 3.3 that the experimental conditions for the concentration experiments were similar to the ones for the velocity measurements. One important difference is that concentration experiments were taken at many angles (refer to Figure 3.7). This was necessary because it was discovered from the velocity measurements that 
the flow was not symmetric with respect to the angular coordinate. This will be explained more thoroughly in the next chapter.

Table 3.3 Experimental conditions for the concentration measurements.

\begin{tabular}{|c|c|c|c|}
\hline $\begin{array}{c}\text { Carrier } \\
\text { Gas }\end{array}$ & $\begin{array}{l}\text { Reacting Gas } \\
\text { (Jet Velocity) }\end{array}$ & Angle & $\begin{array}{c}\text { Axial } \\
\text { Locations }\end{array}$ \\
\hline $\begin{array}{c}\mathrm{N}_{2}: \\
46.8 \mathrm{l} / \mathrm{min}\end{array}$ & $\begin{array}{ll}\text { - } & \mathrm{CH}_{4}: 1.6 \mathrm{l} / \mathrm{min}(2.3 \mathrm{~m} / \mathrm{s}) \\
\text { - } & \mathrm{CH}_{4}: 3.3 \mathrm{l} / \mathrm{min}(4.6 \mathrm{~m} / \mathrm{s}) \\
\text { - } & \mathrm{CH}_{4}: 3.3 \mathrm{l} / \mathrm{min}-\mathrm{N}_{2}: 3.0 \mathrm{l} / \mathrm{min}(8.8 \mathrm{~m} / \mathrm{s}) \\
\text { - } & \mathrm{CH}_{4}: 3.3 \mathrm{l} / \mathrm{min}-\mathrm{N}_{2}: 5.9 \mathrm{l} / \mathrm{min}(12.9 \mathrm{~m} / \mathrm{s}) \\
\text { - } & \mathrm{CH}_{4}: 3.3 \mathrm{l} / \mathrm{min}-\mathrm{N}_{2}: 12.3 \mathrm{l} / \mathrm{min}(21.9 \mathrm{~m} / \mathrm{s}) \\
\text { - } & \mathrm{CH}_{4}: 3.8 \mathrm{l} / \mathrm{min}-\mathrm{N}_{2}: 23.4 \mathrm{l} / \mathrm{min}(38.2 \mathrm{~m} / \mathrm{s})\end{array}$ & $\begin{array}{ll}\text { - } & 0^{\circ} \\
\text { - } & 60^{\circ} \\
\text { - } & 120^{\circ}\end{array}$ & $\begin{array}{l}\text { - } 3.3 \mathrm{~cm} \\
\text { - } \quad 7.6 \mathrm{~cm} \\
\text { - } 12.7 \mathrm{~cm} \\
\text { - } 22.0 \mathrm{~cm} \\
35.6 \mathrm{~cm}\end{array}$ \\
\hline $\begin{array}{c}\text { He: } \\
44.7 \mathrm{l} / \mathrm{min}\end{array}$ & $\begin{array}{l}\text { - } \mathrm{CH}_{4}: 1.6 \mathrm{l} / \mathrm{min}(2.3 \mathrm{~m} / \mathrm{s}) \\
\text { - } \mathrm{CH}_{4}: 3.3 \mathrm{l} / \mathrm{min}(4.6 \mathrm{~m} / \mathrm{s}) \\
\text { - } \mathrm{CH}_{4}: 3.3 \mathrm{l} / \mathrm{min}-\mathrm{He}: 5.6 \mathrm{l} / \mathrm{min}(12.5 \mathrm{~m} / \mathrm{s}) \\
\text { - } \mathrm{CH}_{4}: 3.9 \mathrm{l} / \mathrm{min}-\mathrm{He}: 22.8 \mathrm{l} / \mathrm{min}(37.5 \mathrm{~m} / \mathrm{s})\end{array}$ & $\begin{array}{ll}- & 0^{\circ} \\
\text { - } & 60^{\circ} \\
\text { - } & 120^{\circ}\end{array}$ & $\begin{array}{l}\text { - } 3.3 \mathrm{~cm} \\
\text { - } 7.6 \mathrm{~cm} \\
\text { - } 12.7 \mathrm{~cm} \\
\text { - } 22.0 \mathrm{~cm} \\
\text { - } 35.6 \mathrm{~cm}\end{array}$ \\
\hline
\end{tabular}

\subsection{Limitations of the System}

When converting the signal from the detector to concentration, it was assumed that the concentration in the reactor was constant over the entire reactor diameter. This is a major assumption and it deserves more attention. Many conditions favor a uniform radial concentration: the tracer may be injected uniformly over the reactor cross section with a flat velocity profile, the radial dispersion coefficient may be high, the reactor radius may be small or the average residence time in the reactor can be very long. In most cases, however, it is a combination of those factors that is of concern.

In a stimulus-response type of experiment such as a RTD experiment, a non-uniform velocity profile favors a non-zero radial concentration gradient even if the tracer is uniformly injected over the reactor cross section. The following three graphs illustrate this effect. Consider the theoretical experiment where one would inject a step input of concentration $C_{0}$ at $t=0$ uniformly over the reactor cross section. Laminar flow with no 
diffusion is said to occur in the reactor. The molecules injected in the center of the reactor will escape much faster than the ones closer to the wall because of the higher velocity at the center. This can be expressed by the following equations

$$
\begin{array}{cc}
\frac{C}{C_{0}}(r, t)=0 \text { for } t \leq \frac{\tau}{2}\left(1-\left(\frac{r}{r_{0}}\right)^{2}\right) & \begin{array}{c}
\text { exit concentration for a step } \\
\text { input at } t=0 \text { in a laminar flow }
\end{array} \\
\frac{C}{C_{0}}(r, t)=1 \text { for } t \geq \frac{\tau}{2}\left(1-\left(\frac{r}{r_{0}}\right)^{2}\right) & \text { tubular reactor }
\end{array}
$$

where $r$ is any radial location and $r_{0}$ is the reactor radius. Figure 3.12 displays the resulting radial concentration profiles at different times.

If a concentration measuring device such as the one described in this thesis is placed at the reactor exit, then the measured concentration is in error compared to the mixing cup outlet concentration. The measured concentration is given by

$$
\frac{C}{C_{0}}=\frac{I_{0} \exp \left(-2 \alpha \int_{0}^{r_{0}} C(r, t) d r\right)}{C_{0}} \quad \begin{aligned}
& \text { measured concentration } \\
& \text { at the reactor exit }
\end{aligned}
$$

while the mixing cup concentration is obtained by equations 2.2 and 2.9 . Figures 3.13 and 3.14 display the measured and mixing cup concentrations and the error between the two, respectively. At least for a small time portion of the overall experiment, the relative error is large. In such a situation, a solution would be to make measurements not only through the centerline of the reactor but also at other locations. The reactor concentration profile would then be calculated mathematically using Abel's inversion.

For the reactor used in this research, it is unlikely that the methane is uniformly injected over the entire cross section. For fully developed pipe flow with the same Reynolds number, the radial Peclet number

$$
\mathrm{Pe}_{\mathrm{r}}=\frac{\mathrm{vd}}{\mathrm{D}_{\mathrm{r}}} \quad \begin{array}{r}
\text { radial Peclet } \\
\text { number }
\end{array}
$$

was measured to be approximately 40 (Levenspiel and Bischoff ${ }^{(3)}$ ). However, this value is expected to be lower close to the radial injection location because of the mixing induced by the jets. This is especially true at high jet velocities. Soucy, Jurewicz and 
Boulos $^{(7)}$ found under conditions similar to the ones used here that a reactor length of about $50 \mathrm{~mm}$ was enough to obtain complete radial mixing. They used a radial injector with four jets of $0.8 \mathrm{~mm}$ in diameter and a total gas flow through the jets of $12.1 \mathrm{1} / \mathrm{min}$ (STP). Their reactor diameter was $127 \mathrm{~mm}$, which is significantly larger than the one used for this research.

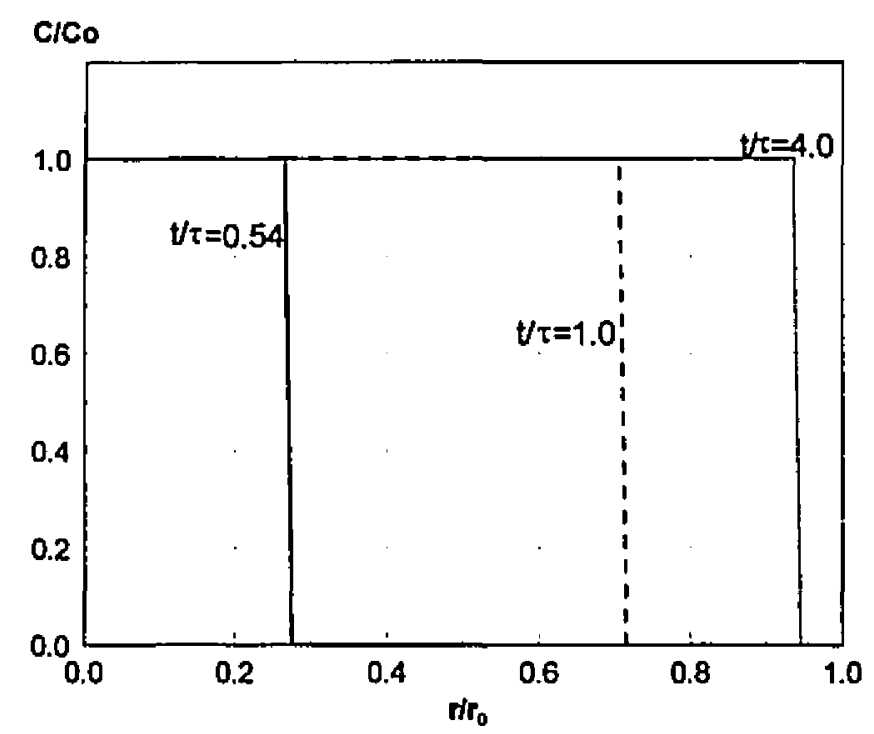

Figure 3.12 Radial concentration profiles at the reactor exit at different times for a step input of tracer in a laminar flow reactor.

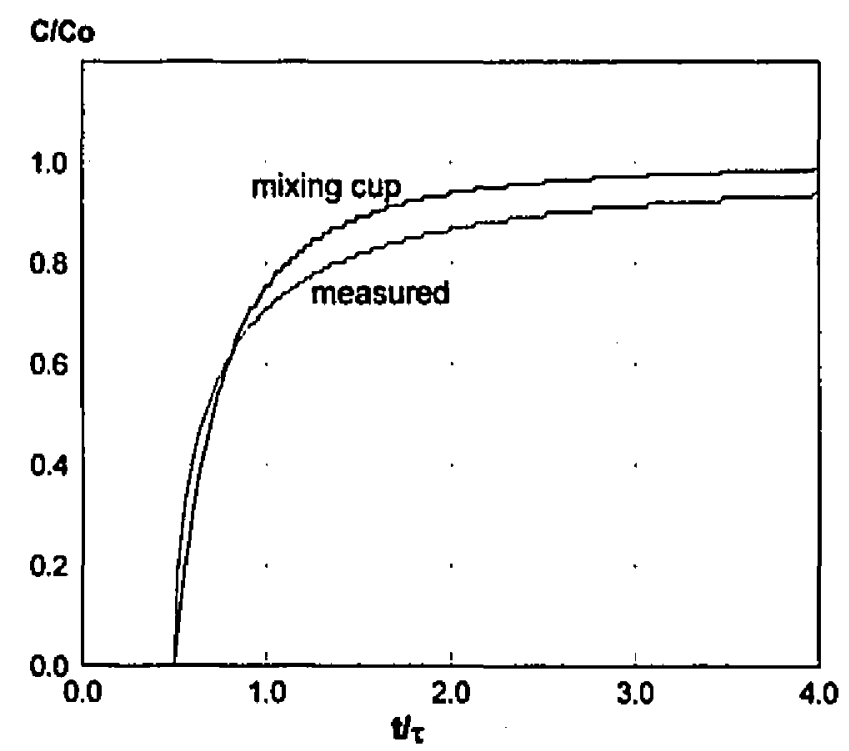

Figure 3.13 Mixing cup and measured concentration versus time for a step input of tracer in a laminar flow reactor. 


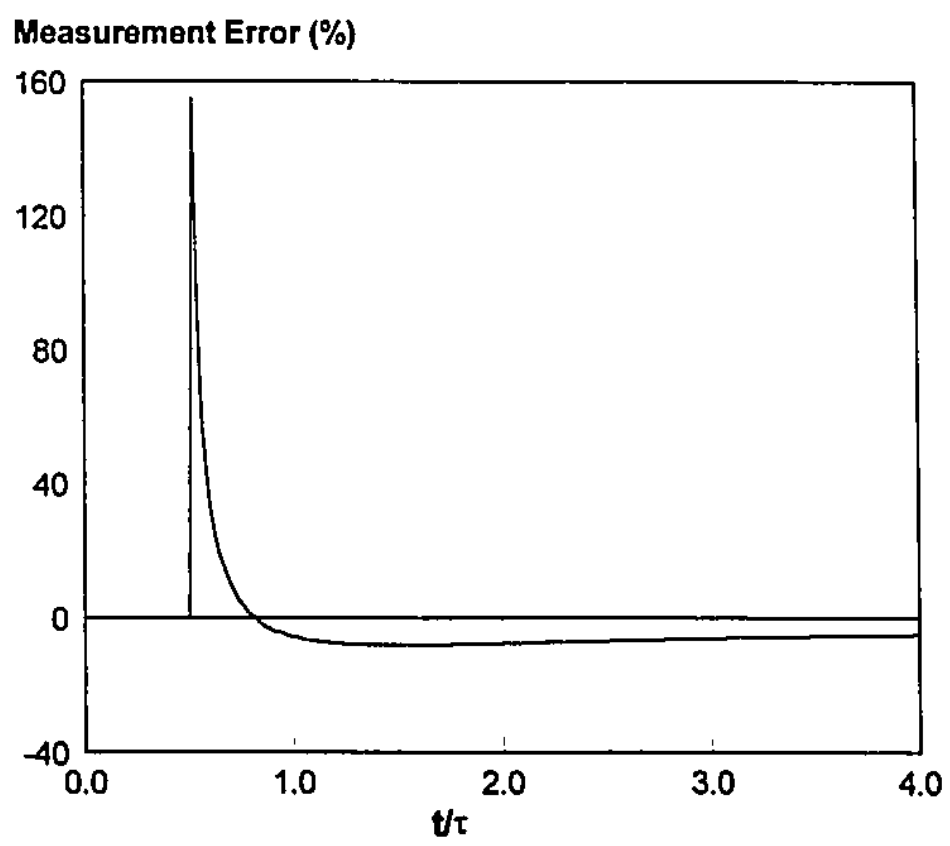

Figure 3.14 Percent error between the measured and mixing cup concentrations versus time for a step input of tracer in a laminar flow reactor.

Another limitation of the system used was that the input function to the reactor was not known precisely. It was neither a step nor a pulse and the function could not be estimated accurately. In consequence, the input had to be measured at some reactor location downstream of the radial injector. This means that all the RTD information between the injector location and the input measurement location was lost.

The solenoid valves used had a response time in the 4 to $8 \mathrm{~ms}$ range. Compared to the average residence time of most experiments performed (150 ms and higher), this can be considered to be close to a step input. However, experiments showed that the input to the reactor, i.e., in the reactor at the radial injection location, was no longer a step. Instead, the input looked like a diffused step as shown in Figure 3.15. This occurred by the combination of two effects:

1. Significant dispersion occurred in the length of pipe connecting the solenoid valves to the reactor injection chamber. 
2. The volume of the injector chamber was large enough so that it took a significant time to reach a constant $\mathrm{CH}_{4}$ concentration throughout the chamber. In addition, methane escaped first through the holes placed directly below the pipe connector.

It was found experimentally that $\Delta t_{v}<\Delta t_{p}<\Delta t_{r}$ (refer to Figure 3.15) and that $\Delta t_{r}$ was ranging from about 1100 to $30 \mathrm{~ms}$ for reacting gas flows of 1.6 to $27.2 \mathrm{l} / \mathrm{min}$, respectively. This was determined by placing the detection device directly at the exit of the pipe and the injector holes.

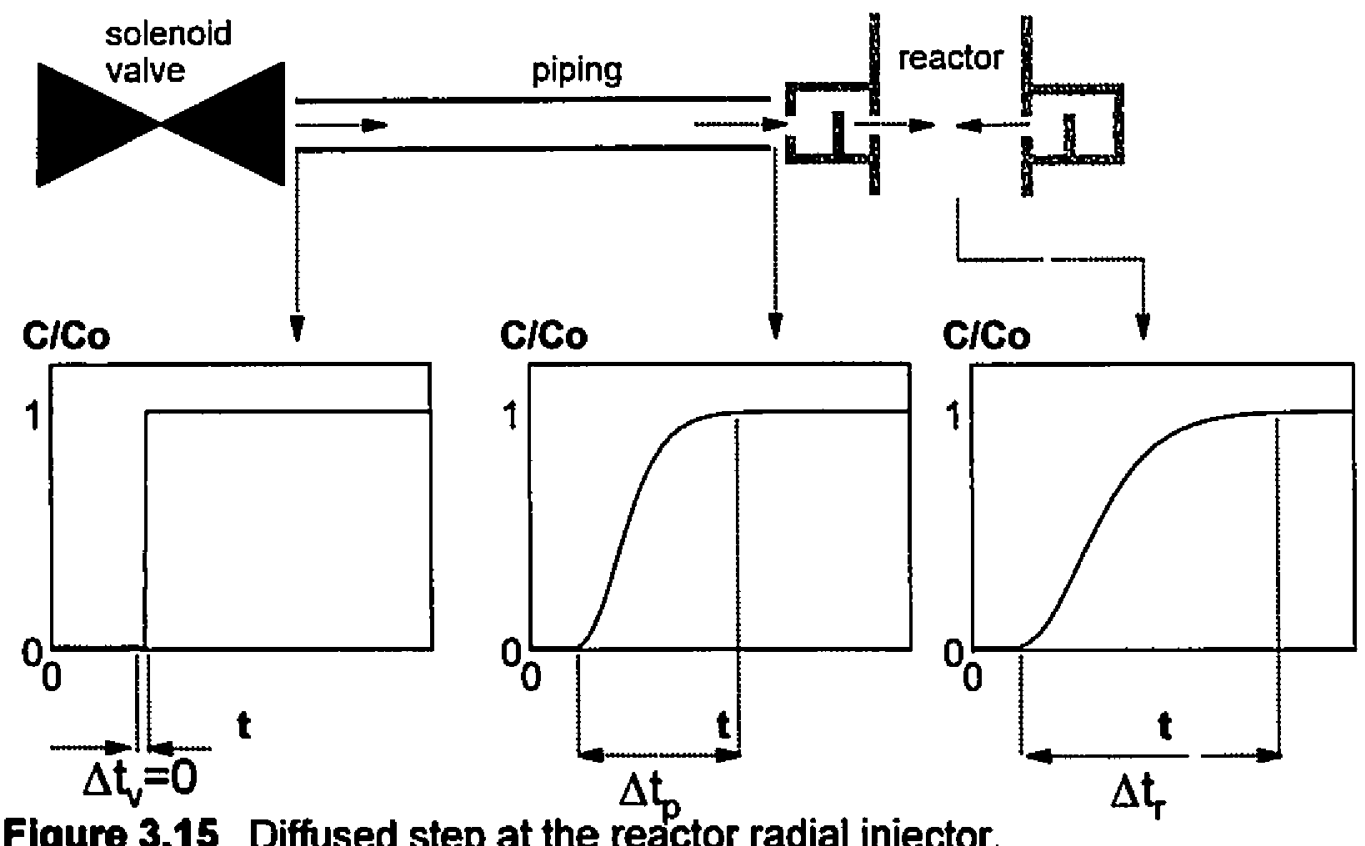

Figure 3.15 Diffused step at the reactor radial injector.

\subsection{Residence Time Distribution Measurements}

The purpose of this section is to discuss how the RTD information was extracted from the concentration experiments. Several methods were used; some of them were mentioned in chapter 2 . The experimental concentration curves were modeled by using functions with a known RTD.

The injector chamber and the piping between the valve and the reactor introduced a time delay from the time when the solenoid valves were triggered to the moment where the 
first $\mathrm{CH}_{4}$ molecule entered the reactor. This time delay was measured for the various reacting gas flow rates. It was done by placing the infrared laser beam in the axial direction of the reactor, under the jet placed directly under the pipe connector. As mentioned previously, this jet was the one where the methane escaped first after triggering the solenoid valves. The time delay was then easily determined from the absorption data: the moment at which the laser intensity started to decrease indicated the presence of methane. The measured time delays were subtracted from the time data of the concentration experiments.

Because the models that will be discussed shortly did not take into account angular variations of the concentration, the concentration vs time experiments made at different angles (but with the same flow rates and axial positions) were averaged. Also, to simplify the modeling of the concentration data, the methane concentration was normalized with respect to its steady state concentration, $C_{0}$. The values of $C / C_{0}$ were then ranging from 0 at the beginning to 1 at the end of an experiment. Using the normalized concentration data, the determination of the RTD was then independent of the absorptivity $(\alpha)$.

The input to the reactor was the variation of the concentration with time experiments made at an axial location as close to the radial injection point as possible. This location was selected to be the reactor entrance. The data had to be reliable, i.e., no significant radial concentration gradients should be present. The choice of the appropriate axial location for the reactor input will be discussed in the next chapter. An equation was fitted to the input data in order to smooth them. In all cases, the equation was of the form

$$
\left.\frac{C}{C_{0}}=0.51-\operatorname{erf}\left(\frac{\sqrt{P e_{\text {in }}} \frac{1-t / \tau_{\text {in }}}{2}}{\sqrt{t / \tau_{\text {in }}}}\right)\right]
$$

reactor input function

and an excellent fit was obtained with two adjustable parameters: $P e_{\text {in }}$ and $\tau_{\text {in }}$.

The axial position where the outlet measurement was taken was considered to be the reactor exit. Two different models were used to fit the concentration output. The first model was a reactor divided into two portions: a plug flow section and a laminar flow 
section. For an input function given by equation 3.6 , the concentration at the reactor outlet could then be described by

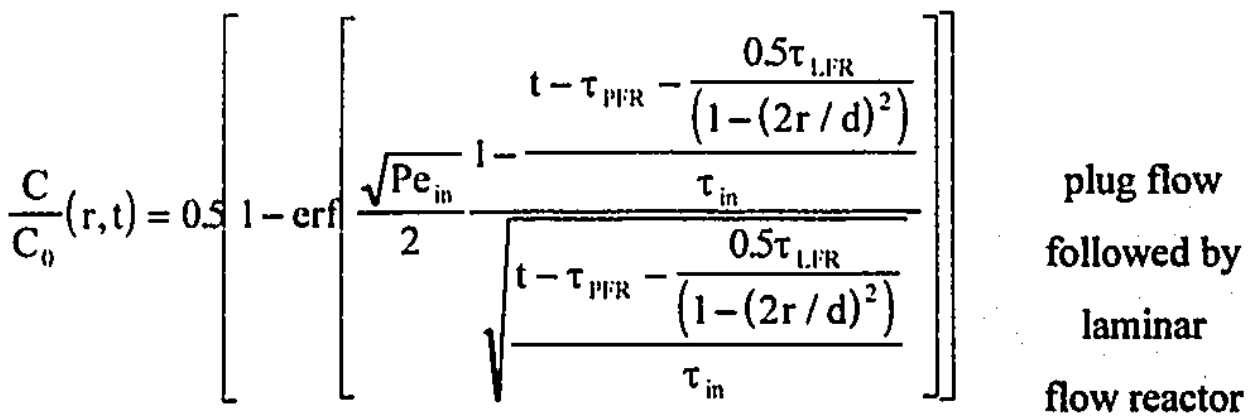

$$
\begin{aligned}
& \text { for } t>\tau_{P R R R}-0.5 \tau_{1 . F R} \\
& \text { model } \\
& \frac{C}{C_{0}}(r, t)=0 \text { for } t<\tau_{\text {PliR }}-0.5 \tau_{\text {LIPR }}
\end{aligned}
$$

where the adjustable parameters were $\tau_{\mathrm{PFR}}$ and $\tau_{\mathrm{LFR}}$, the space times for the plug flow and the laminar flow reactor portions, respectively. This is a one parameter model because the sum of the two space times has to be equal to $\tau$ which can be calculated from the total gas flow rate and the reactor volume. Equation 3.7 can be integrated numerically over the reactor cross section to obtain the mixing cup concentration. The optimal values of $\tau_{\mathrm{PFR}}$ and $\tau_{\mathrm{LFR}}$ were obtained by least square curve fitting. With these parameters, the RTD function $F(t)$ could then be determined by equation 2.8 and 2.9.

The second model was a tubular reactor with axial dispersion and flat velocity profile: the parameter to fit to the experimental data was the Peclet number. A closed-open type of vessel was assumed: the closed end was the inlet while the outlet was considered opened. By inspection of the reactor configuration, assuming a vessel with open-open boundary conditions would seem to be a more logical choice. In such a case, however the mean residence time $(\mu)$ would not equal the space time $(\tau)$. Instead the relation between the two would be (Fogler ${ }^{(14)}$ )

$$
\tau=\frac{\mu}{(1+2 / \mathrm{Pe})} . \quad \text { space time for open-open vessel }
$$

Because the values of Pe calculated were in the approximate range 8 to 30 , the average residence time $(\mu)$ should be significantly higher than the space time $(\tau)$ according to this 
equation for at least some experiments. As shown in Table 3.4, this was not the case. The assumption of a closed-open system thus appeared more appropriate.

Table 3.4 Comparison of mean residence times and space times for measurements done with nitrogen.

\begin{tabular}{|c|c|c||c|c|}
\hline \multirow{2}{*}{$\begin{array}{c}\text { Jet Velocity } \\
(\mathrm{m} / \mathrm{s})\end{array}$} & \multicolumn{2}{|c|}{$\tau(\mathrm{s})$} & \multicolumn{2}{c|}{$\mu(\mathrm{s})$} \\
\cline { 2 - 5 } & $z=7.6-22.0 \mathrm{~cm}$ & $z=7.6-35.6 \mathrm{~cm}$ & $z=7.6-22.0 \mathrm{~cm}$ & $z=7.6-35.6 \mathrm{~cm}$ \\
\hline \hline 12.9 & 0.246 & 0.479 & 0.238 & 0.472 \\
21.9 & 0.222 & 0.431 & 0.207 & 0.420 \\
38.2 & 0.187 & 0.364 & 0.166 & 0.352 \\
\hline
\end{tabular}

Two different approaches were used to calculate the Pe value that would fit best the reactor output. The first one was a curve fitting method similar to the one for the laminar flow model. The equation used was the dispersion differential equation

$$
-v \frac{\partial C}{\partial z}+D_{L} \frac{\partial^{2} \mathrm{C}}{\partial \mathrm{z}^{2}}=\frac{\partial \mathrm{C}}{\partial \mathrm{t}} \quad \text { dispersion equation (1-dim.) }
$$

with the following boundary conditions:

$$
\begin{aligned}
& \text { at } z=0: v \frac{C}{C_{0}}(t)=-D_{L}\left(\frac{\partial C}{\partial z}\right)_{>0)}+v(C)_{z>0} \text { where } \frac{C}{C_{0}}(t) \text { was given by equation } 3.6 \\
& \text { at } \mathrm{P}>L: \frac{\partial C}{\partial z}=0 \text {. }
\end{aligned}
$$

It was integrated numerically by using the Galerkin finite element method.

The second method was statistical: it is described in Section 2.1 by equation 2.12. This equation is normally employed for open-open reactor configurations. However, the author found that the simplification of the more general expressions derived by Bischoff and Levenspiel ${ }^{(8)}$ gave the same relation for a closed-open vessel (letting $x_{0}=0, x_{m}=x_{e}$, $P_{b}=P$ and $P_{a}$ be very small in equation 4 of reference 8 ). The RTD function was calculated from equation 2.10 . 


\section{Chapter 4}

\section{Results and Discussion}

A large number of experimental results under various conditions were obtained. Only some representative examples are shown in this chapter in order to avoid overcrowding it. Additional results are included in Appendix A through C, referring to Sections 4.1 to 4.3, respectively.

\subsection{Velocity Measurements}

\subsubsection{Gas Flow without Radial Injection}

For velocity measurements, the porous plate intended to even the carrier gas flow was not employed because the carrier gas contained solid particles which would have clogged the plate. This caused problems since the carrier gas inlet was placed radially (refer to Figure 3.1). Figure 4.1 displays velocity data for no reacting gas flow at $L=2.7 \mathrm{~cm}$. (In these graphs, $v_{j c t}$ is the jet velocity: the reacting gas flow rate divided by the area of the 24 injection holes). The radial velocity profile was nearly flat with nitrogen but not with helium since helium is more viscous. This suggests that the measurements done with helium were affected by the lack of a porous plate while the ones with nitrogen were not significantly affected. When a reacting gas was injected, this phenomenon lost importance due to the interaction of the jets with the axial flow. 


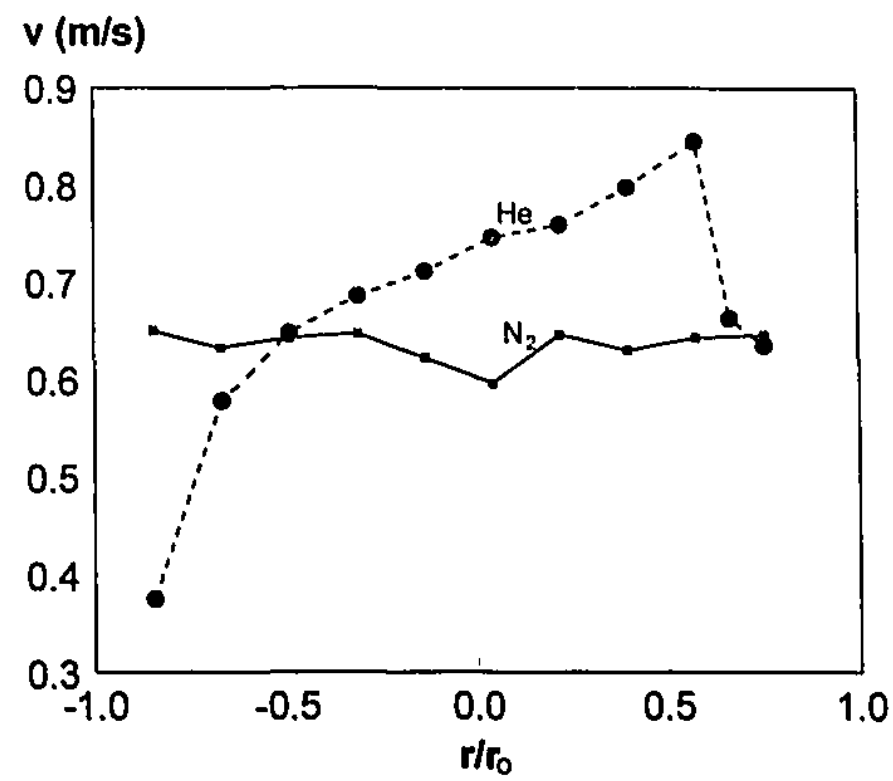

Figure 4.1 Radial velocity profiles $-v_{\text {jet }}: 0 \mathrm{~m} / \mathrm{s}, L=2.7 \mathrm{~cm}$.

\subsubsection{Effect of Axial Position}

Figures 4.2 and 4.3 display axial velocity measurements at various radial and axial locations (z) for nitrogen and helium experiments, respectively. The radial velocity profiles exhibited a core of high velocity at axial positions close to the radial injector $(\mathrm{L}=2.7 \mathrm{~cm})$. This core of high velocity was not centered radially; its causes will be explained below. When the radial jets had enough momentum to cross the axial tlow, which was believed to be the case for all but one experiment, they met at the center of the tube. This created an axial jet in the central region of the reactor. At equal reacting gas flow rates, the velocities were higher in this region with helium than nitrogen due to the more viscous flow. 


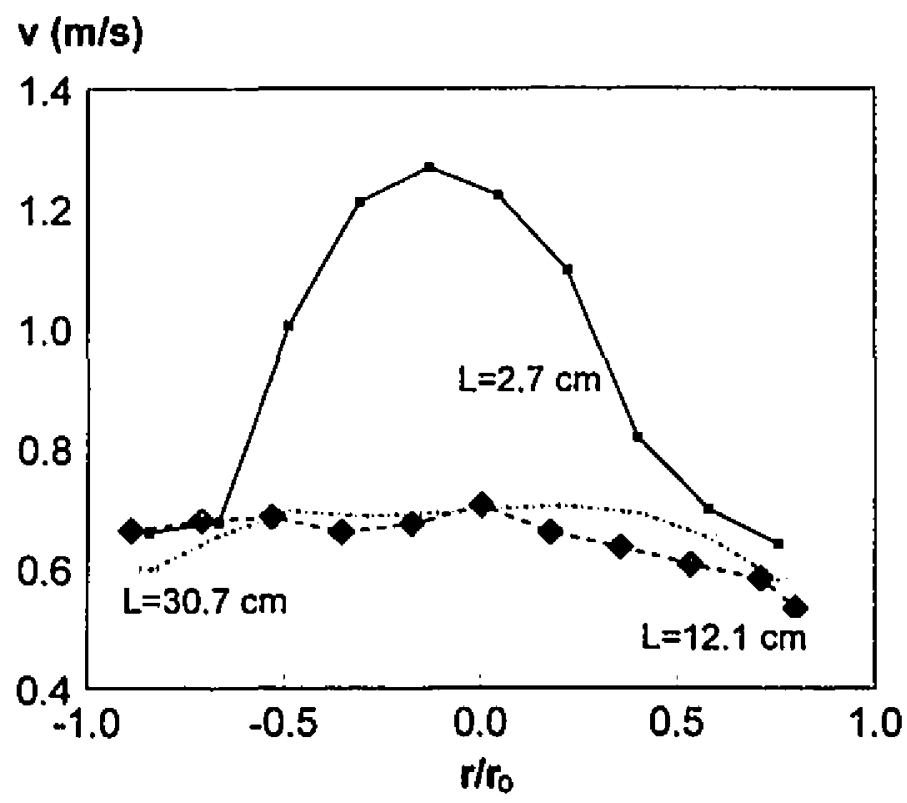

Figure 4.2 Radial velocity profiles at various axial locations - carrier gas: $\mathrm{N}_{2}$, $v_{\text {jet: }}: 8.1 \mathrm{~m} / \mathrm{s}, \operatorname{Re}=1550$.

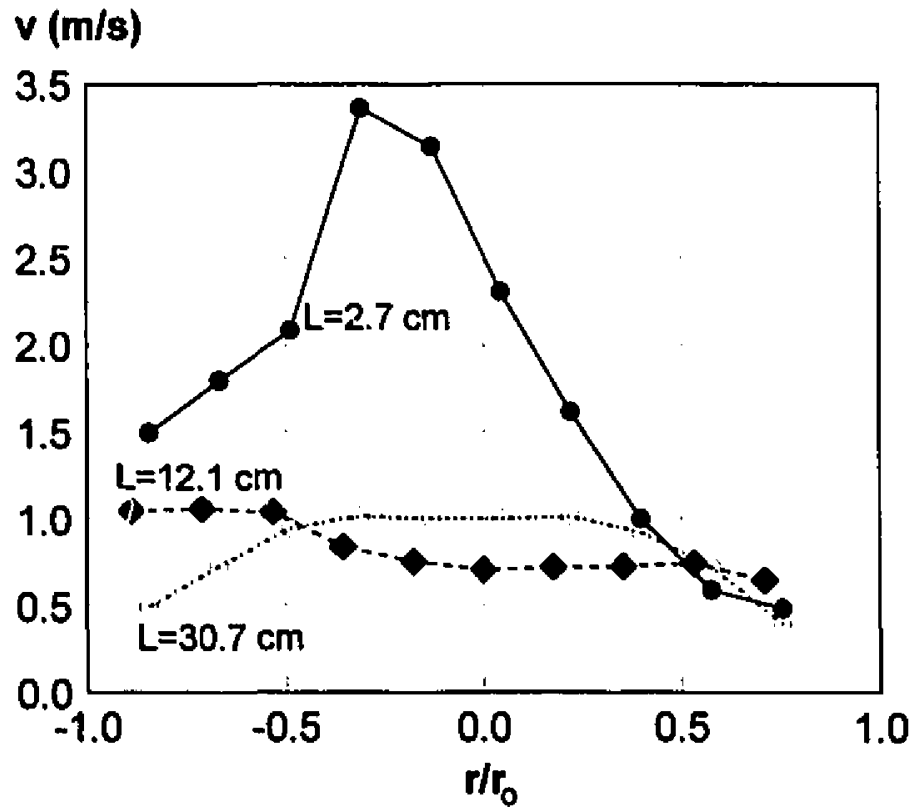

Figure 4.3 Radial velocity profiles at various axial locations - carrier gas: He, $v_{\text {jet }}: 15.0 \mathrm{~m} / \mathrm{s}, \operatorname{Re}=250$.

Further consideration of Figures 4.2-4.3 shows also that with an increase in L, the flow progressively became more symmetric about $r=0$ and the boundary layer close to the 
reactor wall started to develop. If the reactor were long enough, the radial velocity protile would eventually become parabolic, i.e., laminar flow conditions would prevail. Also, the boundary layer was more developed at $L=30.7 \mathrm{~cm}$ in Figure 4.3 than in Figure 4.2 due to the higher kinematic viscosity of He.

\subsubsection{Effect of Jet Velocity}

The effects of varying the amount of gas injected radiaiiy are displayed in Figures 4.4 through 4.7. As shown in Figures 4.4 and 4.6 at $L=2.7 \mathrm{~cm}$, when the jet velocity was increased, the axial velocity also increased because the total amount of gas injected in the reactor was larger. Also, the central high velocity core became more pronounced at higher jet velocities. This can mainly be attributed to the larger amount of reacting gas that was injected.

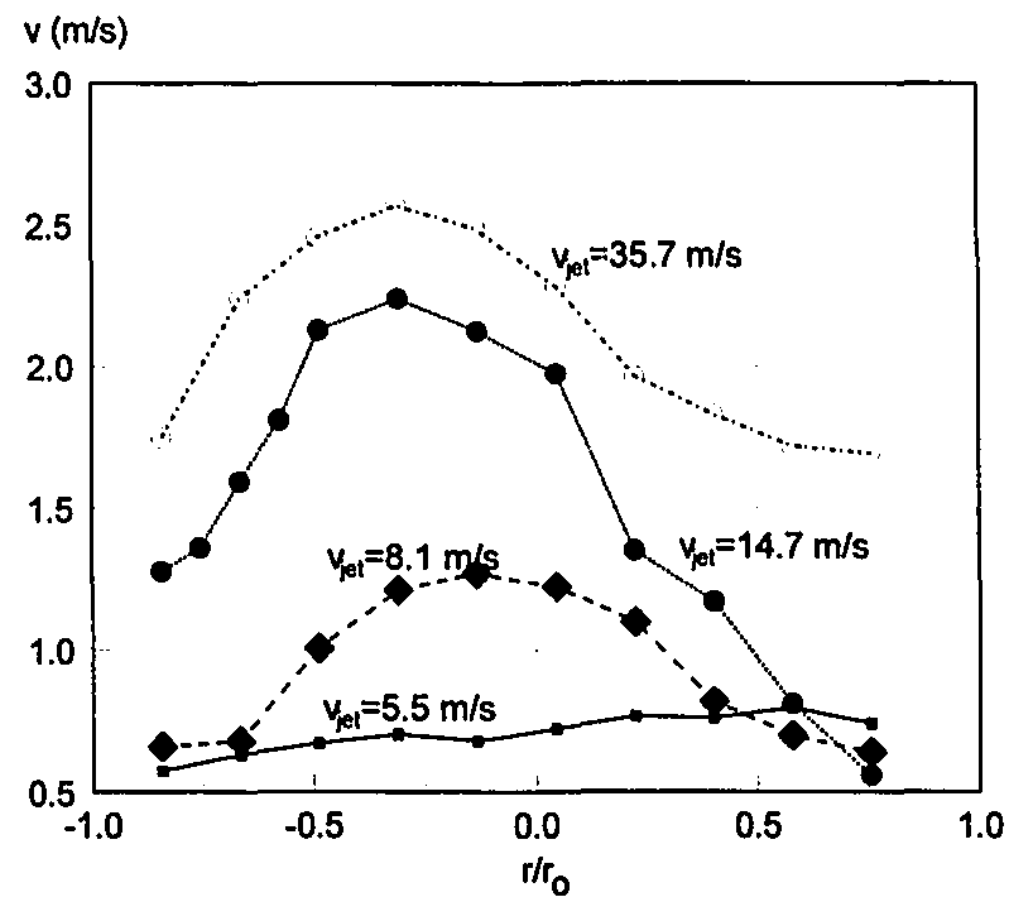

Figure 4.4 Radial velocity profiles for various jet velocities - carrier gas: $\mathrm{N}_{2}$, $\mathrm{L}=2.7 \mathrm{~cm}, \mathrm{Re}=1420-2370$. 


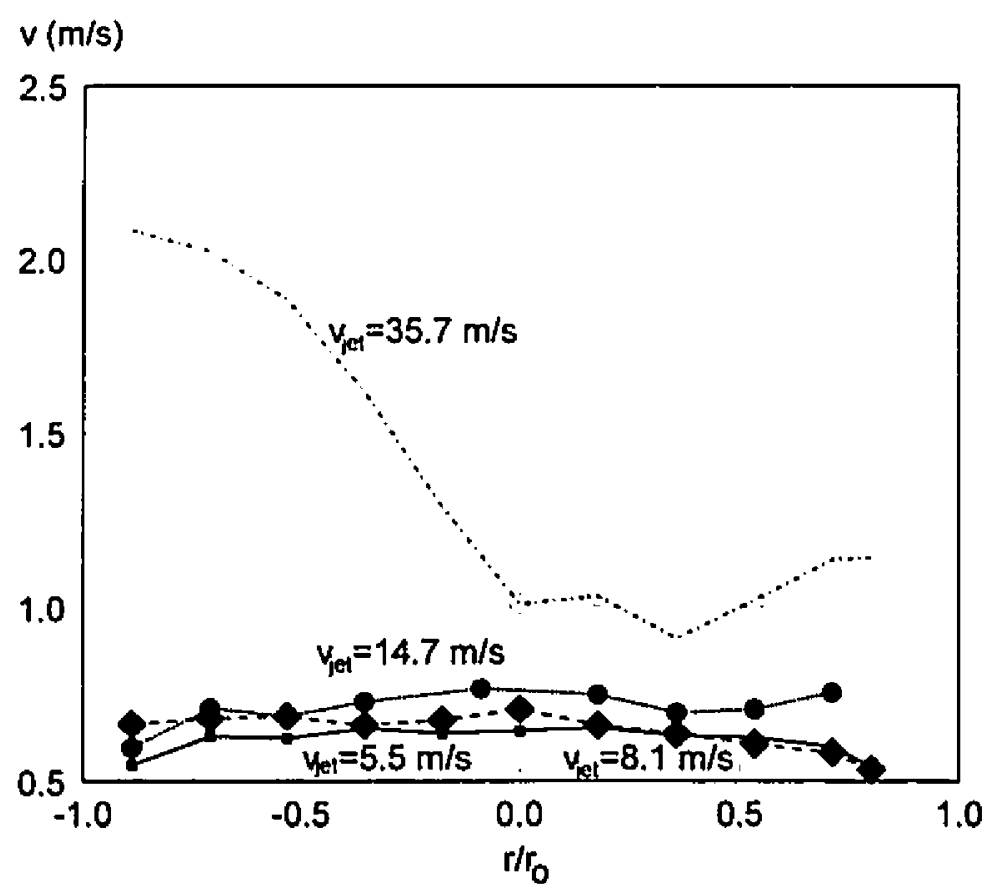

Figure 4.5 Radial velocity profiles for various jet velocities - carrier gas: $\mathrm{N}_{2}$, $L=12.1 \mathrm{~cm}, \operatorname{Re}=1420-2370$.

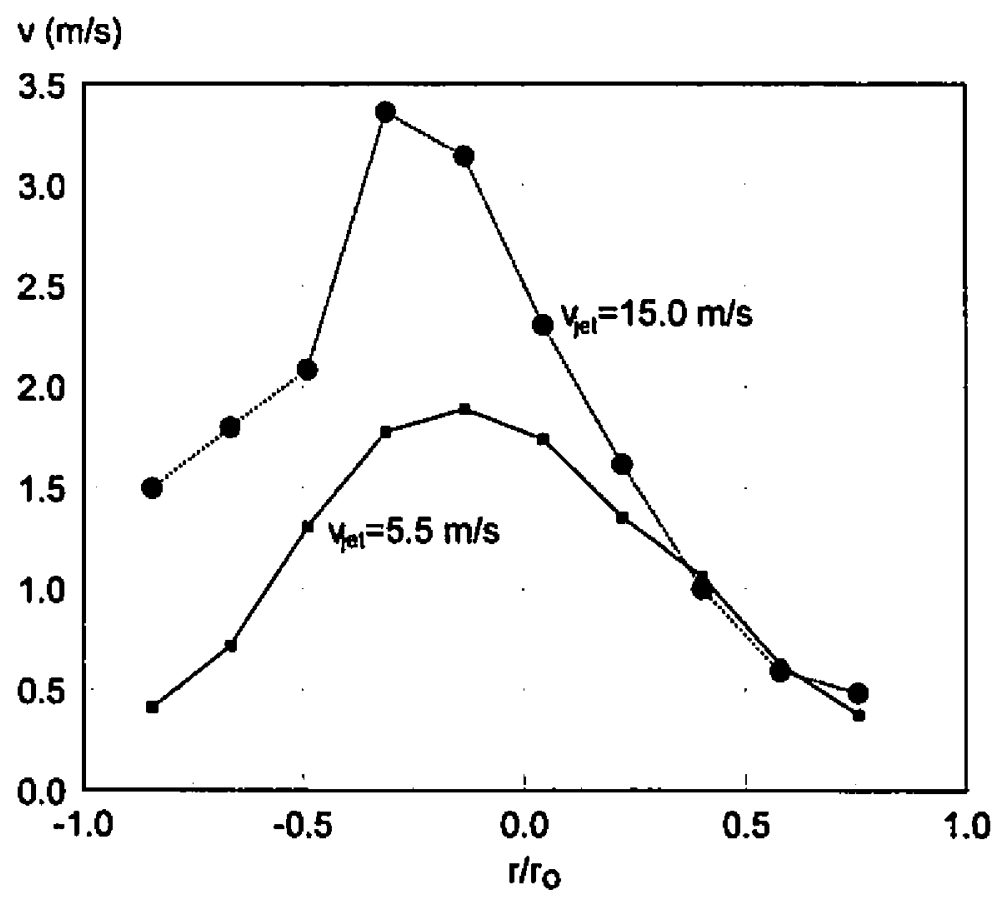

Figure 4.6 Radial velocity profiles for various jet velocities - carrier gas: $\mathrm{He}$ $\mathrm{L}=2.7 \mathrm{~cm}, \mathrm{Re}=240-250$. 


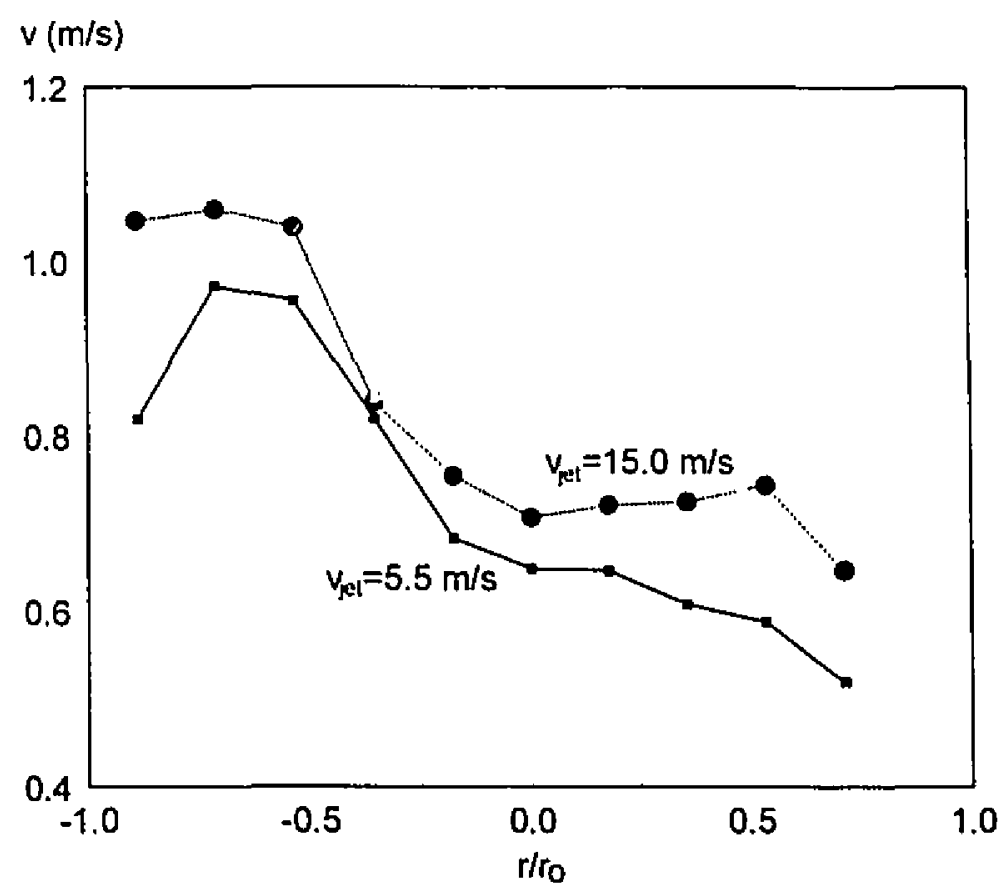

Figure 4.7 Radial velocity profiles for various jet velocities - carrier gas: He, $L=12.1 \mathrm{~cm}, R e=240-250$.

When the measurements done at $12.1 \mathrm{~cm}$ are compared to the ones at $2.7 \mathrm{~cm}$, it is observed that the high velocity core has shifted to the left reactor wall (negative $r / r_{\text {, }}$, values). This suggests that the velocity vector was not parallel to the reactor axis close to the injector. Instead, it had a radial component pointing to the left side of the wall. The same trend was displayed in Figures 4.2-4.3 but it was not as visible due to the larger scale of the velocity axis.

\subsubsection{Behavior of the Radial Injector}

In the light of the previous observations, it appeared that the flow close to the injector was not symmetric with respect to the radial coordinate. This was confirmed by a simple experiment: the reacting gas was replaced by water and no carrier gas was injected. $A$ picture of the water flow is displayed in Figure 4.8. Once the individual radial jets crossed each other, the resultant jet was not straight in the axial direction. It had a strong 
radial component at an angle $\theta$ around $90-120^{\circ}$ from the injector pipe connector (counterclockwise direction). This behavior was caused by two factors:

- the individual radial jets did not all impact each other at the same location

- some radial jets had lower velocities than others.

When a gas is used in the injector, the lower density of the gas probably results in a less pronounced anomalous behavior compared to the one with water. Figure 4.9 is a drawing showing the general shape of the expected velocity profile across the reactor: it is not to scale.

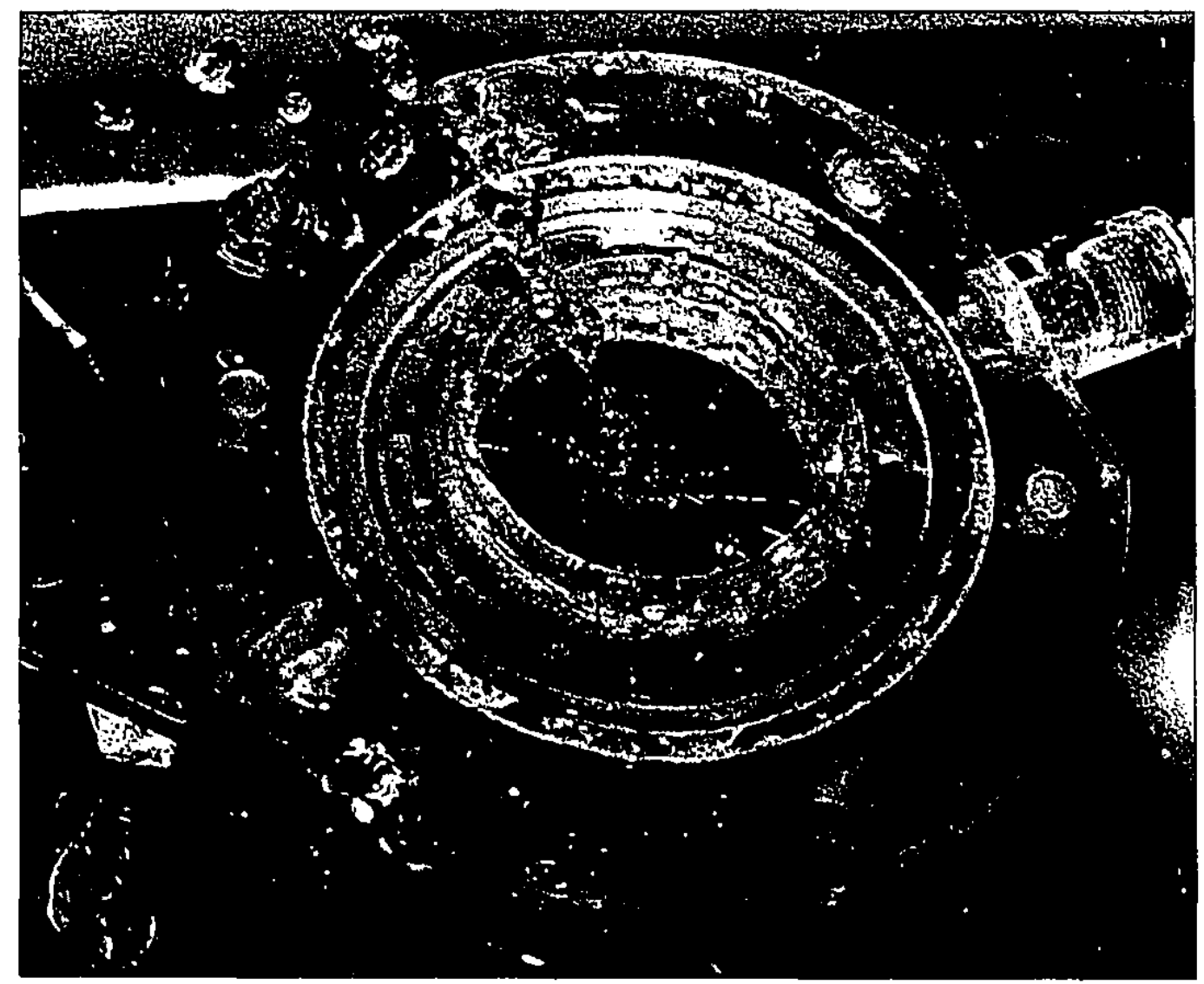

Figure 4.8 Picture of the radial injector when water was substituted to the reacting gas. 


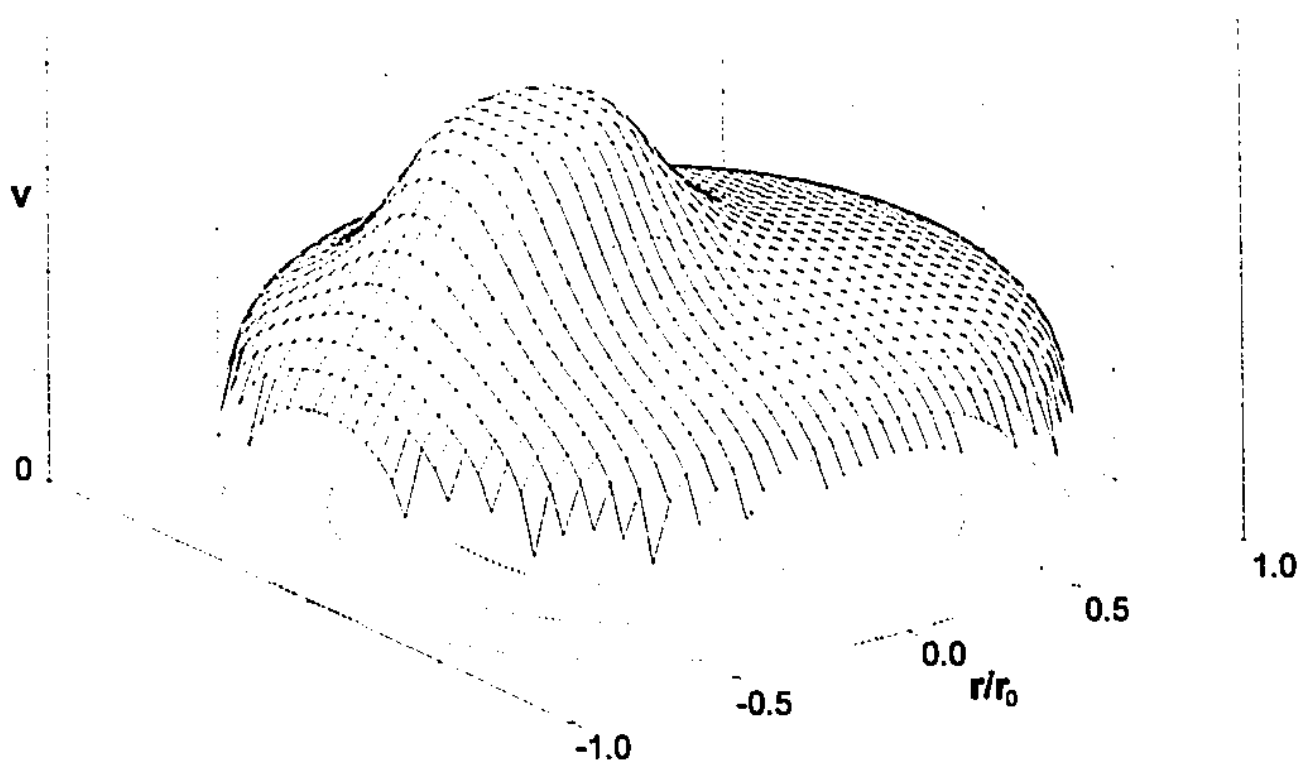

Figure 4.9 Probable velocity profile (axial component) over the reactor crosssection close to the radial injector $(L \approx 1-3 \mathrm{~cm})$ : the graph is not to scale.

The radial velocity profiies were integrated numerically over the reactor cross section and the flow rates calculated were compared with the known gas flow rate values. The relative error was defined as the difference between the two values above divided by the true value. The results are displayed in Figures 4.10-4.11 for nitrogen and helium, respectively. As a rule, the percentage error increased with jet velocity and it was larger for axial locations closer to the radial injector. This is easily understandable since the velocity profiles were less symmetric both in the radial and angular directions as $\mathbf{v}_{\mathrm{jet}}$ increased and $L$ decreased. There was a constant percentage error equal to about $-10 \%$ for experiments at low $v_{j e t}$ and/or at large $L$. It can be explained by the fact that the velocity was interpolated linearly between the measurements closest to the wall and the $r / r_{0}=1$ location where $v$ was assumed to be $0 \mathrm{~m} / \mathrm{s}$. The true average velocity in that reactor region was probably higher than the value obtained by linear interpolation. This 
reduced significantly the calculated flow rate value, thus causing the percentage error to be negative.

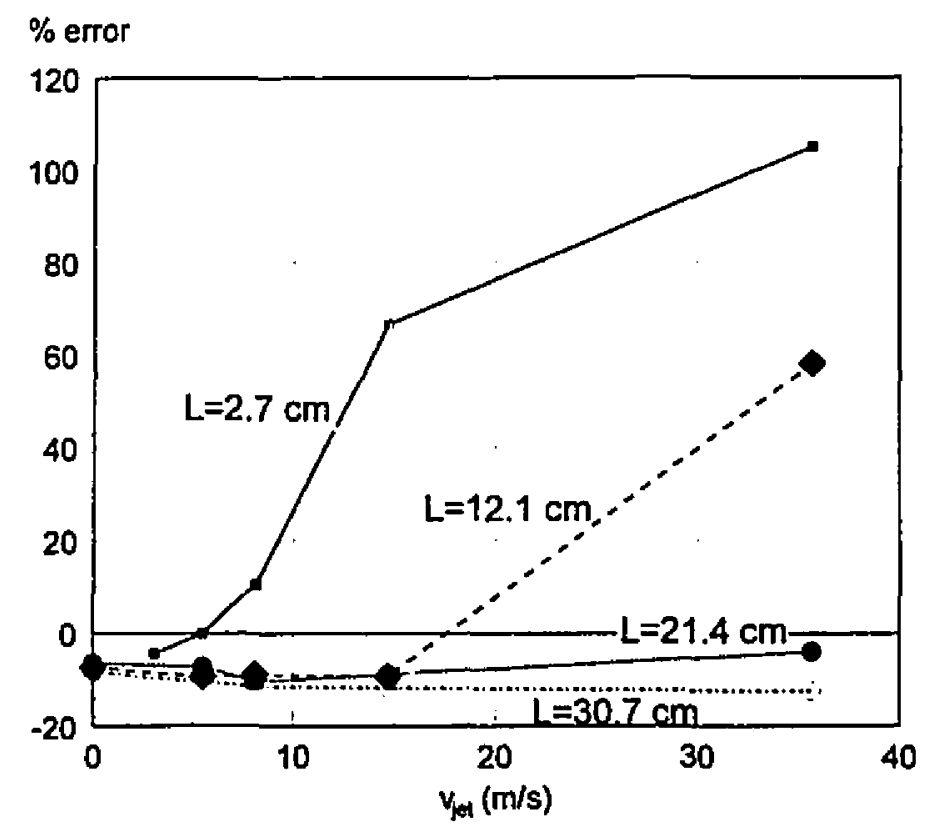

Figure 4.10 Error between the total flow rate calculated from the radial velocity profile and the measured value for various experiments - carrier gas: $N_{2}$.

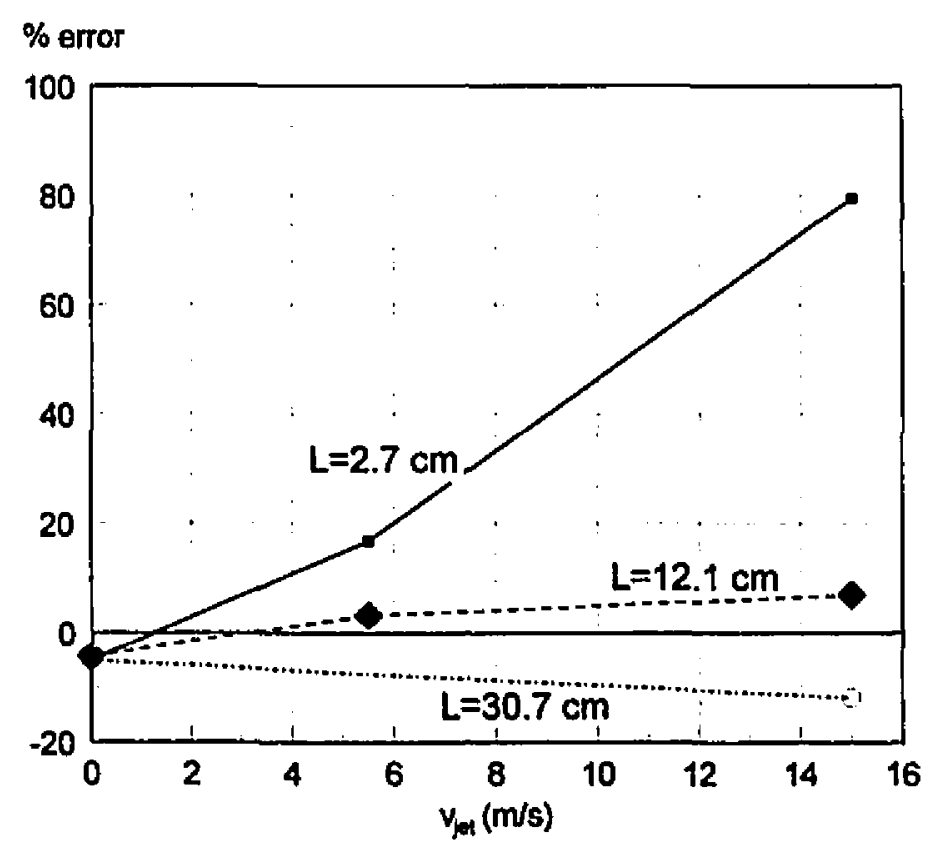

Figure 4.11 Error between the total flow rate calculated from the radial velocity profile and the measured value for various experiments --carrier gas: He. 


\subsubsection{Turbulence Intensity}

Because each velocity measurement by the LDA was an average of many particle velocities, each measurement consisted of a density function of velocities. The mean value was the actual velocity displayed in the previous graphs. The turbulence intensity is defined as the ratio of the standard deviation of the velocity density lunction over its mean value:

$$
\text { turbulence }=\frac{\sigma_{\mathrm{v}}}{\mu_{\mathrm{v}}} . \quad \text { turbulence intensity }
$$

Turbulence intensity values were calculated and averaged over an entire radial velocity profile. The results are shown in Figures 4.12 and 4.13. Although some exceptions were present, a clear trend is that the turbulence intensity increased with jet velocity and decreased when moving downstream of the injector. This is consistent with theory since the radial jets introduced a large amount of turbulence to the flow: this slowly decayed as the flow developed downstream.

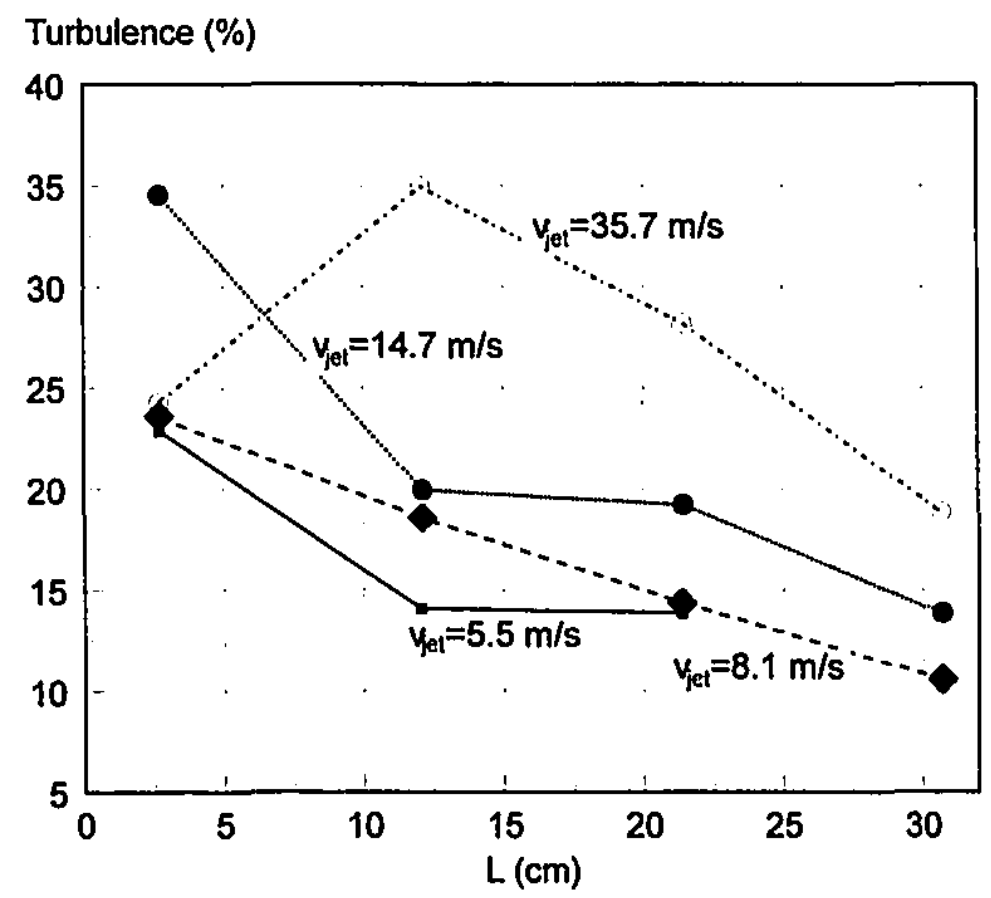

Figure 4.12 Turbulence intensity vs measurement axial location for various jet velocities - carrier gas: $\mathrm{N}_{2}, \mathrm{Re}=1420-2370$. 


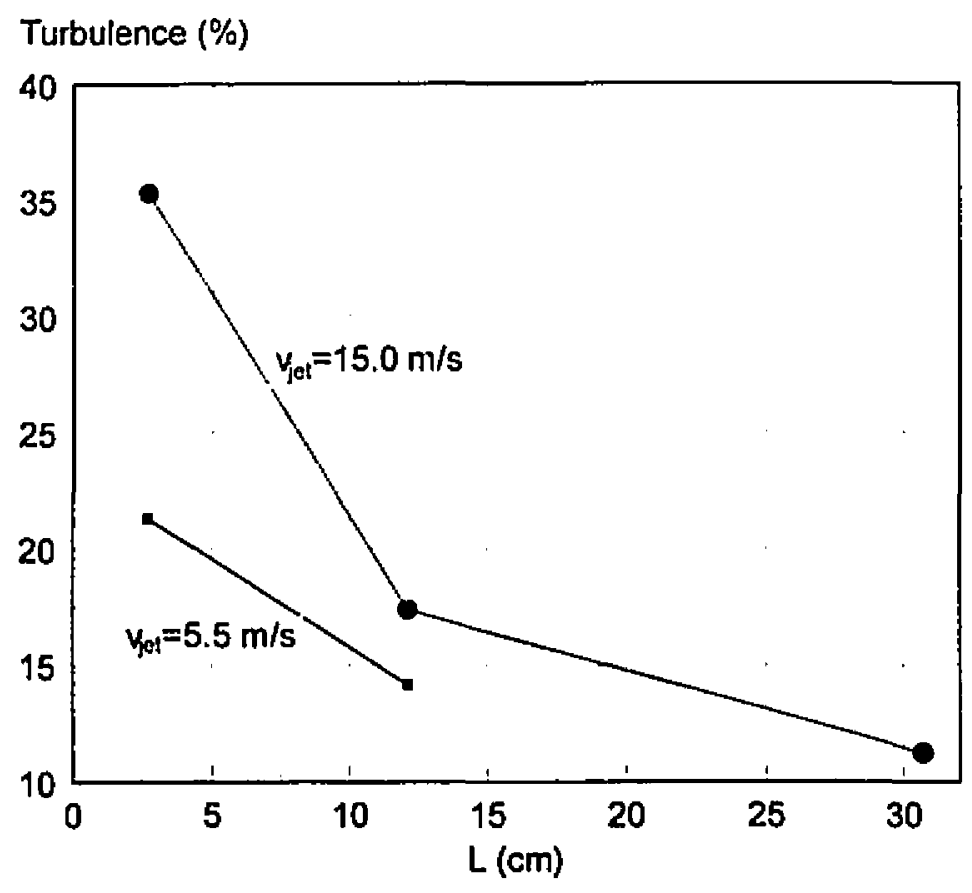

Figure 4.13 Turbulence intensity vs measurement axial location for various jet velocities - carrier gas: $\mathrm{He}, \mathrm{Re}=\mathbf{2 4 0 - 2 5 0}$.

\subsection{Concentration Experiments}

For the experiments shown in the next two sections, no $\mathrm{CH}_{4}$ was present in the reactor for $t<0$ and $t=0$ corresponded to the first trace of $\mathrm{CH}_{4}$ entering the reactor. The effect of the angle of measurement, the injector jet velocity (reacting gas flow rate) and the axial location of the measurement will be covered first. Then, a comparison is made between the measured steady state concentrations and their theoretical values.

\subsubsection{Effect of the Angle of Measurement}

Significant differences were found for experiments performed at different angles but with the other conditions (axial location, jet velocity and carrier gas) kept constant. Typical 
results are displayed in Figures 4.14 to 4.17, others are in Appendix B. In all cases, the greatest angular variations were for axial locations close to the injector and with small jet velocities. This was explained by

- the increased turbulence level induced by high velocity jets favored better mixing

- a longer reactor, i.e., a larger $L$ value, allowed more time for the fluid to achicve a uniform concentration profile since the space time $(\tau)$ was increased.

With nitrogen, a jet velocity in the range of $12.4-21.9 \mathrm{~m} / \mathrm{s}$ was determined to be the minimum for a relatively uniform angular concentration at $\mathrm{L}=3.3 \mathrm{~cm}$. This value dropped to the $8.8-12.4 \mathrm{~m} / \mathrm{s}$ range at $\mathrm{L}=12.7 \mathrm{~cm}$ and $\mathrm{L}=35.6 \mathrm{~cm}$. A similar trend was found with helium.

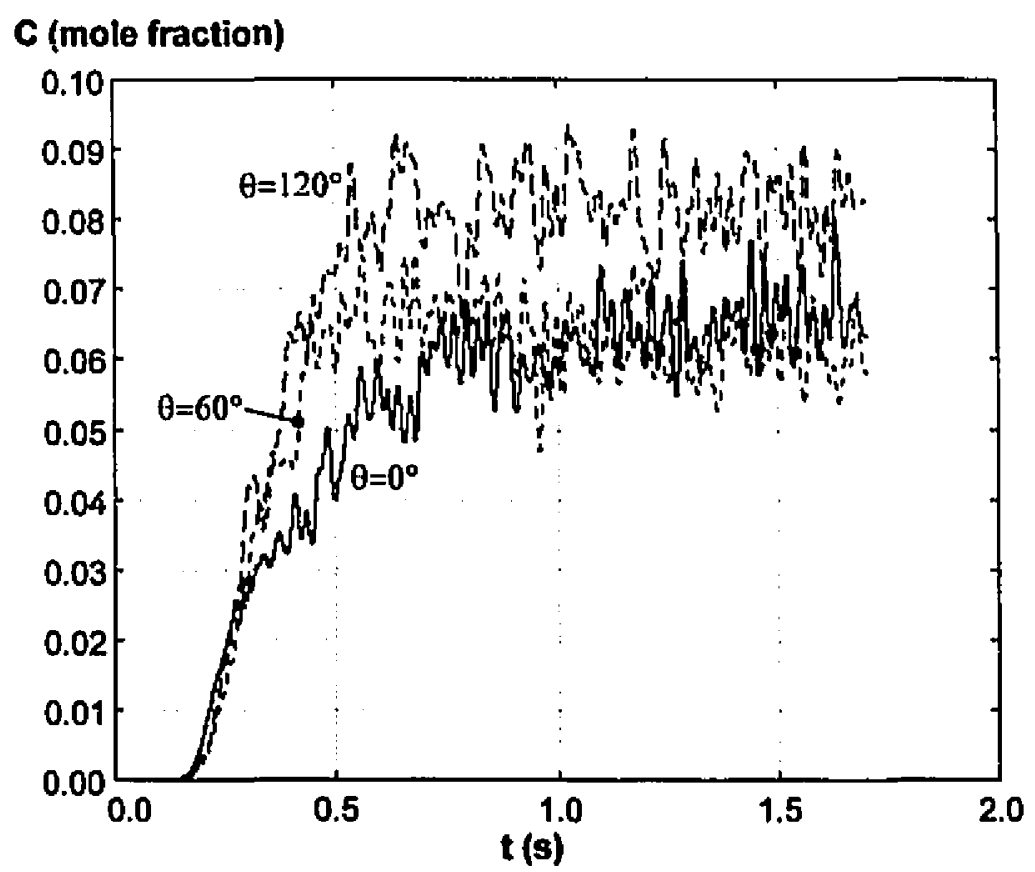

Figure 4.14 Concentration vs time experiments at different angles - carrier gas: $N_{2}, V_{\text {jet }}: 4.6 \mathrm{~m} / \mathrm{s}, L=3.3 \mathrm{~cm}, \operatorname{Re}=1480$. 


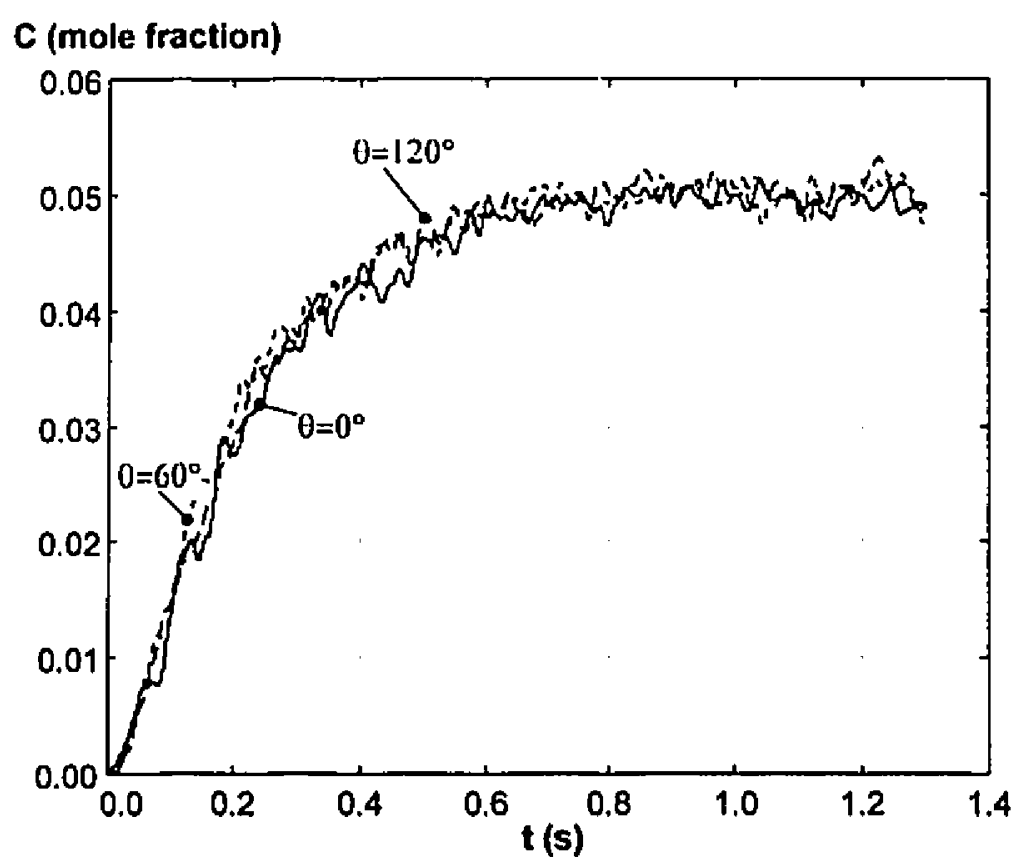

Figure 4.15 Concentration vs time exneriments at different angles - carrier gas: $N_{2}, v_{j e t}: 38.2 \mathrm{~m} / \mathrm{s}, L=3.3 \mathrm{~cm}, R e=2183$.

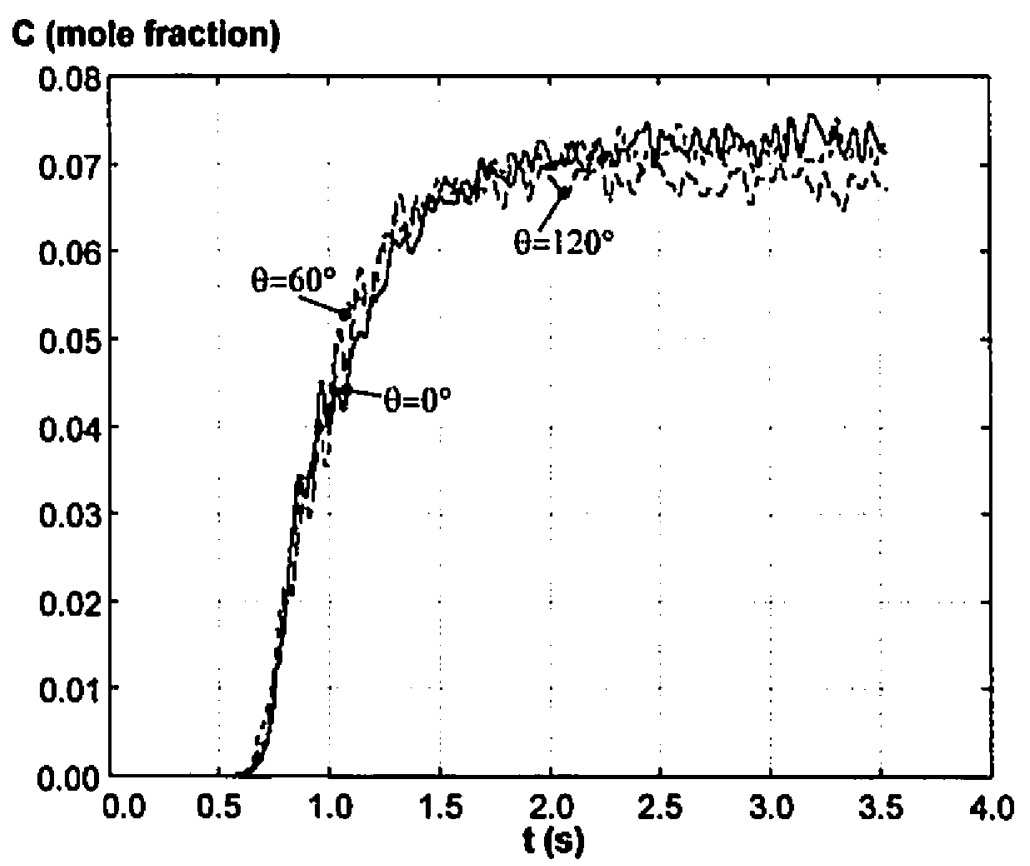

Figure 4.16 Concentration vs time experiments at different angles - carrier gas: $\mathrm{N}_{2}, v_{\mathrm{jet}}: 4.6 \mathrm{~m} / \mathrm{s}, \mathrm{L}=35.6 \mathrm{~cm}, R e=1480$. 


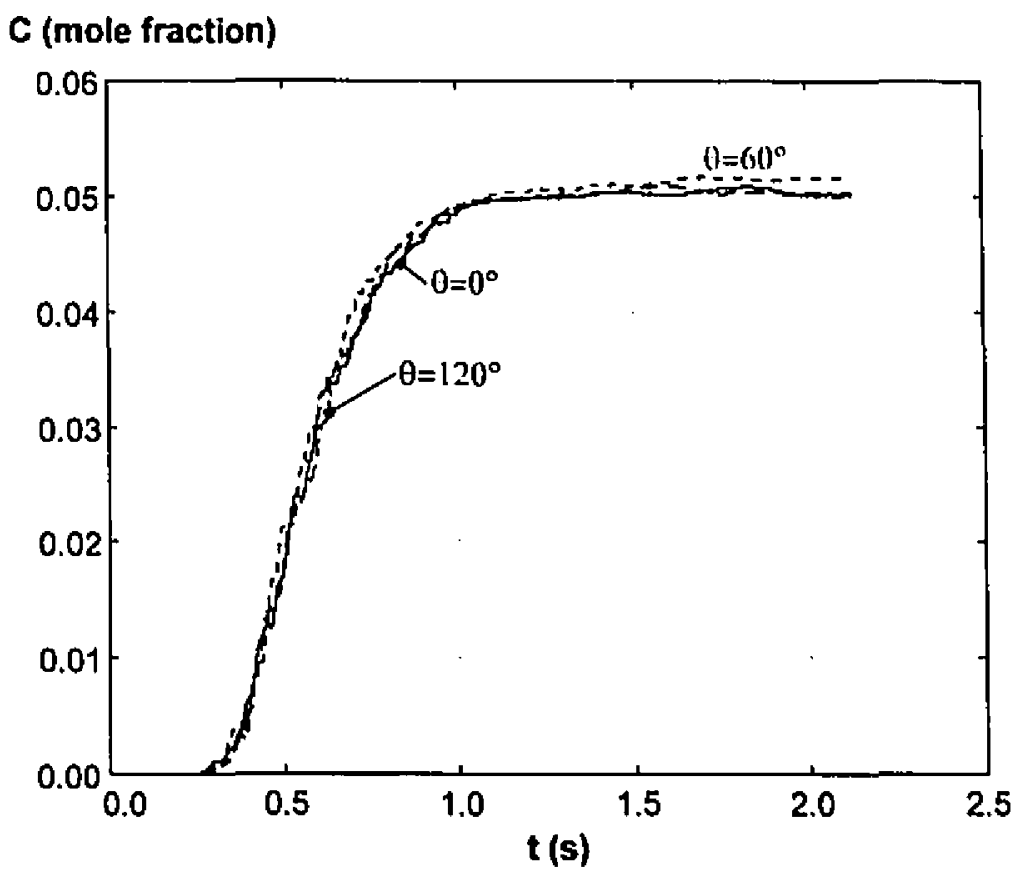

Figure 4.17 Concentration vs time experiments at different angles - carrier gas: $\mathrm{N}_{2}, \mathrm{v}_{\text {jat: }} \mathbf{3 8 . 2} \mathrm{m} / \mathrm{s}, \mathrm{L}=35.6 \mathrm{~cm}, \operatorname{Re}=2 \cdot \mathrm{i} 80$.

\subsubsection{Effect of the Jet Velocity and Axial Position}

From this point on to the end of the chapter, each concentration vs time curve is the average of the measurements over the three angles $\left(\theta=0,60\right.$ and $\left.120^{\circ}\right)$. In Figures 4.18 through 4.24 , the concentration as a function of time is plotted for different experimental conditions. An interesting characteristic of the different plots is the intensity of the instantaneous concentration fluctuations. These fluctuations appeared randomly and were believed to be caused by imperfect turbulent mixing. As with the turbulence intensity (Figures 4.12 and 4.13) and the angular variations of the concentration (Figures 4.14 to 4.17), the instantaneous concentration fluctuations were higher at small $L$ and high $v_{j c t}$ This is an additional observation which proved that a better mixing inside the reactor was achieved with a larger amount of gas injected radially and with longer reactors (larger $\tau$ ). 


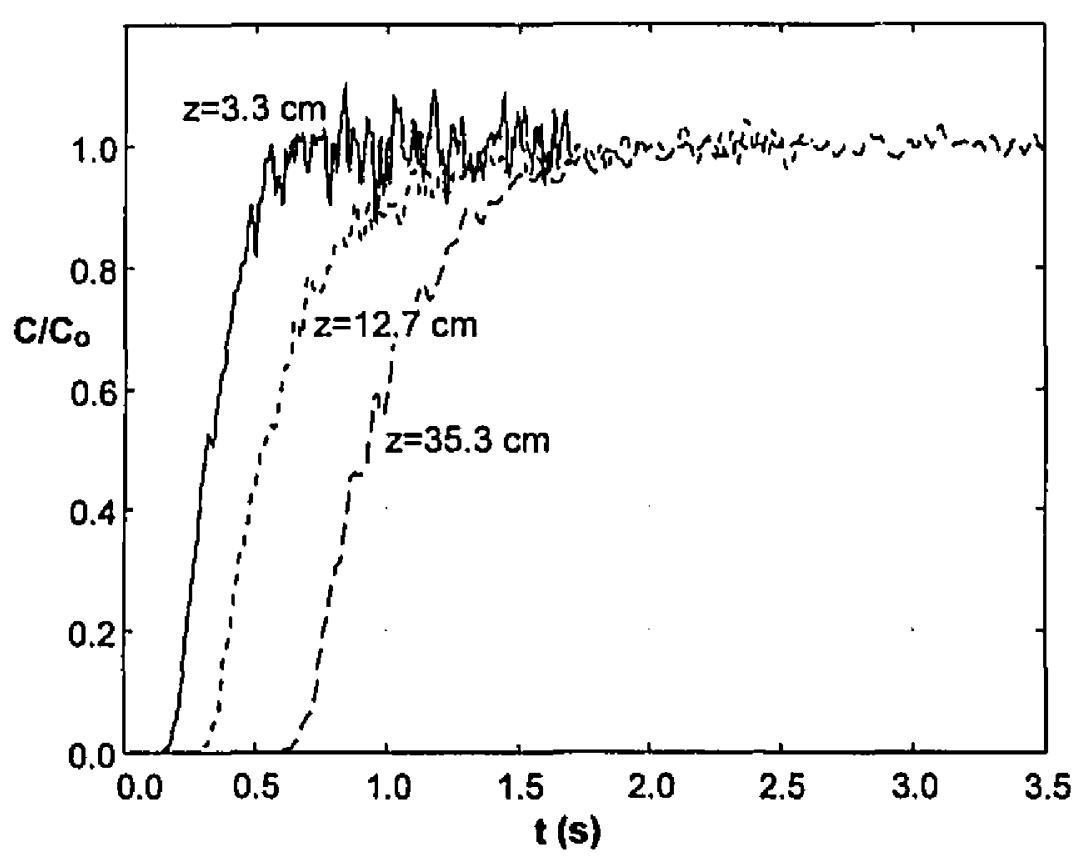

Figuure 4.18 Concentration vs time experiments at various axial positions carrier gas: $\mathrm{N}_{2}, \mathrm{v}_{\mathrm{jet}}: 4.6 \mathrm{~m} / \mathrm{s}, \mathrm{Re}=1480$.

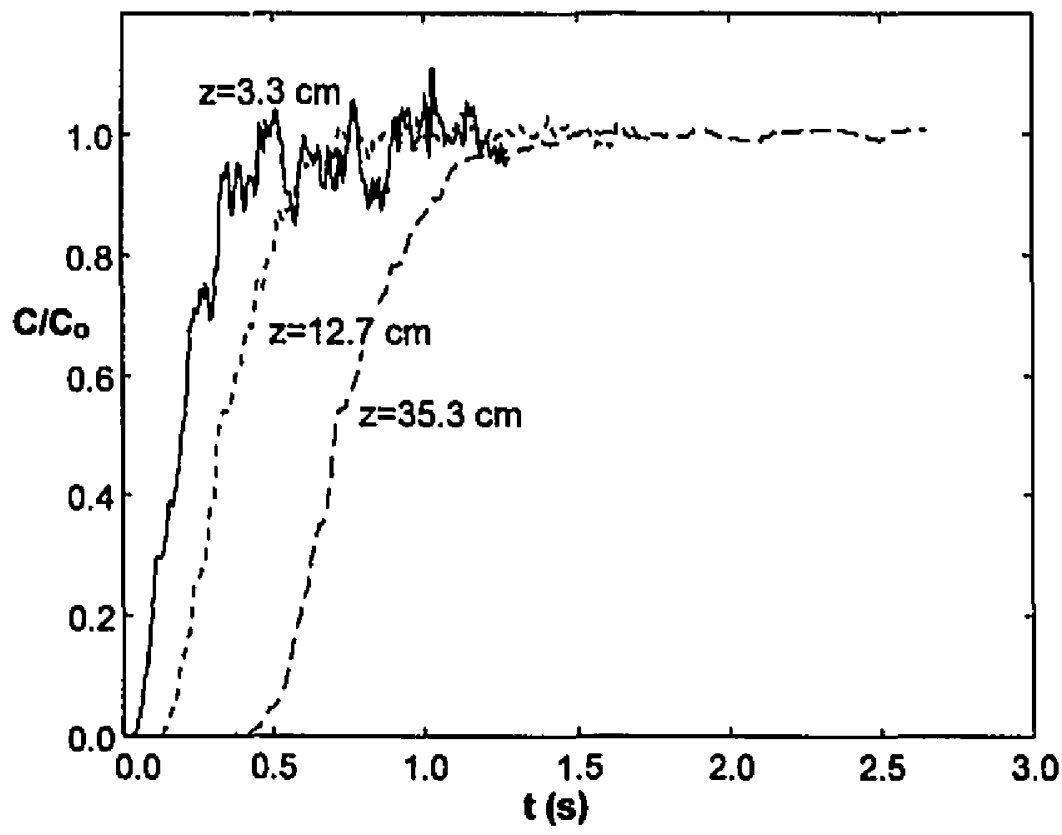

Figure 4.19 Concentration vs time experiments at various axial positions carrier gas: $\mathrm{N}_{2}, \mathrm{~V}_{\text {jot }}: 12.9 \mathrm{~m} / \mathrm{s}, \mathrm{Re}=1660$. 


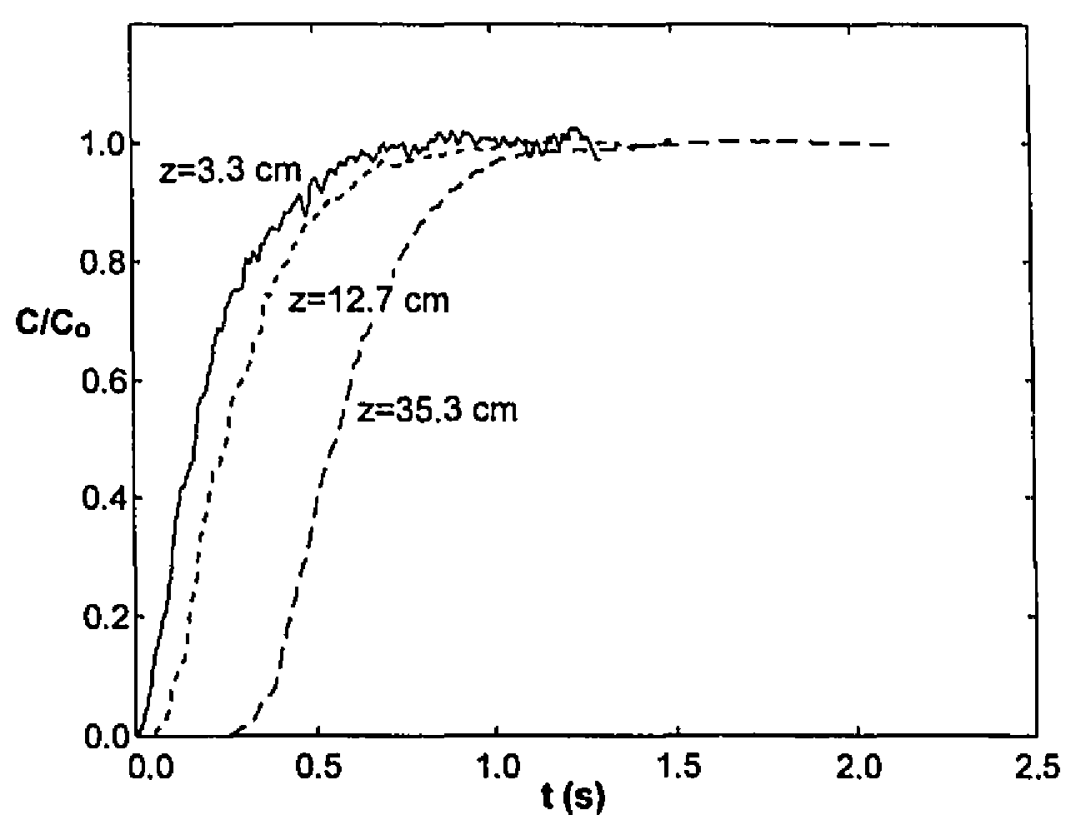

Figure 4.20 Concentration vs time experiments at various axial positions carrier gas: $\mathrm{N}_{2}, v_{\mathrm{jet}}: 38.2 \mathrm{~m} / \mathrm{s}, \mathrm{Re}=2180$.

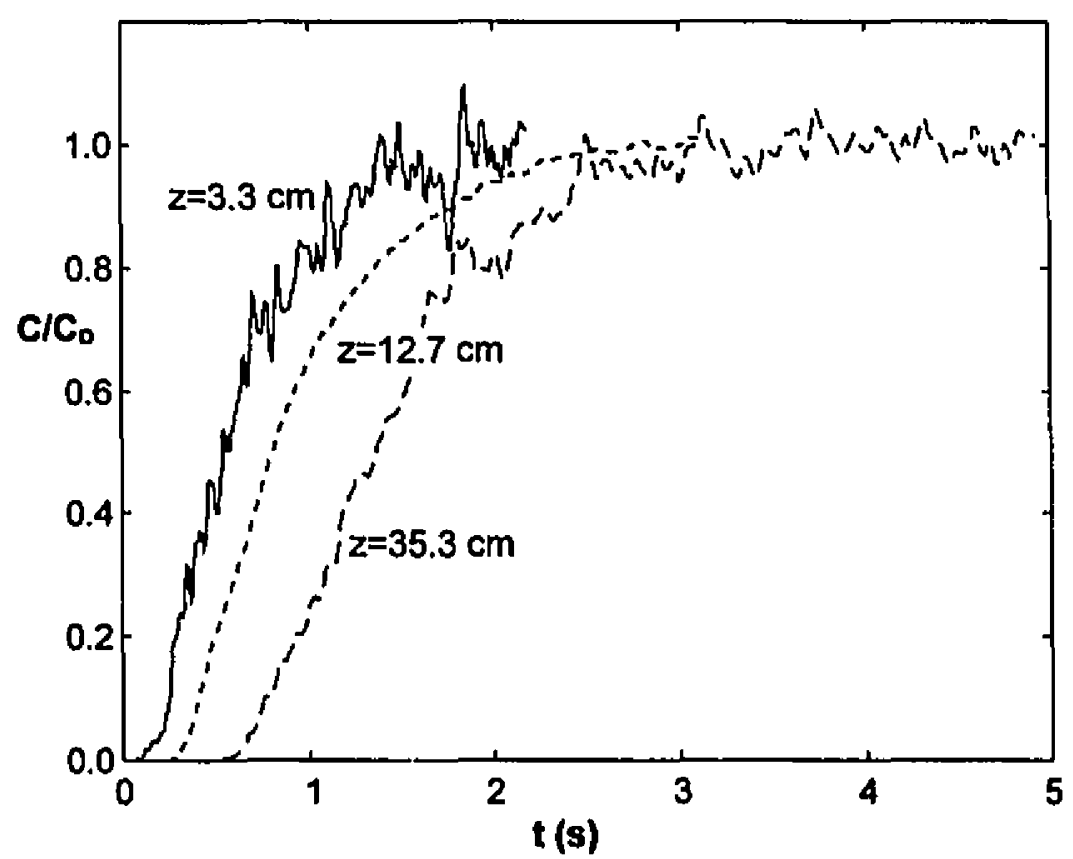

Figure 4.21 Concentration vs time experiments at various axial positions carrier gas: He, $v_{\text {jet }}: 2.3 \mathrm{~m} / \mathrm{s}, \mathrm{Re}=190$. 


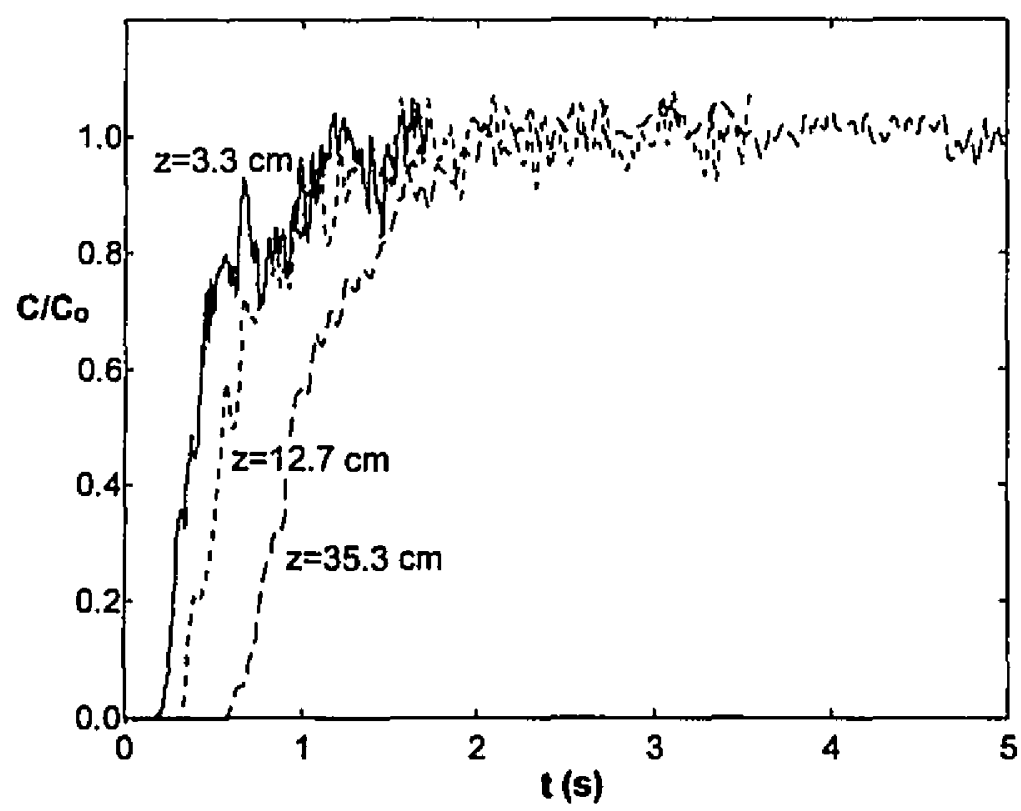

Figure 4.22 Concentration vs time experiments at various axial positions carrier gas: $\mathrm{He}, v_{\mathrm{jet}}: 4.6 \mathrm{~m} / \mathrm{s}, \mathrm{Re}=210$.

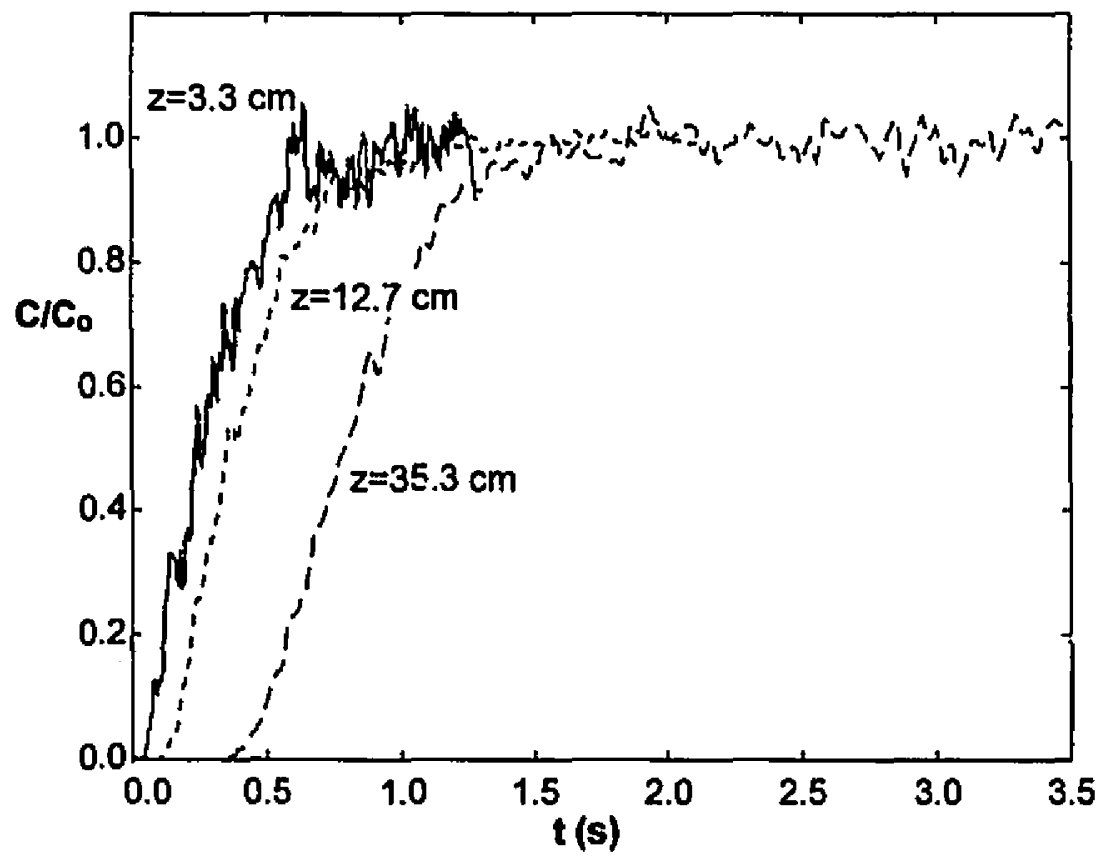

Figure 4.23 Concentration vs time experiments at various axial positions carrier gas: $\mathrm{He}, \mathrm{v}_{j \theta \mathrm{\theta}}: 12.5 \mathrm{~m} / \mathrm{s}, \mathrm{Re}=240$. 


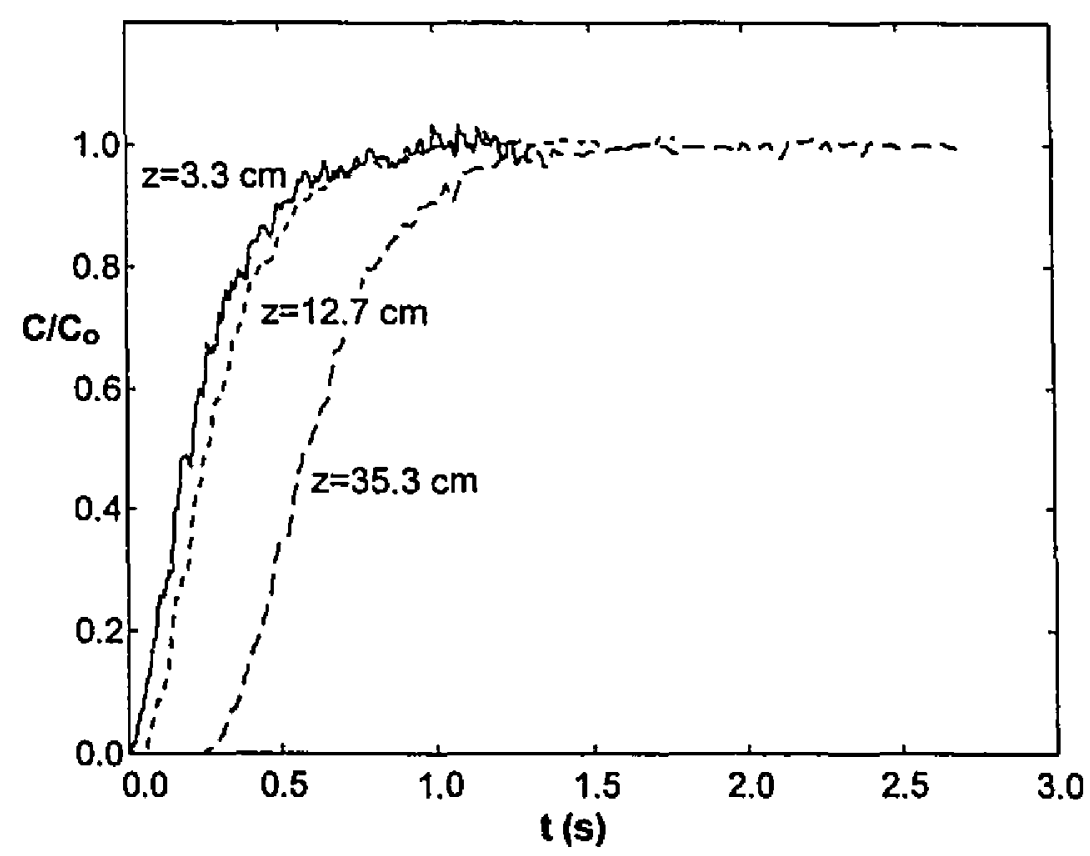

Figure 4.24 Concentration vs time experiments at various axial positions carrier gas: $\mathrm{He}, v_{\text {jet }}: 37.5 \mathrm{~m} / \mathrm{s}, \mathrm{Re}=310$.

A noticeable exception to the above conclusion occurred with helium experiments at the lowest jet velocity (Figure 4.21 ). The concentration fluctuations were high at $L=3.3 \mathrm{~cm}$, then they were almost non-existent in between $L=7.6$ and $12.7 \mathrm{~cm}$ and they gradually reappeared downstream of that location. It is believed that at locations close to the radial injector ( 3.3 to $12.7 \mathrm{~cm}$ ), the turbulence induced by the low velocity jets were rapidly damped by the relatively viscous flow of helium. In that portion, however, the tracer concentration was not uniform throughout the reactor cross section. Further downstream ( $\mathrm{L}>12.7 \mathrm{~cm}$ ), a partial mixing occurred due to the turbu!ence induced by the end effects. These end effects were caused by the exhaust system placed after the reactor. They were significant only for helium (a significantly lighter gas than air) experiments at low jet velocities and long reactor lengths. 


\subsubsection{Steady State Concentrations}

It was mentioned in Section 3.4 that a non-uniform radial concentration profile could induce an error in the measured concentration relative to the true (mixing cup) value. The measured steady state $\mathrm{CH}_{4}$ concentration in an experiment was compared to the theoretical value calculated from the different gas flow rates injected in the reactor. This was done in order to assess the error introduced by the uniform concentration profile assumption. The error was calculated as the difference between the two values divided by the theoretical steady state concentration value. While a large error value probably implies that the error was also large for measurements before steady state was established, a small value does not necessarily mean that the error was small before steady state conditions. Figures 4.25 and 4.26 display the percentage error for various experimental conditions. As a rule, the percentage error decreased with increasing jet velocity and longer reactor lengths. This confirmed that a more uniform radial concentration profile was favored under the above conditions.

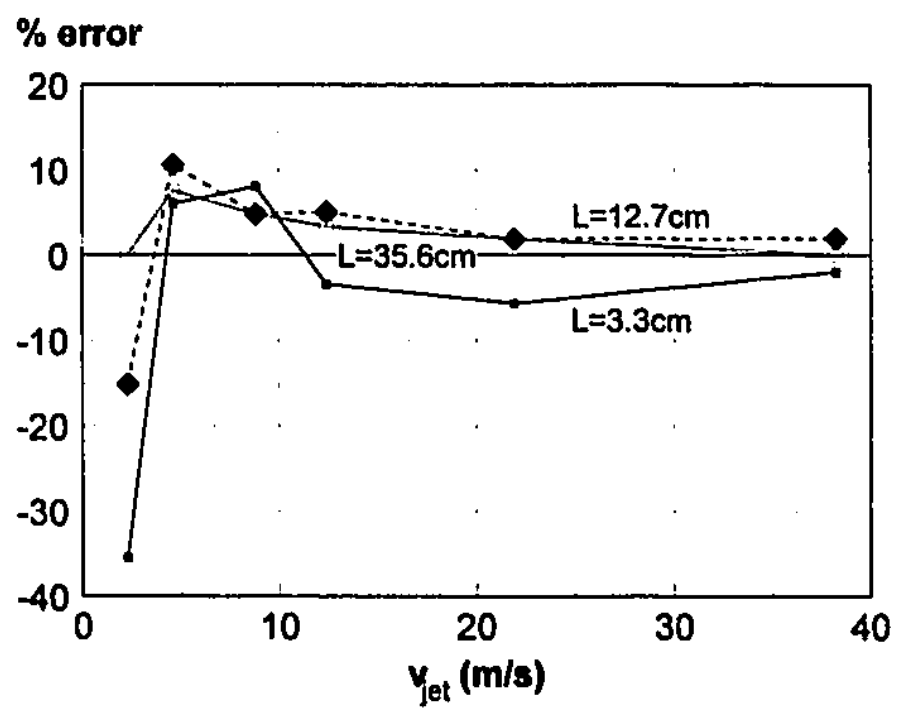

Figure 4.25 Error between the measured steady state $\mathrm{CH}_{4}$ concentration and the theoretical value for various experimental conditions - carrier gas: $\mathbf{N}_{\mathbf{2}}$. 


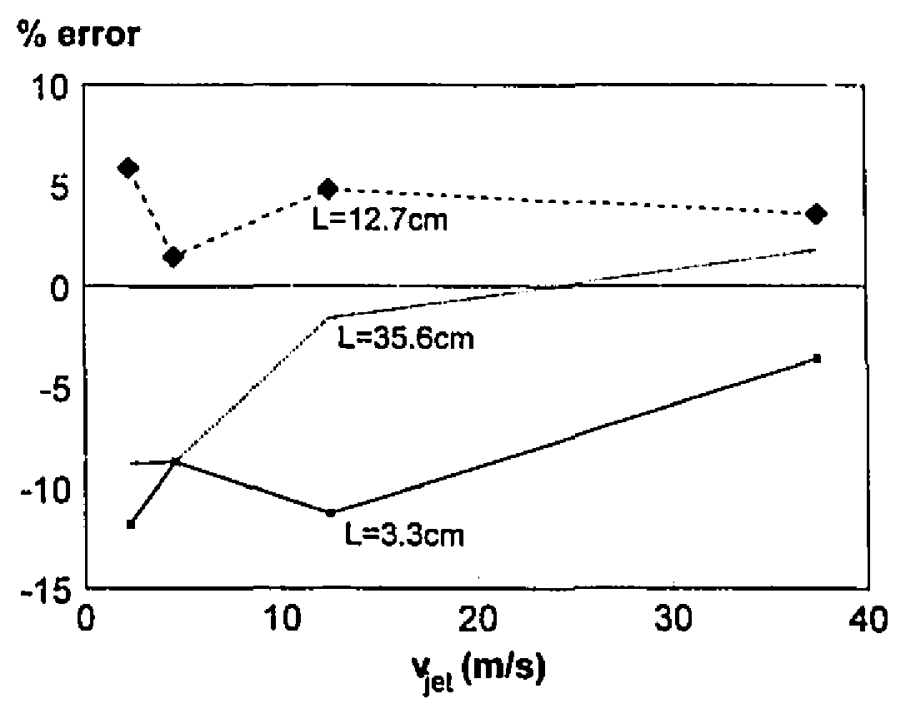

Figure 4.26 Error between the measured steady state $\mathrm{CH}_{4}$ concentration and the theoretical value for various experimental conditions-carrier gas: He.

\subsection{Residence Time Distribution Results}

Not all the concentration vs time results were used for RTD calculations. This section will first explain which ones were chosen and why. An analysis of the different parameters obtained from the modeling then follows. The relation of the parameters to the different experimental conditions are investigated and the experimental values are compared to others from the literature.

\subsubsection{Selection of Experiments for RTD Analysis}

The axial location for the reactor input was selected to be at $7.6 \mathrm{~cm}$ downstream of the radial injector. The main factor justifying this choice was that the concentration was uniform radially at an axial location of $50 \mathrm{~mm}$ past the injector (Soucy \& al. ${ }^{(7)}$, see Section 3.4). Because Soucy et al. used a reacting gas flow rate of $12.1 \mathrm{l} / \mathrm{min}$ (STP), using significantly lower flow rates seemed inappropriate. In consequence, only the 
experiments with a reacting gas flow equal to or above $9.2 \mathrm{l} / \mathrm{min}(\mathrm{T}=298 \mathrm{~K}, \mathrm{P}=1 \mathrm{~atm}$ ) with $N_{2}\left(v_{j c t} \geq 12.9 \mathrm{~m} / \mathrm{s}\right)$ and $8.9 \mathrm{l} / \mathrm{min}$ with $\mathrm{He}\left(v_{\mathrm{jct}} \geq 12.5 \mathrm{~m} / \mathrm{s}\right)$ were used for RTD modeling. Considering the error for the steady state concentrations at $\mathrm{L} \geq 7.6 \mathrm{~cm}$ (Figure 4.25 and 4.26 ), all the values were about $5 \%$ or lower for the experiments retained for RTD modeling. It can also be observed that the magnitude of the turbulent concentration fluctuations was significantly lower for jet velocities above $12.5 \mathrm{~m} / \mathrm{s}$ (Figure 4.27 and 4.28). This should improve the accuracy of the models discussed below since the fitting is then less sensitive to the random fluctuations.

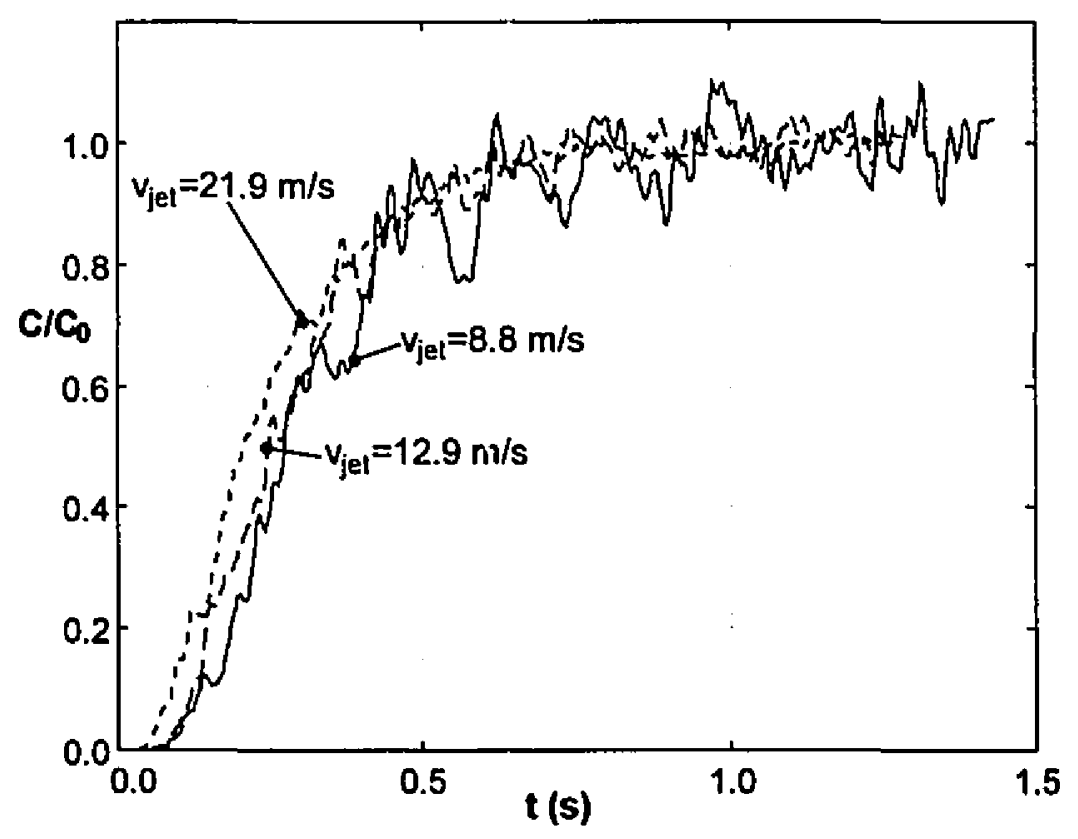

Figure 4.27 Concentration vs time for different jet velocities - carrier gas: $\mathbb{N}_{2}$, $\mathrm{L}=7.6 \mathrm{~cm}$. 


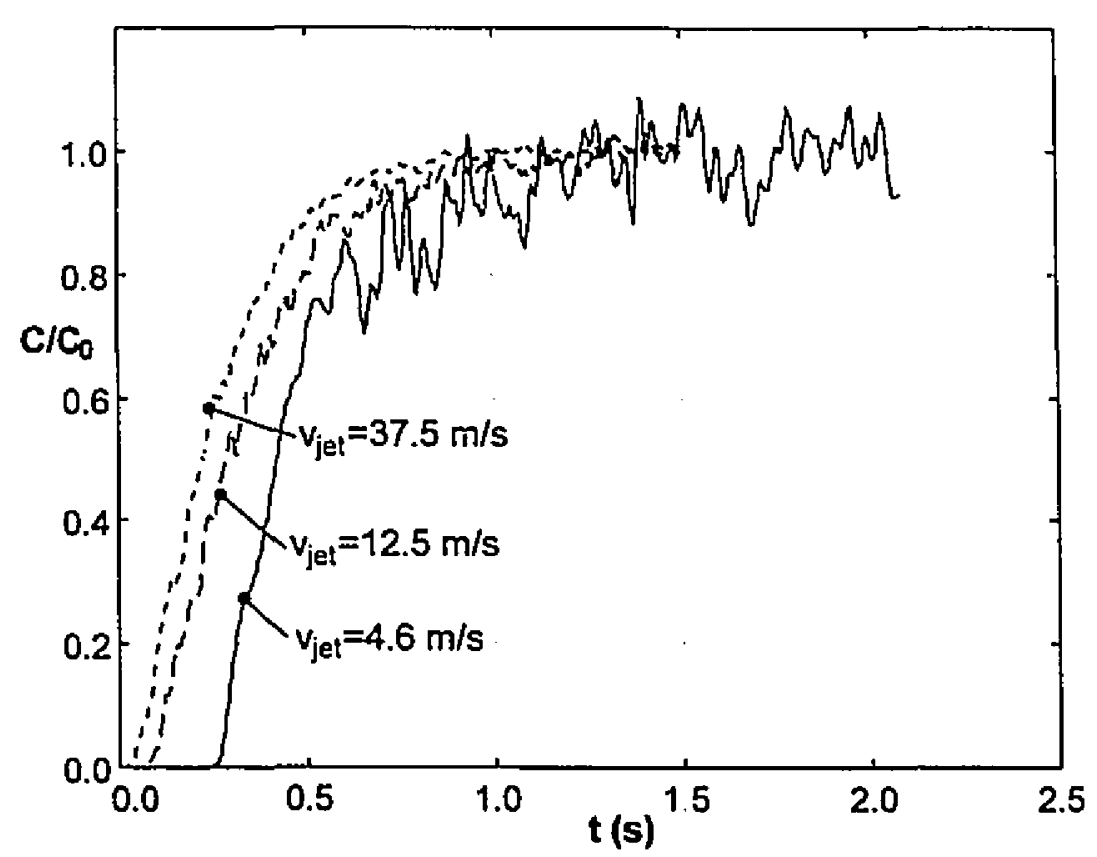

Figure 4.28 Concentration vs time for different jet velocities - carrier gas: He, $\mathrm{L}=7.6 \mathrm{~cm}$.

\subsubsection{RTD Modeling}

The concentration experiments done with nitrogen were modeled using the axial dispersion model. It was judged inappropriate to use the laminar flow model since the velocity measurements did not show any evidence of a parabolic radial velocity profile. For jet velocities ranging from $12.9 \mathrm{~m} / \mathrm{s}$ to $38.2 \mathrm{~m} / \mathrm{s}$, the axial dispersion coefficients were evaluated by using the differential equation and the statistical methods (Section 3.5). Two axial locations were used for the reactor exit: $22.0 \mathrm{~cm}$ and $35.6 \mathrm{~cm}$, thus giving two reactor lengths $(14.4$ and $28.0 \mathrm{~cm}$ ). Typical input and output data (experimental and model) are displayed in Figures 4.29 through 4.32 .

The values of the calculated axial dispersion coefficients are presented in Table 4.1. The axial dispersion coefficients for fully developed pipe flow were taken from Levenspiel ${ }^{(15)}$ for similar Reynolds and Schmidt number values. It was found that the $D_{Z}$ values calculated from the differential equation model consistently fitted the experimental data 
better, in a least square sense, than the ones obtained by the statistical method. This wis expected since the differential equation method used the goodness of fit to find the optimal dispersion coefficient. The statistical method, on the other side, relied on only two parameters: the mean value and the variance. The variance was particularly sensitive to turbulent fluctuations. This can explain why the statistical $D_{Z}$ values were quite different from the differential equation ones, particulariy at the $22.0 \mathrm{~cm}$ output location where the fluctuations where greatest.

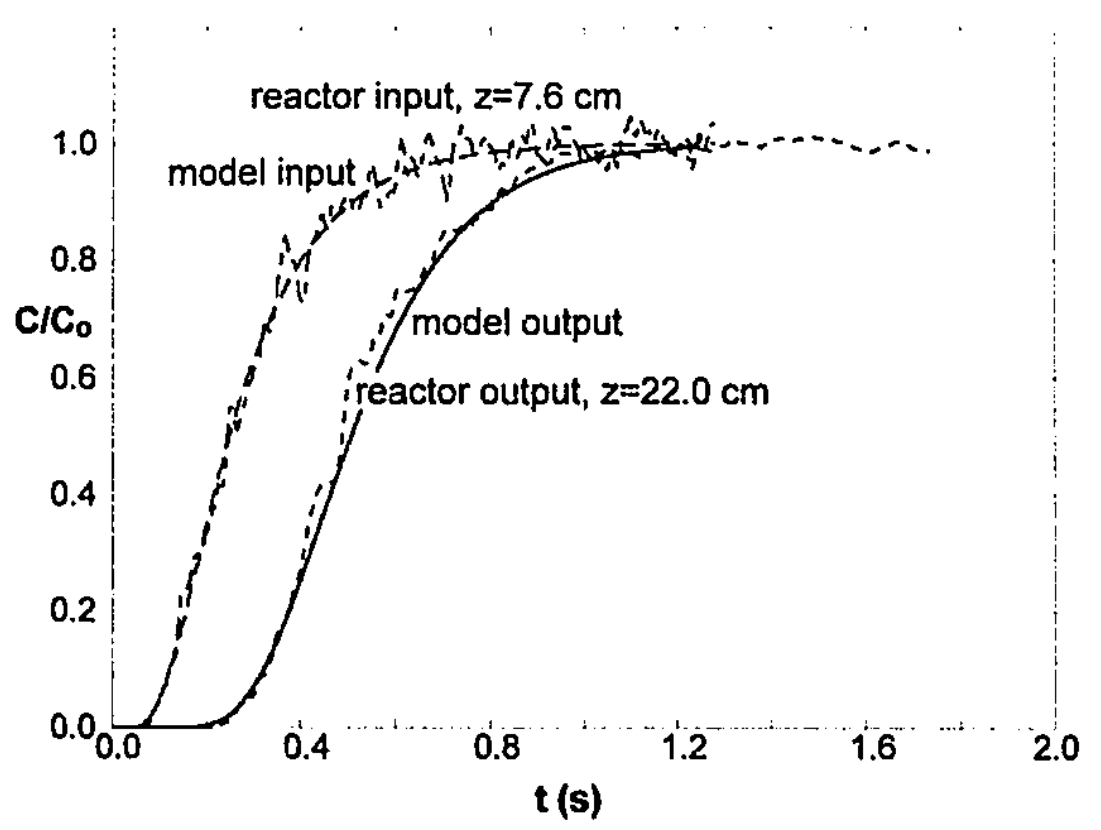

Figure 4.29 Reactor input and output data with the differential equation axial dispersion model - carrier gas: $N_{2}, v_{\text {jet: }}: 12.9 \mathrm{~m} / \mathrm{s}, z_{\text {in }}=7.6 \mathrm{~cm}$, $z_{\text {out }}=22.0 \mathrm{~cm}, D_{z}=0.0085 \mathrm{~m}^{2} / \mathrm{s}$. 


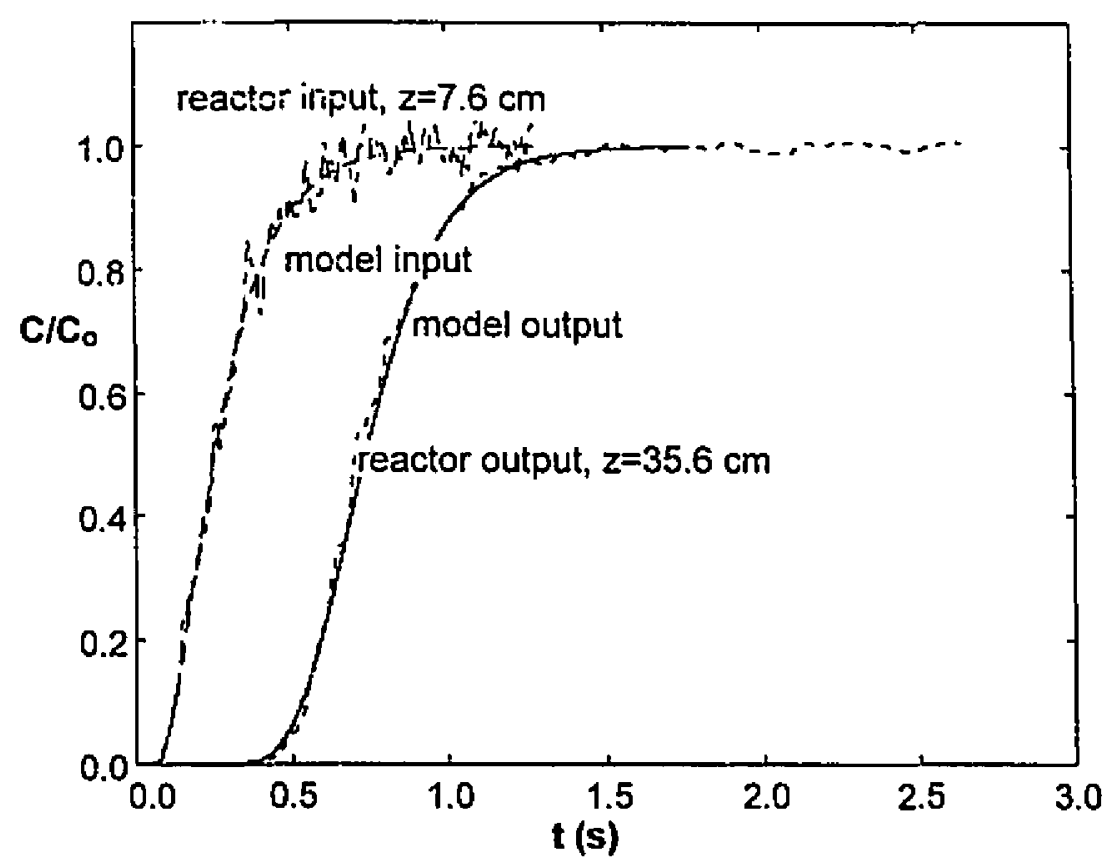

Figure 4.30 Reactor input and output data with the differential equation axial dispersion model - carrier gas: $N_{2}, v_{\text {jet: }}: 12.9 \mathrm{~m} / \mathrm{s}, z_{\text {in }}=7.6 \mathrm{~cm}$, $\mathrm{z}_{\text {out }}=35.6 \mathrm{~cm}, D_{2}=0.0060 \mathrm{~m}^{2} / \mathrm{s}$.

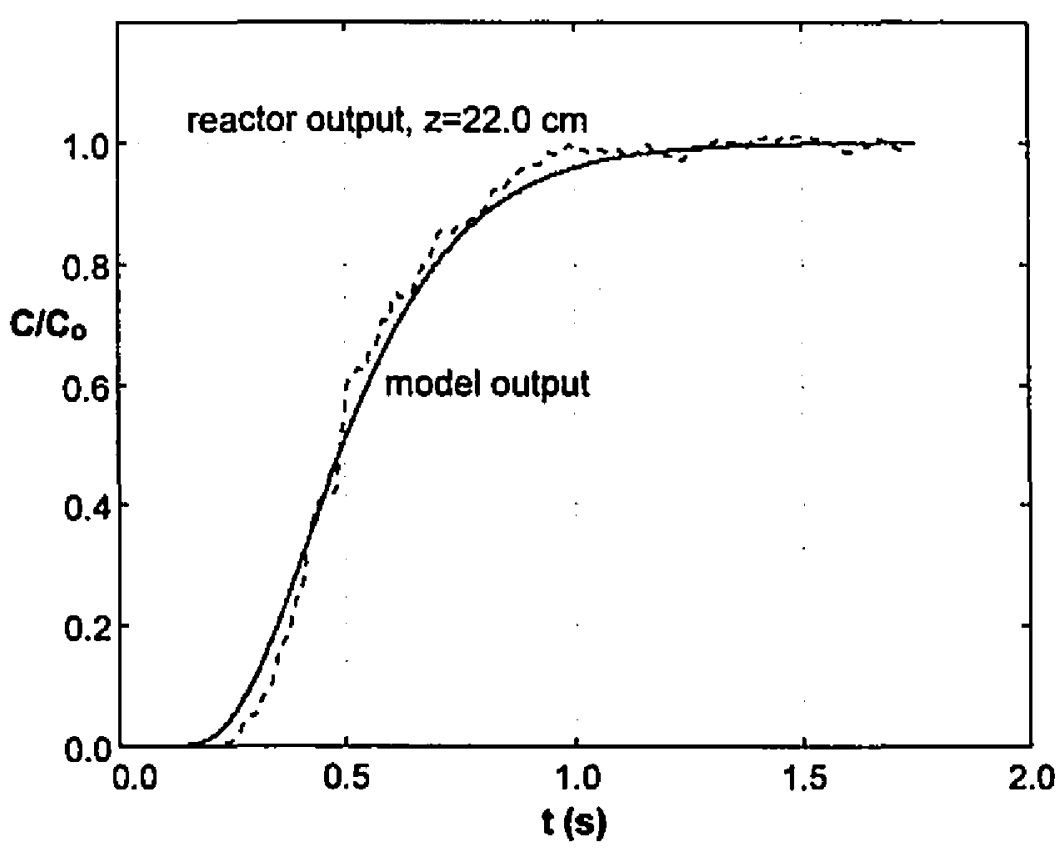

Figure 4.31 Reactor output data with the statistical axial dispersion model carrier gas: $N_{2}, v_{j e t}: 12.9 \mathrm{~m} / \mathrm{s}, z_{\text {in }}=7.6 \mathrm{~cm}, \mathrm{z}_{\text {out }}=22.0 \mathrm{~cm}, D_{2}=0.0220$ $\mathrm{m}^{2} / \mathrm{s}$. 


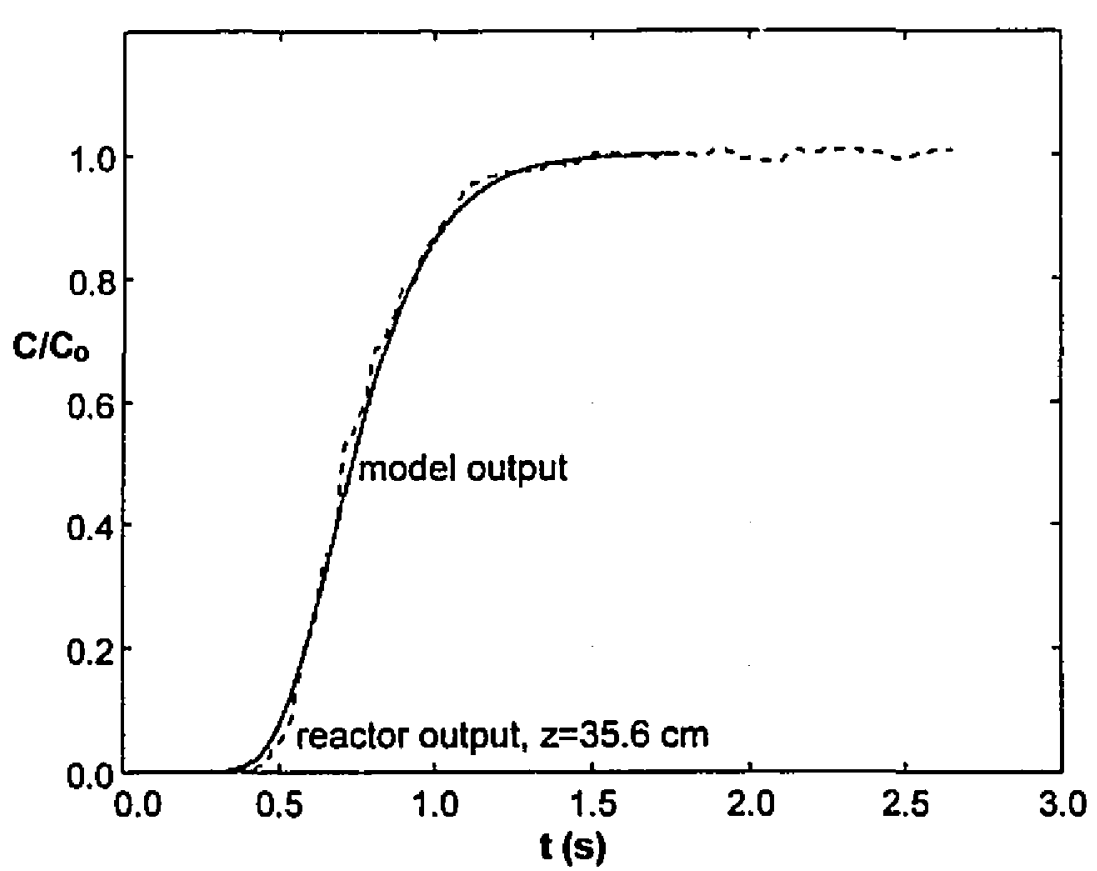

Figure 4.32 Reactor output data with the statistical axial dispersion model carrier gas: $N_{2}, v_{\text {jet }}: 12.9 \mathrm{~m} / \mathrm{s}, z_{\text {in }}=7.6 \mathrm{~cm}, z_{\text {oul }}=35.6 \mathrm{~cm}, D_{z}=0.0076$ $\mathrm{m}^{2} / \mathrm{s}$.

Table 4.1 Axial dispersion coefficients - carrier gas: $\mathrm{N}_{2}$.

\begin{tabular}{|c|c|c|c|c|}
\hline $\begin{array}{l}\text { Reactor } \\
\text { Inletloutlot } \\
\text { locations } \\
\text { (cm) }\end{array}$ & $v_{\text {lot }}(\mathrm{m} / \mathrm{s})$ & $\begin{array}{c}\text { Dz from } \\
\text { differential } \\
\text { oquation model } \\
\left(\mathrm{m}^{2} / \mathrm{s}\right)\end{array}$ & $\begin{array}{l}D_{2} \text { from } \\
\text { staflstical } \\
\text { model } \\
\left(\mathrm{m}^{2} / \mathrm{s}\right)\end{array}$ & $\begin{array}{l}D_{z} \text { for fully } \\
\text { developed } \\
\text { pipe flow } \\
\left(\mathrm{m}^{2} / \mathrm{s}\right)\end{array}$ \\
\hline \multirow[t]{3}{*}{$7.6 / 22.0$} & 12.9 & 0.0085 & 0.0220 & 0.058 \\
\hline & 21.9 & 0.0050 & 0.0069 & 0.071 \\
\hline & 38.2 & 0.0135 & 0.0250 & 0.105 \\
\hline \multirow[t]{3}{*}{$7.6 / 35.6$} & 12.9 & 0.0060 & 0.0076 & 0.058 \\
\hline & 21.9 & 0.0065 & 0.0081 & 0.071 \\
\hline & 38.2 & 0.0090 & 0.0083 & 0.105 \\
\hline
\end{tabular}

Replicate experiments were done to assess the statistical significance of the difference between the various dispersion coefficients of Table 4.1 . A $95 \%$ confidence interval led a variation of $D_{Z}$ from the differential equation model of about $\pm 15 \%$. For the statistical method, the $95 \%$ confidence interval on $D_{z}$ rose to $\pm 30 \%$. In Figures 4.33 and 4.34 , the 
lower limit, central value and upper limit of the confidence interval are plotted along with the corresponding experimental data. The uncertainty on the differential equation $\mathrm{D}_{\text {, }}$ introduced little error considering that the curve fit was good for all three $\mathrm{D}$ \% values. With the confidence interval in mind, it appeared that most of the variations between the values of Table 4.1 were statistically significant.

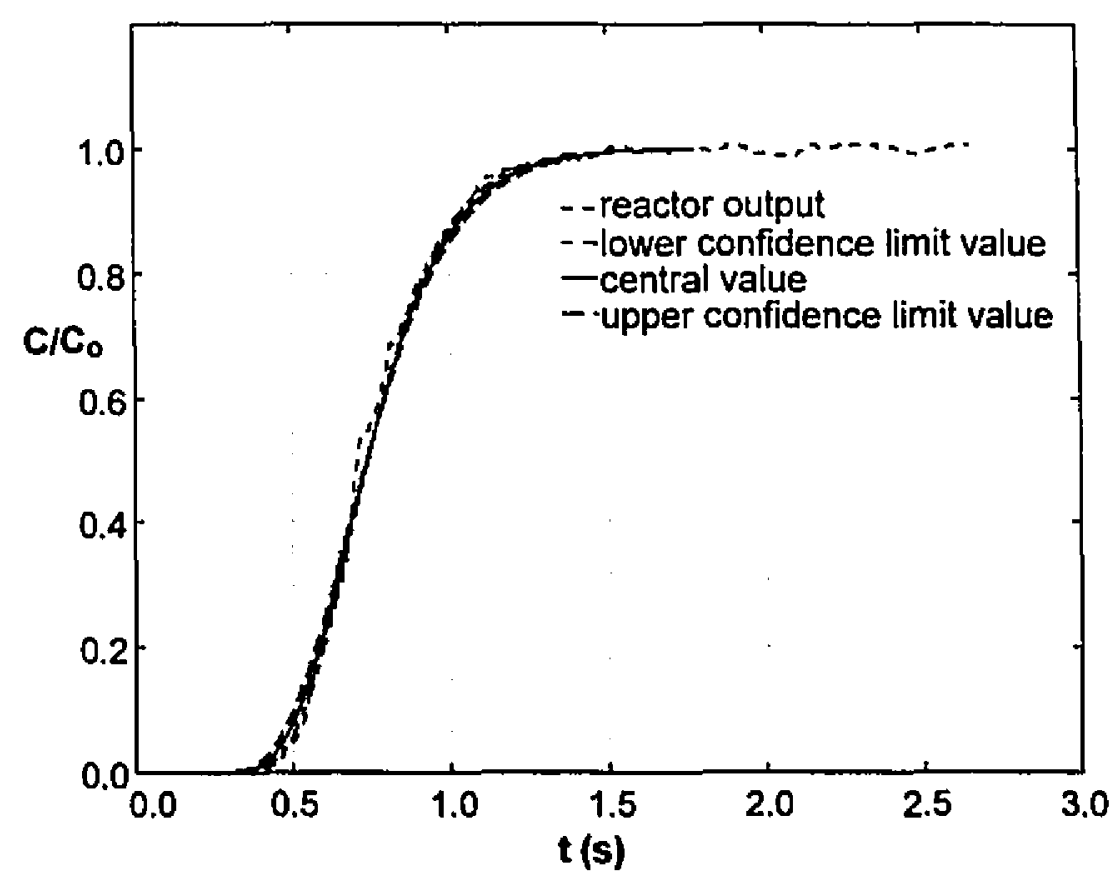

Figure 4.33 Concentration vs time curves calculated from various dispersion coefficient values for a differential equation axial dispersion model - carrier gas: $\mathrm{N}_{2}, v_{\text {jet }}: 12.9 \mathrm{~m} / \mathrm{s}, z_{\text {in }}=7.6 \mathrm{~cm}, z_{\text {out }}=35.6 \mathrm{~cm}$. 


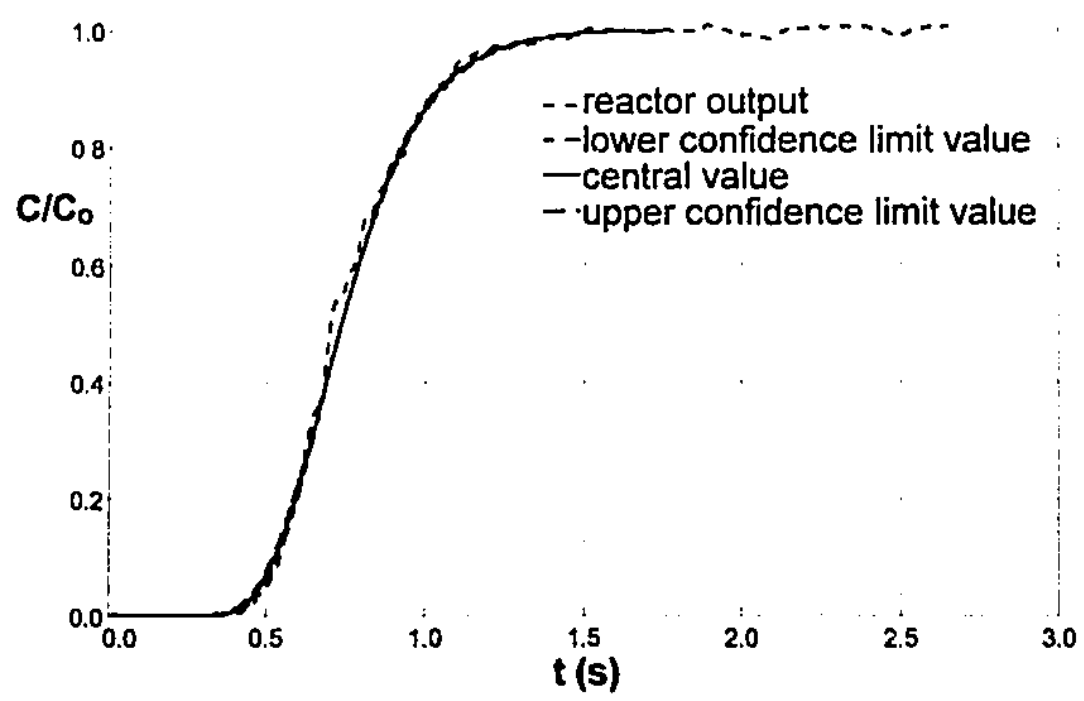

Figure 4.34 Concentration vs time curves calculated from various dispersion coefficient values for a statistical axial dispersion model - carrier gas: $N_{2}, v_{\text {iet: }}: 12.9 \mathrm{~m} / \mathrm{s}, z_{\text {in }}=7.6 \mathrm{~cm}, z_{\text {out }}=35.6 \mathrm{~cm}$.

With an increase in jet velocity, many effects took place:

- More turbulent mixing was present close to the injector, thus increasing $D_{Z}$.

- The radial velocity profile started to exhibit a high velocity central core (Section 4.1) close to the injector. This increased the value of $D_{Z}$ in that region since it was calculated assuming a flat radial velocity profile.

- The increased turbulence probably caused the boundary layer formation to be retarded. The consequence of this was that $D_{z}$ decreased downstream of the injector because the radial velocity profile was then flatter.

The magnitude of each effect was not known as a function of the jet velocity; neither was the exact region in which each took place. The variations in $D_{Z}$ were caused by the sum of all of them. The relative change in magnitude of one with the others dictated the direction of change of $D_{2}$ for varying experimental conditions.

The experimental values of $D_{Z}$ were roughly one order of magnitude lower than the ones published by Levenspiel ${ }^{(14)}$ for fully developed pipe flow (see Table 4.1). It is believed that the dominant effect was the non-flat velocity profile, present mostly in fully 
developed pipe flow since the radial velocity profile was parabolic (laminar flow region). This would explain the higher axial dispersion coeflicient values of Levenspiel. It also shows that the radial velocity gradient can contribute to a large extent to the dispersion coefficient (Levenspiel and Bischoff ${ }^{(3)}$ ).

The velocity measurements in helium revealed that a significant boundary layer, although not fully developed, was present near the reactor end. This justified the use of the model consisting of a plug flow foliowed by a laminar flow reactor. Because turbulent dispersion was still present due to the presence of the injector, the axial dispersion model was also tested using the differential equation method. The experimental conditions investigated were similar to the ones for nitrogen. Some input and output results (experimental and model) are shown in Figures 4.35 to 4.38.

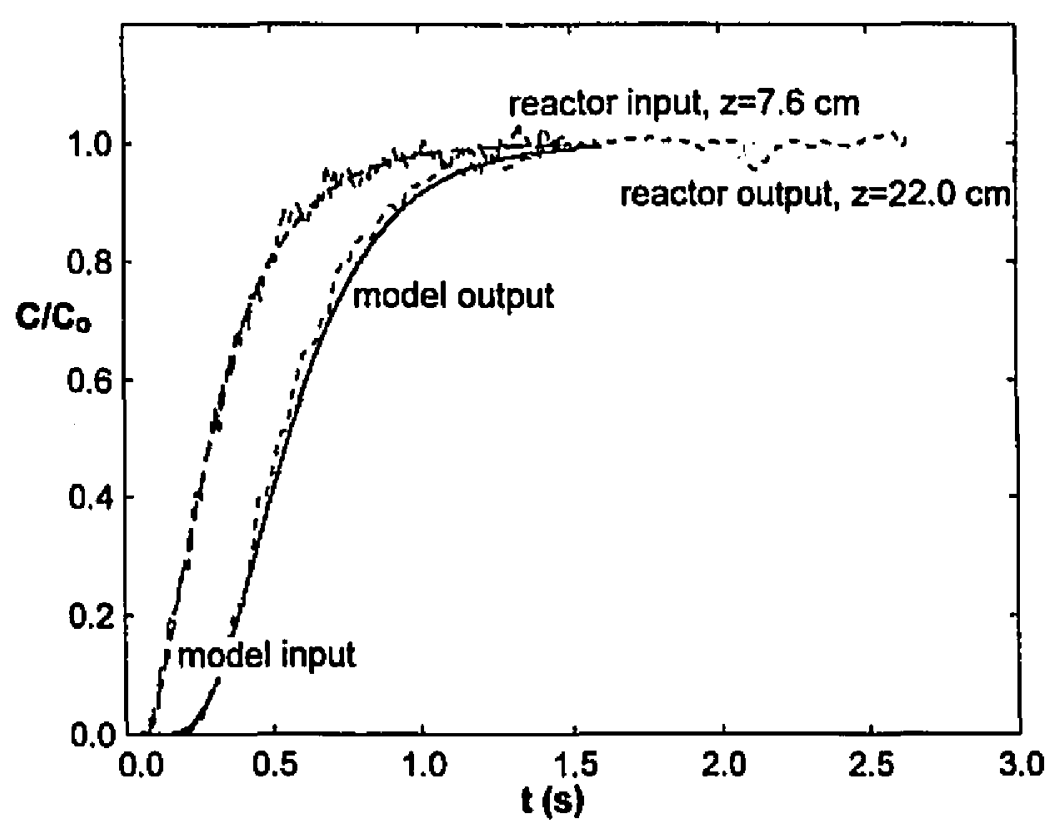

Figure 4.35 Reactor input and output data with the differential equation axial dispersion model — carrier gas: He, $v_{\text {jet: }} 12.5 \mathrm{~m} / \mathrm{s}, z_{i n}=7.6 \mathrm{~cm}$, $\mathrm{z}_{\text {out }}=22.0 \mathrm{~cm}, D_{Z}=0.0170 \mathrm{~m}^{2} / \mathrm{s}$. 


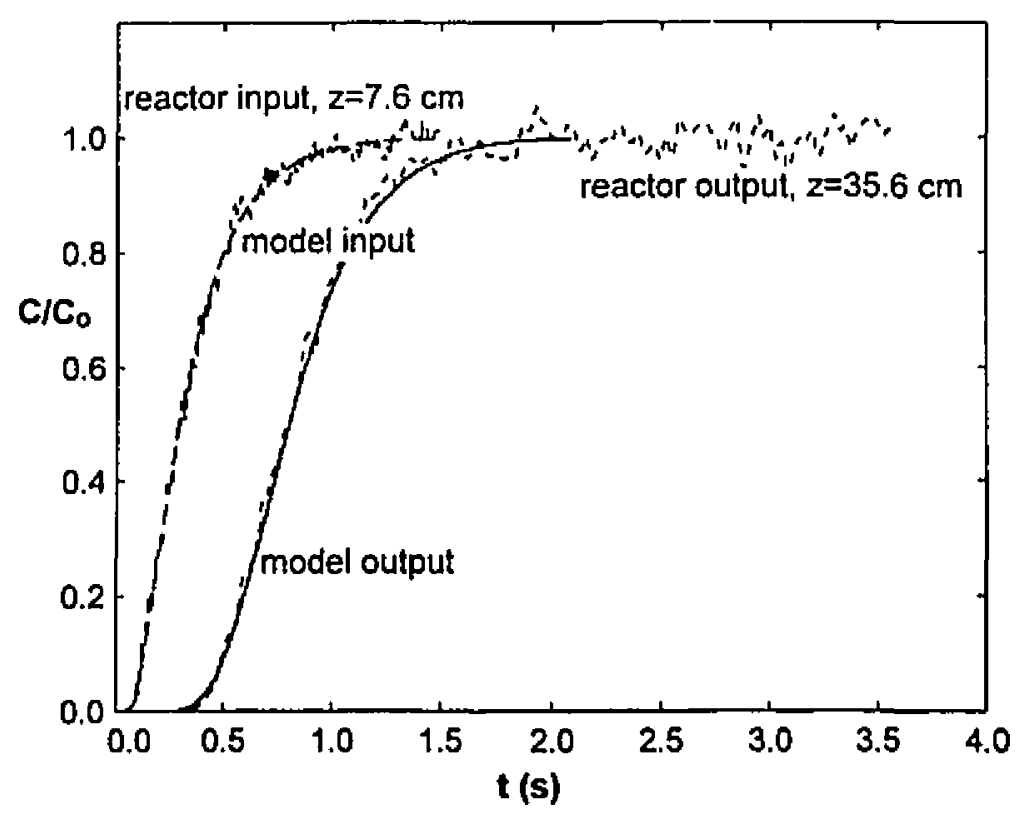

Figure 4.36 Reactor input and output data with the differential equation dispersion model — carrier gas: $\mathrm{He}, v_{\mathrm{jet}:} 12.5 \mathrm{~m} / \mathrm{s}, \mathrm{z}_{\mathrm{in}}=7.6 \mathrm{~cm}$, $\mathrm{Z}_{\text {out }}=35.6 \mathrm{~cm}, D_{z}=0.0140 \mathrm{~m}^{2} / \mathrm{s}$.

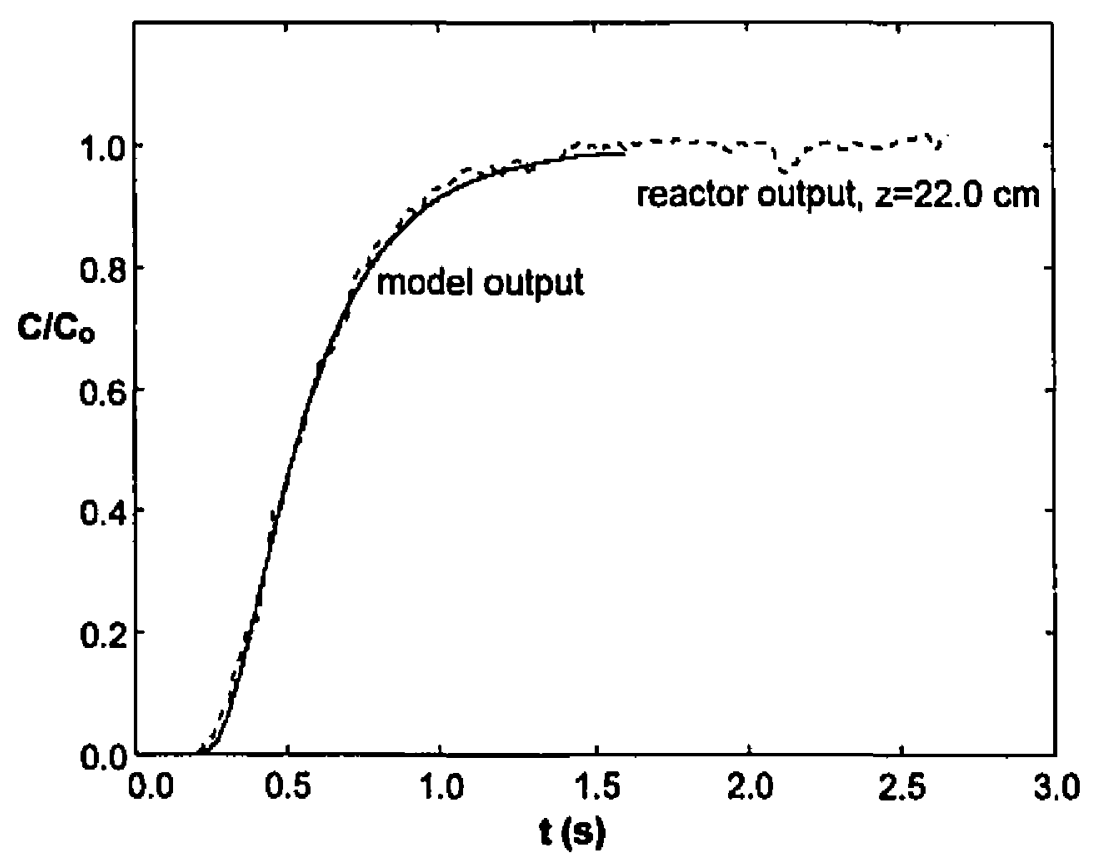

Figure 4.37 Reactor output data with the plug flow + laminar flow model carrier gas: $\mathrm{He}, v_{\text {jet: }}: 12.5 \mathrm{~m} / \mathrm{s}, z_{\text {in }}=7.6 \mathrm{~cm}, z_{\text {out }}=22.0 \mathrm{~cm}, L_{L F R}=0.120$ $m, L_{\text {PFR }}=0.024 \mathrm{~m}$. 


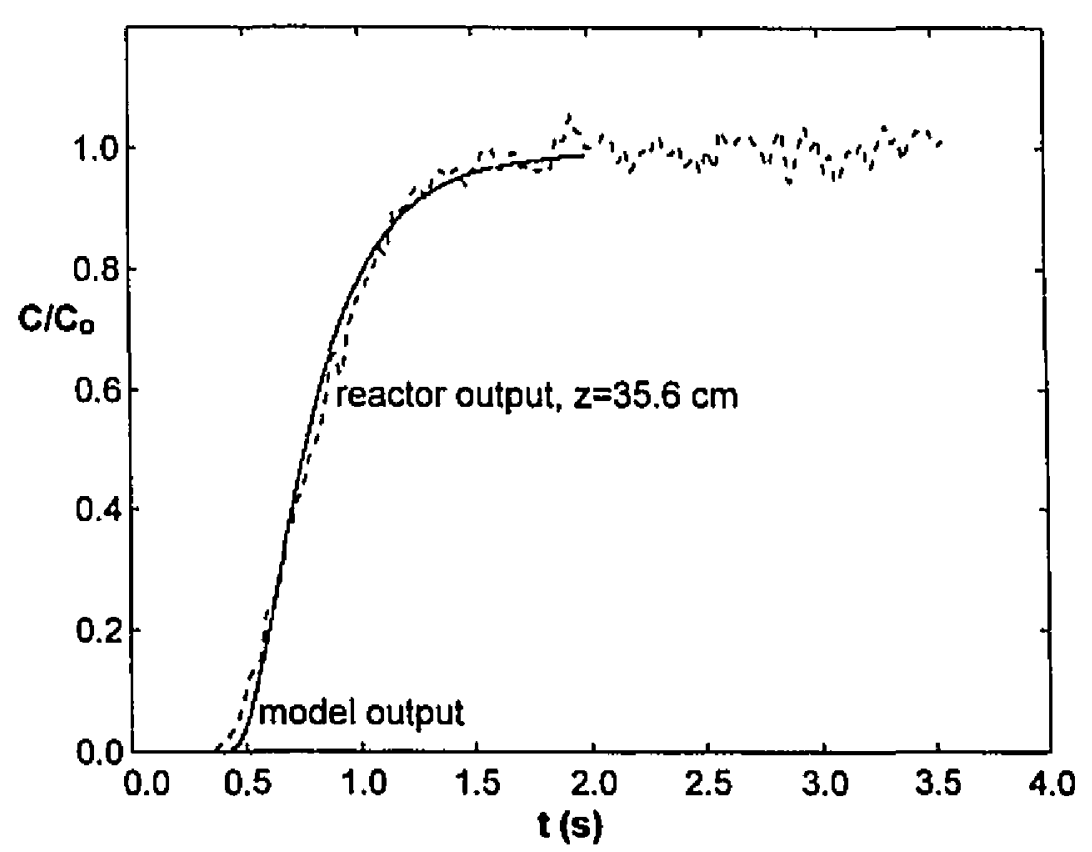

Figure 4.38 Reactor output data with the plug flow + laminar flow model carrier gas: $\mathrm{He}, v_{\text {jet: }}: 12.5 \mathrm{~m} / \mathrm{s}, \mathrm{z}_{\mathrm{in}}=7.6 \mathrm{~cm}, \mathrm{z}_{\text {out }}=35.6 \mathrm{~cm}, L_{L F R}=0.160$ $\mathrm{m}, \mathrm{L}_{\mathrm{PFR}}=0.120 \mathrm{~m}$.

Table 4.2 displays the modeling results for the helium experiments. The dispersion coefficients for fully developed pipe flow came from the same reference as for nitrogen. The axial dispersion model with the differential equation method fitted the experimental data better than the plug flow + laminar flow model for all experiments.

Table 4.2 Estimated parameters for differential equation axial dispersion model and plug flow + laminar flow reactor model - carrier gas: He.

\begin{tabular}{|c|c|c|c|c|}
\hline $\begin{array}{l}\text { Reactor } \\
\text { inlotloutlot } \\
\text { locations } \\
\text { (cm) }\end{array}$ & $v_{p e}(\mathbf{m} / \mathbf{s})$ & $\begin{array}{l}\text { Dz from } \\
\text { difierential } \\
\text { equation model } \\
\left(\mathrm{m}^{2} / \mathrm{s}\right)\end{array}$ & $L_{L F R}(m)$ & $\begin{array}{l}\text { Dz for fully } \\
\text { doveloped } \\
\text { plpoflow } \\
\left(\mathrm{m}^{2} / \mathrm{s}\right)\end{array}$ \\
\hline \multirow[t]{2}{*}{$7.6 / 22.0$} & 12.5 & 0.0170 & 0.120 & 0.056 \\
\hline & 37.5 & 0.0360 & 0.140 & 0.101 \\
\hline \multirow[t]{2}{*}{$7.6 / 35.6$} & 12.5 & 0.0140 & 0.160 & 0.056 \\
\hline & 37.5 & 0.0210 & 0.180 & 0.101 \\
\hline
\end{tabular}


The above data showed that an increase in jet velocity caused an increase in the dispersion coefficient or laminar flow reactor length. The main factor affecting this behavior was probably the pronounced gradients of the radial velocity profile past the injector. The velocity measurements showed that these gradients were quite large in helium at $v_{\mathrm{jet}}=15 \mathrm{~m} / \mathrm{s}$ at $\mathrm{L}=12.1 \mathrm{~cm}$. It seems possible that the radial velocity gradients were even more pronounced at higher $v_{\text {jet }}$, such as $37.5 \mathrm{~m} / \mathrm{s}$. This would increase the spread of the residence times, thus the higher $\mathrm{D}_{Z}$ or $\mathrm{L}_{\mathrm{L} r \mathrm{R}}$ values.

At $z \geq 12.1 \mathrm{~cm}$, the sharp radial velocity gradients dissipated gradually while the boundary layer developed. Between $z=22.0$ and $35.6 \mathrm{~cm}$, if the dissipation of the velocity gradients was more significant than the boundary layer development, the dispersion coefficient would decrease. This could explain the trend of Table 4.2 where the $D_{Z}$ values for reactors extending from $z=7.6$ to $22.0 \mathrm{~cm}$ were higher than the ones for reactors from $z=7.6$ to $35.6 \mathrm{~cm}$. As in the case of the nitrogen results, the higher values of $D_{z}$ for fully developed pipe flow probably resulted from the fully developed parabolic velocity profile.

Some RTD functions were calculated from the axial dispersion coefficients obtained in Tables 4.1 and 4.2 and equation 2.10. The functions are displayed in Figure 4.39 and 4.40. The abscissa is the dimensionless time $t$ ' defined as

$$
t^{\prime}=\frac{t}{\tau} . \quad \text { dimensionless }
$$

The RTD functions will not be discussed in more details since they are directly related to the dispersion coefficients. The higher the $D_{z}$ values, the more "spread" are the $F(t$ ') curves. 


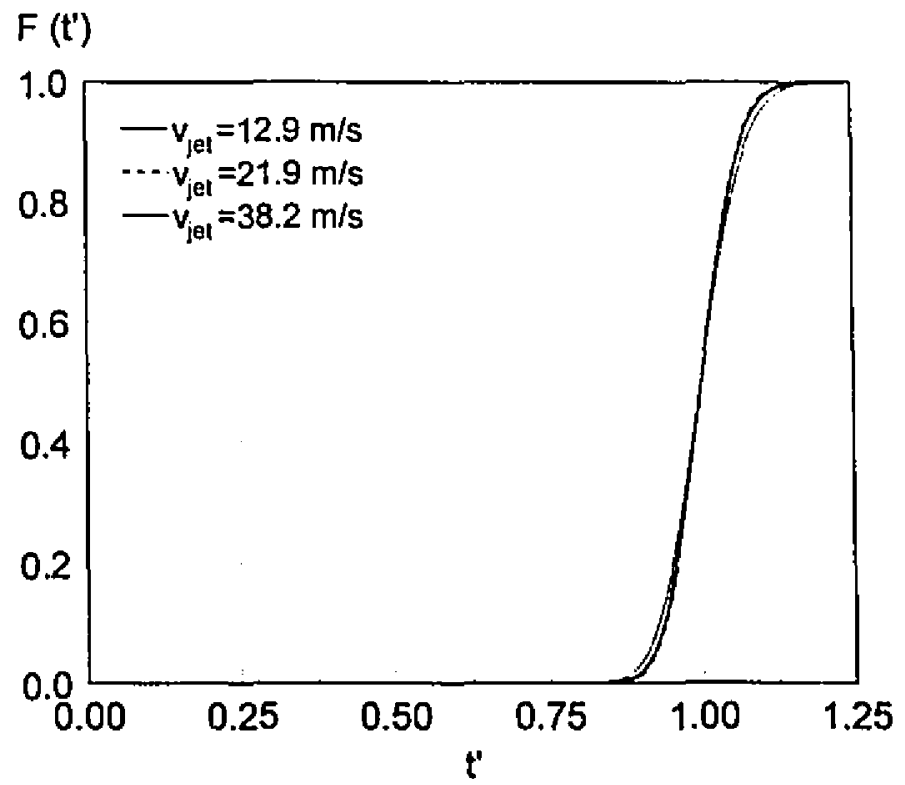

Figure 4.39 Residence time distribution functions vs $t^{\prime}$ at different jet velocities - carrier gas: $\mathrm{N}_{2}, \mathrm{z}_{\text {in }}=7.6 \mathrm{~cm}, \mathrm{z}_{\text {out }}=35.6 \mathrm{~cm}$.

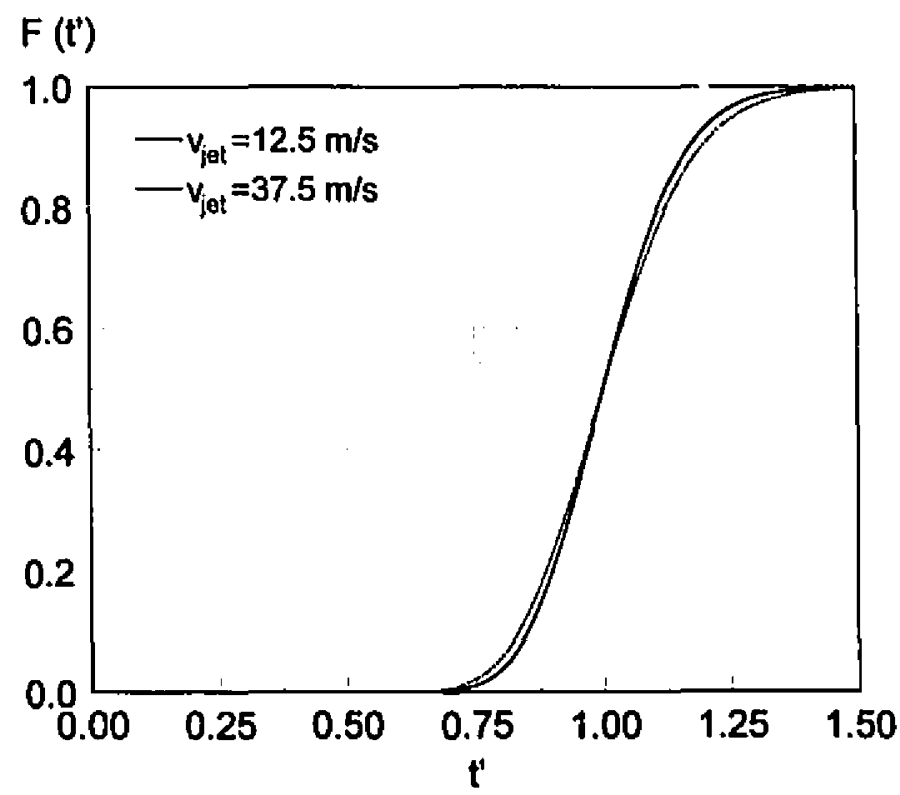

Figure 4.40 Residence time distribution functions vs $t^{\prime}$ at different jet velocities - carrier gas: $\mathrm{He}, \mathrm{z}_{\mathrm{in}}=7.6 \mathrm{~cm}, \mathrm{z}_{\text {out }}=35.6 \mathrm{~cm}$. 


\section{Chapter 5}

\section{Conclusions and Recommendations}

\subsection{Conclusions}

An infrared laser absorption technique was developed to measure the residence time distribution in a reactor with very short space times $(0.04$ to $0.7 \mathrm{~s})$. The measurement technique is non-intrusive and it has a response time of the order of microseconds.

The residence time distributions were successfully measured in a tubular reactor with radial injection of the tracer at ambient temperature and pressure. The main gases used were nitrogen or helium while meth une at a concentration up to $7 \%$ (molar basis) was employed as a tracer. The gas axial velocity ranged from 0.49 to $0.78 \mathrm{~m} / \mathrm{s}$. The velocity of the radial injector jets was varied from 2.3 to $38.2 \mathrm{~m} / \mathrm{s}$. The Reynolds number in the reactor ranged from 250 to 2400 . RTD measurements were taken at axial locations ranging from 0.7 to 7.9 reactor diameters from the radial injector.

Velocity measurements by laser Doppler anemometry showed that the gas flow was not symmetric with respect to the angular coordinate. The main source for this was the non-ideal radial injector since the jets had different angles and velocities. The flow was not fully developed at any axial location in the reactor due to the injector jets.

The residence time distributions were obtained by measuring the inlet and outlet concentrations when a time varying tracer concentration was applied. The tracer concentration was measured by infrared laser absorption spectroscopy. The measurement device consisted of an infrared $\mathrm{He}-\mathrm{Ne}$ laser beam passing through the diameter of the reactor. 
The absorption of the laser light was related to the methane concentration by Becr-l ambert law. The intensity of the laser beam after passing through the reactor was measured with a lead selenide detector. The detector signal was sampled at frequencies from 2 to $8 \mathrm{kHz}$.

The main limitation in the analysis is that it assumes the concentration to be uniform over the cross section of the reactor at the measurement location. In the reactor studied, the validity of this assumption could not be assessed precisely. However, only the experiments with the highest probability that this assumption would hold true were selected for further analysis.

The very fast response of the detection device permitted the monitoring of the concentration fluctuations induced by turbulence. It was observed experimentally that better radial mixing conditions at the exit were obtained with high amounts of gas injected radially and longer reactors. The reactor output was modeled using an axial dispersion model assuming a that radial velocity profile. The dispersion coefficients found were high: from 0.0060 to 0.025 $\mathrm{m}^{2} / \mathrm{s}$ depending on the different experimental conditions. It was believed that a significant contribution to these values came from the non-flat radial velocity profiles in the reactor.

\subsection{Recommendations}

The ultimate objective is to measure the RTD in a high temperature reactor used for ceramic production. Thus, it is worth considering how the method developed here might be implemented to such a reactor. Three considerations are worth mentioning:

- the wavelength shift and intensity of the absorption lines by methane

- the background infrared radiation emitted by the reactor and the hot gas

- the measurement of the mixing cup concentration in the absence of a uniform concentration profile.

The first consideration is probably the most important. As temperature increases, the population of the different vibrational-rotational levels will vary. This means that the line intensity of the infrared spectrum of methane will be different compared to row temperature. 
A low line intensity would lead to a poor signal-to-noise ratio. Another line may then need to be chosen, which would imply using another light source than the non-tunable He-Ne laser. Alternatively, another vibrational-rotational transition may fall at the same wavelength as the He-Ne laser. The absorption lines of methane and other potential tracer at high temperatures should be studied in detail.

At high temperature, the reactor and the gases that it contains will emit large amounts of radiation, primarily in the infrared region. Because this emission (the noise) will be superposed to the laser beam (the signal) at the detector, a poor signal-to-noise ratio may result. It may be necessary to remove a significant portion of the noise for good measurements. One possible way is to shield the laser beam by using a narrow tube extending from the detector to the reactor. This would prevent the reactor radiation to reach the detector except for a small amount from the tube end. Two additional ways would be to use a bandpass filter selecting only the laser wavelength and to use a lock-in amplifier.

High temperature reactors often operate in the laminar flow region due to the high viscosity of gases. It was shown in Section 3.4 that this lead to radial concentration gradients. This can be solved by taking measurements at locations other than the reactor center and then to use Abel's inversion to obtain the radial concentration profile. The radial concentration profile can then be combined with radial velocity measurements to calculate the mixing cup concentration. 


\section{$\underline{\text { References }}$}

1. Young, R. M. and E. Pfender. "Generation and Behavior of Fine Particles in Thermal Plasmas-A Review", Plasma Chemistry and Plasma Processing, v. 5 (1985), p. 1-32.

2. Vogt, G. J. and L. R. Newkirk. "Thermal Plasma Chemical Synthesis of Powders". Proceedings of the Symposium on High Temperature Materials Chemistry - III, Proceedings - The Electrochemical Society, v. 86-2 (1986).

3. Levenspiel, O. and K. B. Bischoff. "Patterns of Flow in Chemical Process Vessels". Advances in Chemical Engineering, v. 4 (1963), p. 95-198.

4. Shinnar, R. Chemical Reaction and Reactor Engineering, edited by J. J. Carberry and A. Varma, Marcel Dekker Inc., New York, 1987, p. 63-149.

5. Moura, F. J. "Vapour phase synthesis of AIN using a transferred arc plasma system", Ph.D. Thesis, McGill University, 1993.

6. Njah, Z., Mostaghimi, J. and M. I. Boulos. "Mathematical modeling of the 3-D mixing in an induction plasma reactor", Int. J. Heat Mass Transfer, v. 36 (1993), no. 16, p. 3909-3919.

7. Soucy, G., Jurewicz, J. W. and M. I. Boulos. "Mixing Study of the Induction Plasma Reactor: Part II. Radial Injection Mode", Plasma Chemistry and Plasma Processing, v. 14 (1994), no. 1, p. 59-71.

8. Bischoff, K. B. and O. Levenspiel. "Fluid dispersion-generalization and comparison of mathematical models - I Generalization of models", Chemical Engineering Science, v. 17 (1962), p 245-256.

9. Hanst, P. L. "Spectroscopic Methods for Air Pollution Measurement", Advances in Environmental Science and Technology, v. 2 (1971), p. 91-213.

10. Jaynes, D. N. and B. H. Beam. "Hydrocarbon Gas Absorption by a He-Ne Laser Beam at a 3.39- $\mu$ Wavelength", Applied Optics, v. 8, no. 8, p. 1741-42.

11. Dailey, Wm. V. "Process infrared analysis (on-line technology): NDIR, NIR, FTIR, PAS and applications - A brief review", Process Control and Quality, v. 3 (1992), p. 99-106. 
12. Wilks, P. A. Jr. "High performance infrared filtometers for continuous liquid and gas sampling", Process Control and Quality, v. 3 (1992), p. 283-293.

13. Durst, F. Principles and practice of laser Doppler anemometry-2nd edition, Academic Press, London (UK), 1981.

14. Fogler, H. S. Elements of Chemical Reaction Engineering $2^{\text {nd }}$ Edition, Prentice-Hall, Englewood Cliffs, N.J., 1992, p.759-793.

15. Levenspiel, O. Chemical Reaction Engineering, Wiley, New York, 1972, p. 284. 


\section{Appendix A}

\section{Additional Velocity Measurements}

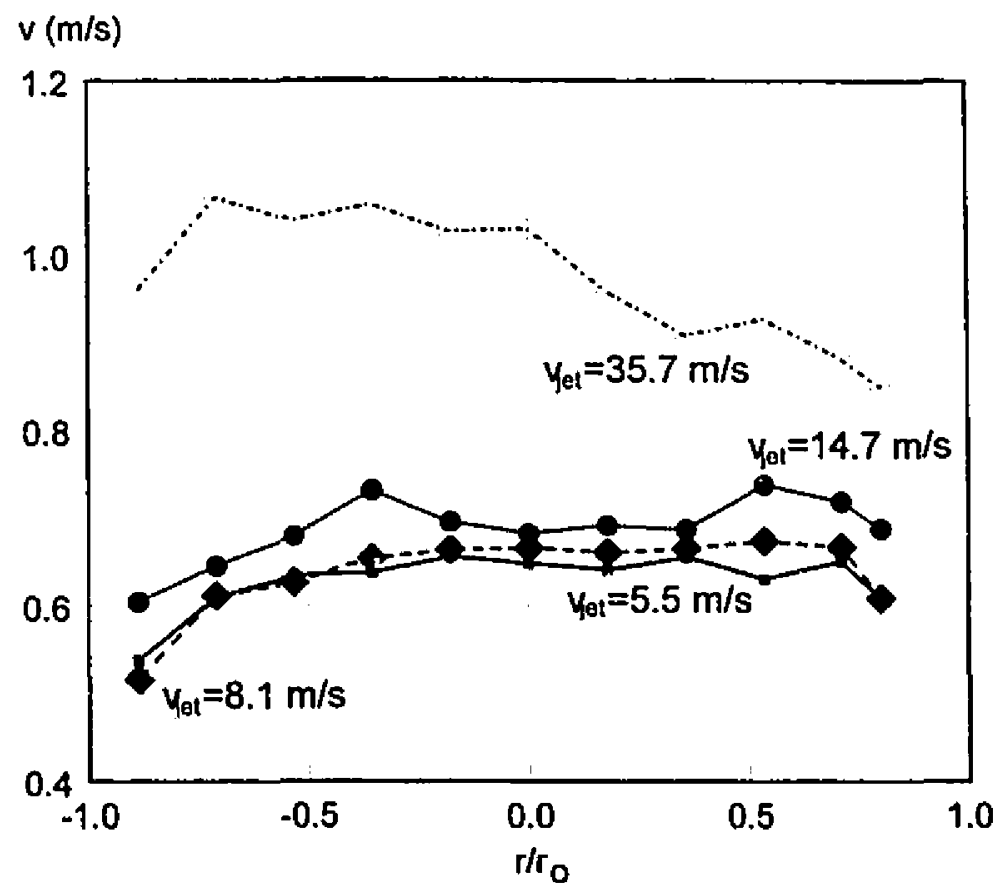

Figure A.1 Radial velocity profiles for various injector velocities - carrier gas: $\mathrm{N}_{2}, \mathrm{~L}=21.4 \mathrm{~cm}, \mathrm{Re}=1420-2370$. 


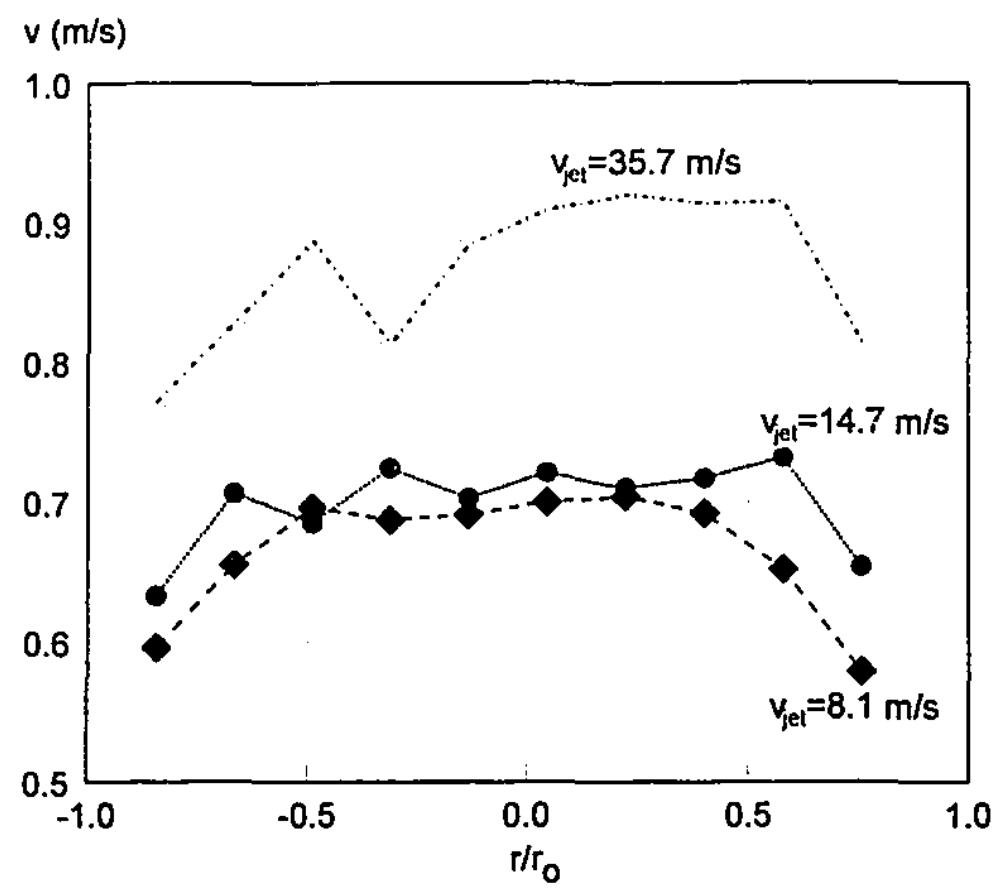

Figure A.2 Radial velocity profiles for various injector velocities - carrier gas: $\mathrm{N}_{2}, \mathrm{~L}=30.7 \mathrm{~cm}, \mathrm{Re}=1550-2370$.

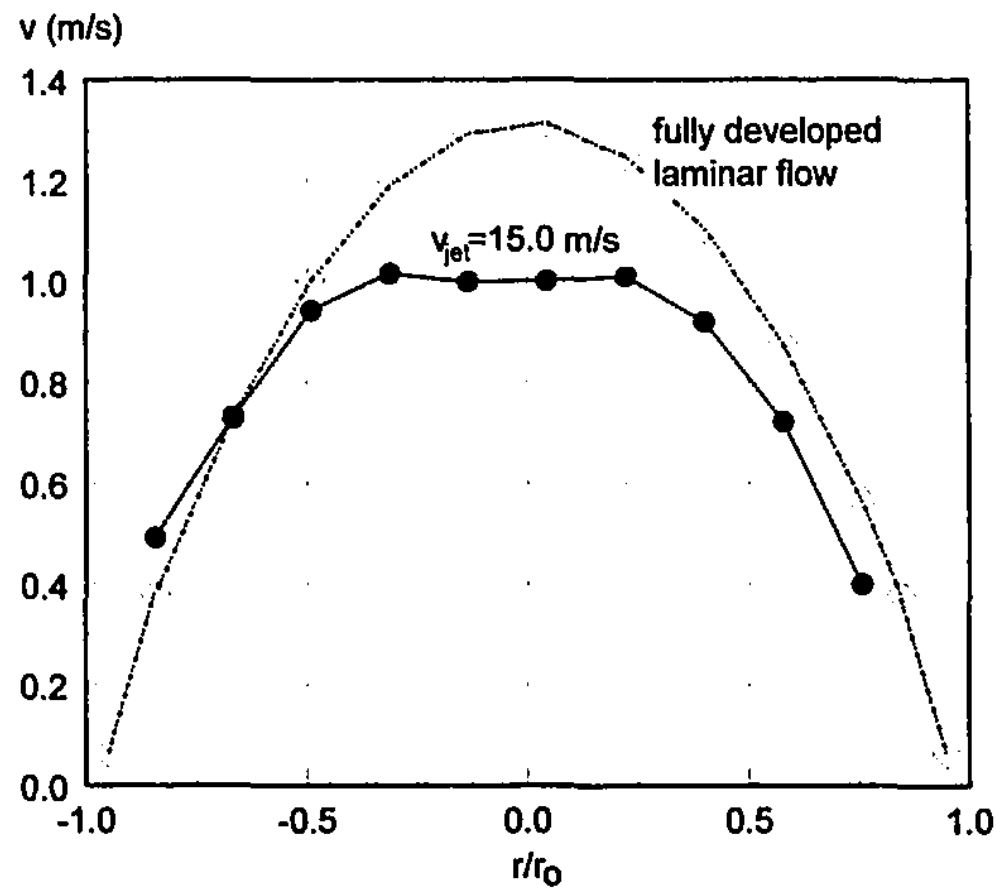

Figure A.3 Radial velocity profiles for various injector velocities - carrier gas: $\mathrm{He}, \mathrm{L}=30.7 \mathrm{~cm}, \mathrm{Re}=250$. The fully developed liaminar profile (parabolic shape) was obtained from the known value of the flow rate. 


\section{Appendix B}

\section{Additional Concentration Measurements}

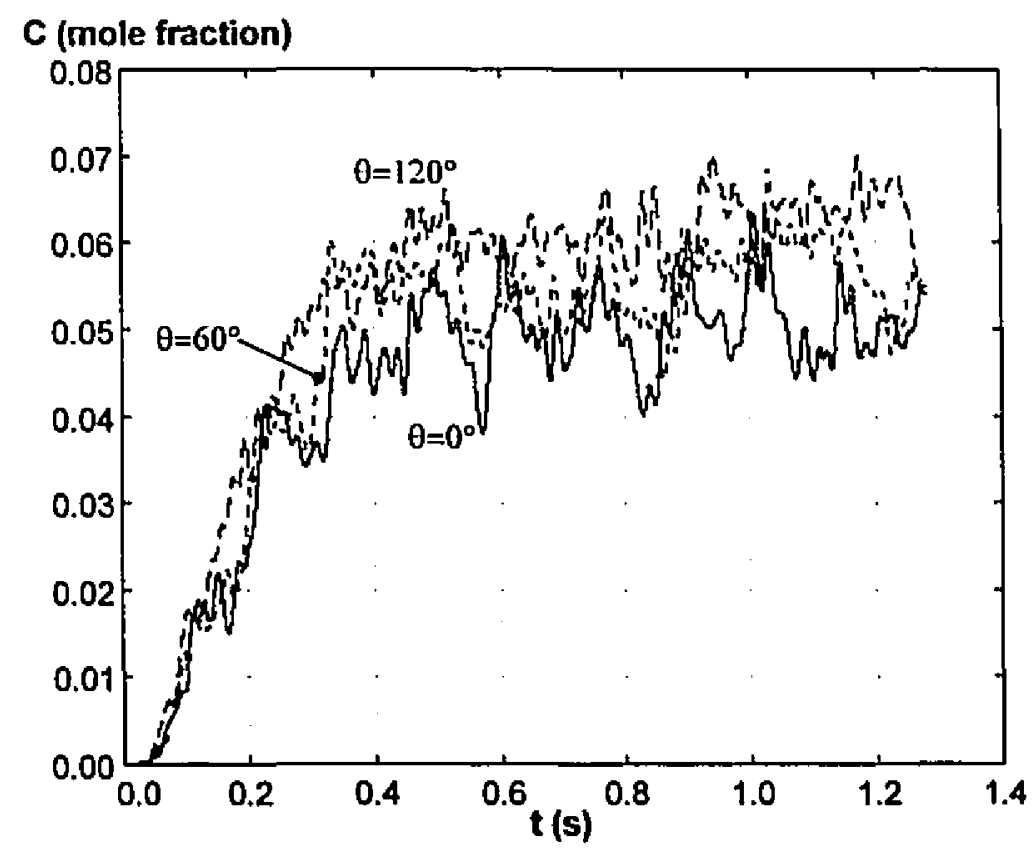

Figure B.1 Concentration vs time experiments at different angles - carrier gas: $\mathrm{N}_{2}, v_{\text {jet }}: 12.9 \mathrm{~m} / \mathrm{s}, \mathrm{L}=3.3 \mathrm{~cm}, \mathrm{Re}=1660$. 


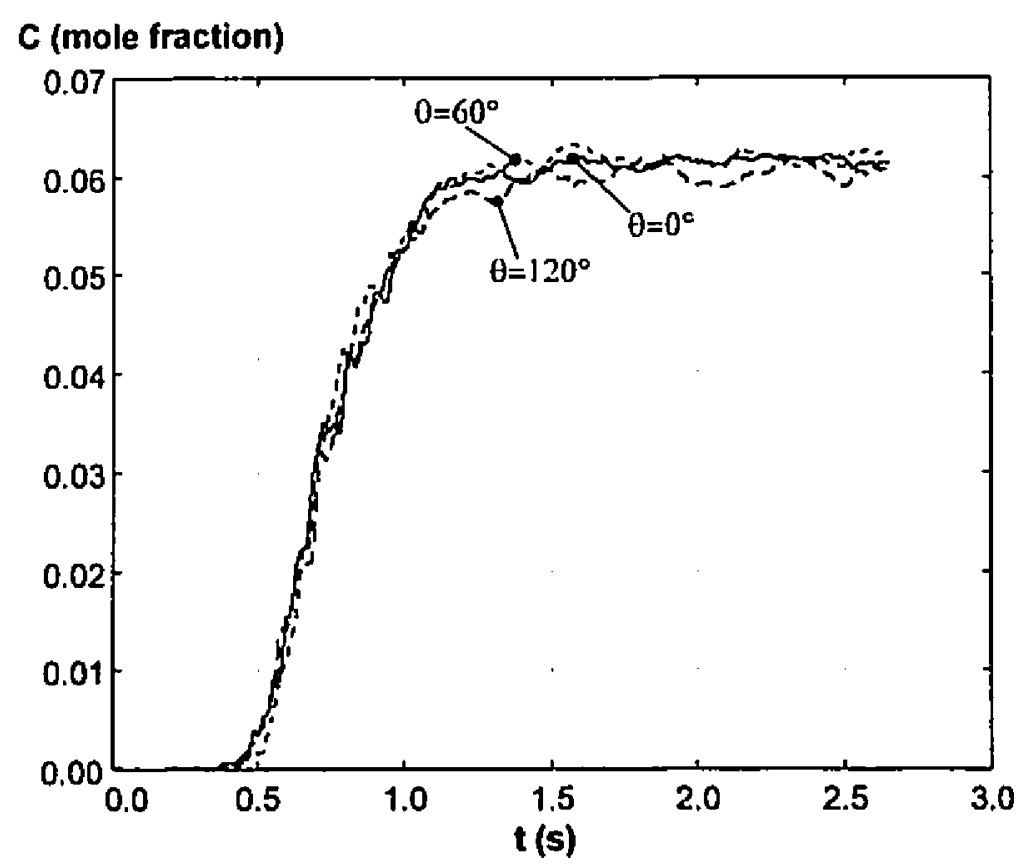

Figure B.2 Concentration vs time experiments at different angles - carrier gas: $\mathrm{N}_{2}, v_{\text {jet: }}: 12.9 \mathrm{~m} / \mathrm{s}, \mathrm{L}=35.6 \mathrm{~cm}, \mathrm{Re}=1660$.

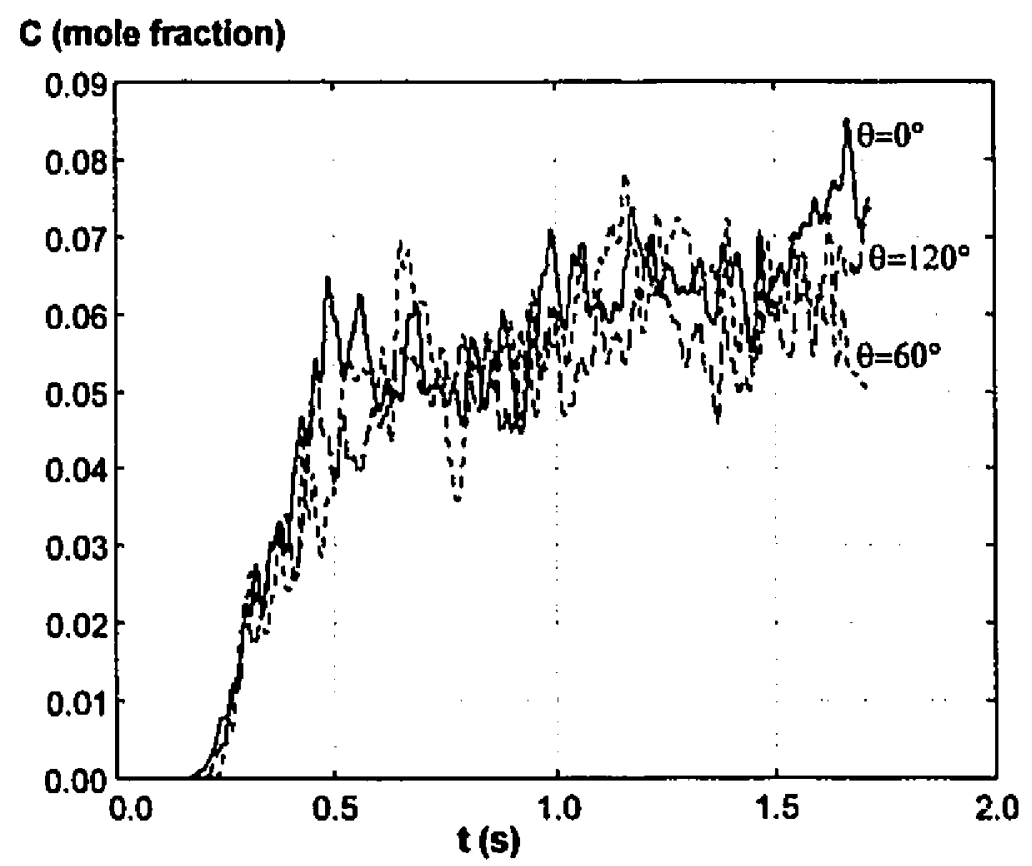

Figure B.3 Concentration vs time experiments at different angles - carrier gas: $\mathrm{He}, v_{\text {jet: }}: 4.6 \mathrm{~m} / \mathrm{s}, \mathrm{L}=3.3 \mathrm{~cm}, \mathrm{Re}=210$. 


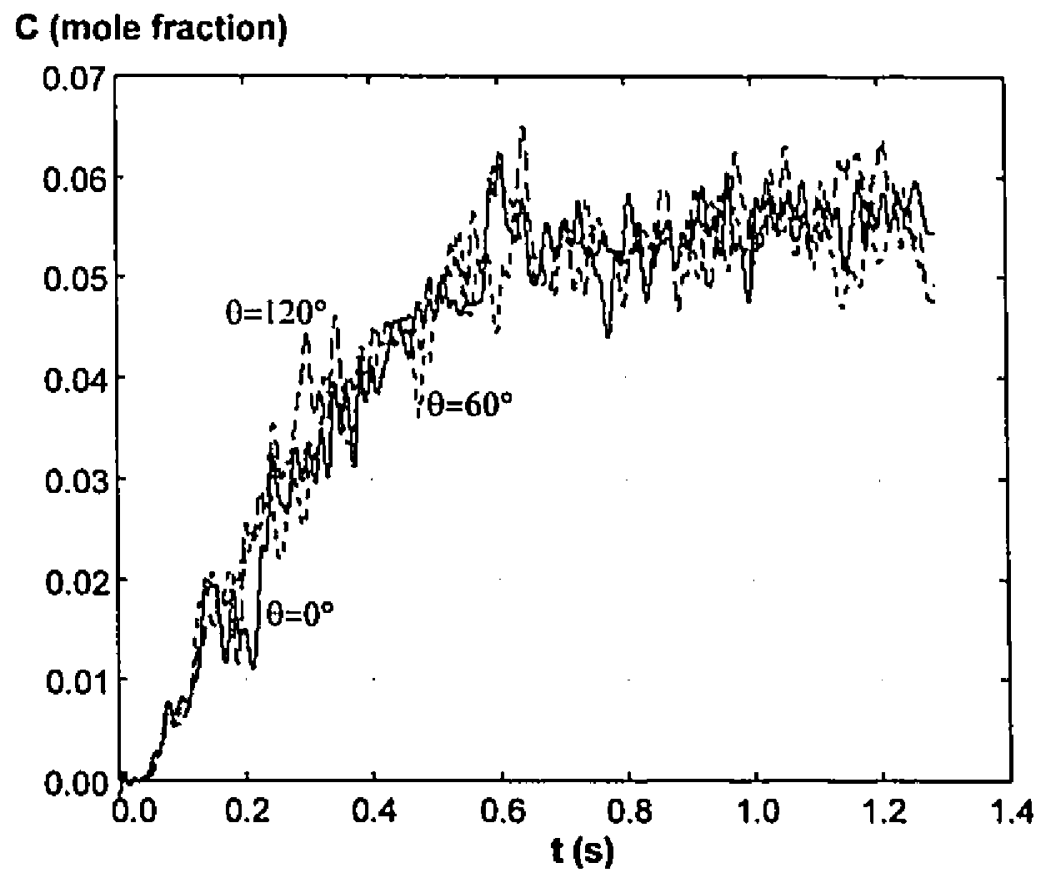

Figure B.4 Concentration vs time experiments at different angles - carrier gas: $\mathrm{He}, v_{\text {jet: }} 12.5 \mathrm{~m} / \mathrm{s}, \mathrm{L}=3.3 \mathrm{~cm}, \mathrm{Re}=240$.

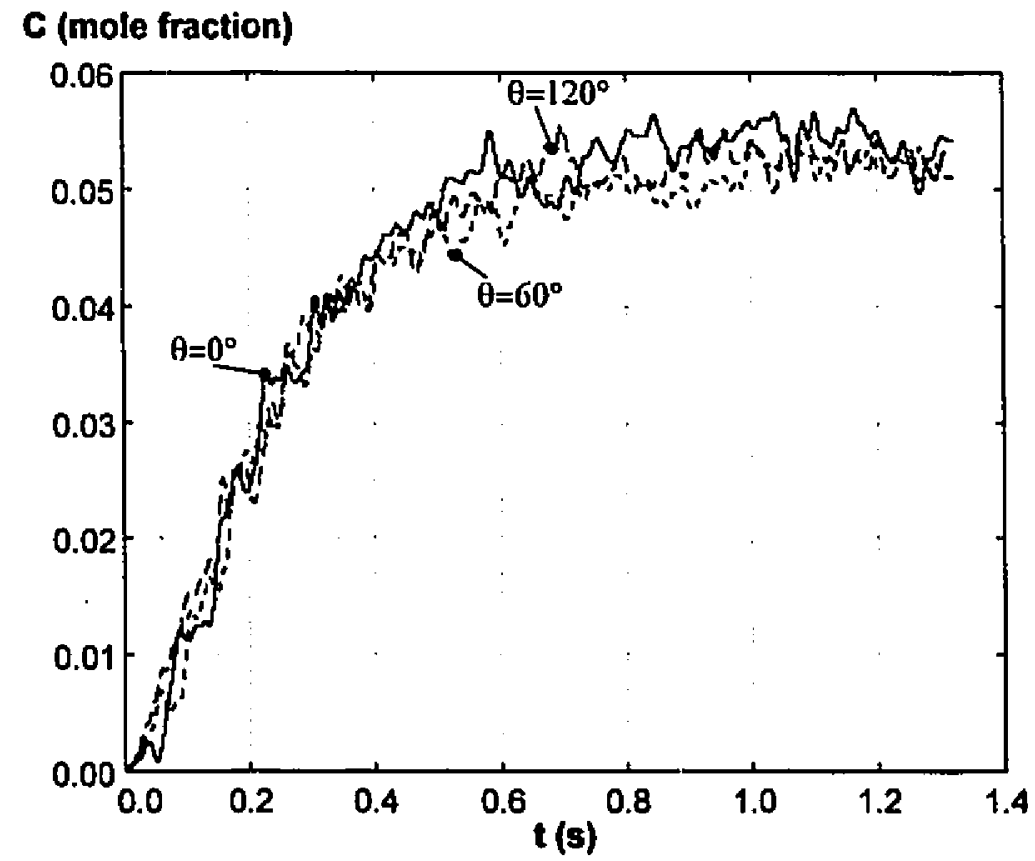

Figure B.5 Concentration vs time experiments at different angles - carrier gas: $\mathrm{He}, v_{\text {jet: }}: 37.5 \mathrm{~m} / \mathrm{s}, \mathrm{L}=3.3 \mathrm{~cm}, \mathrm{Re}=310$. 


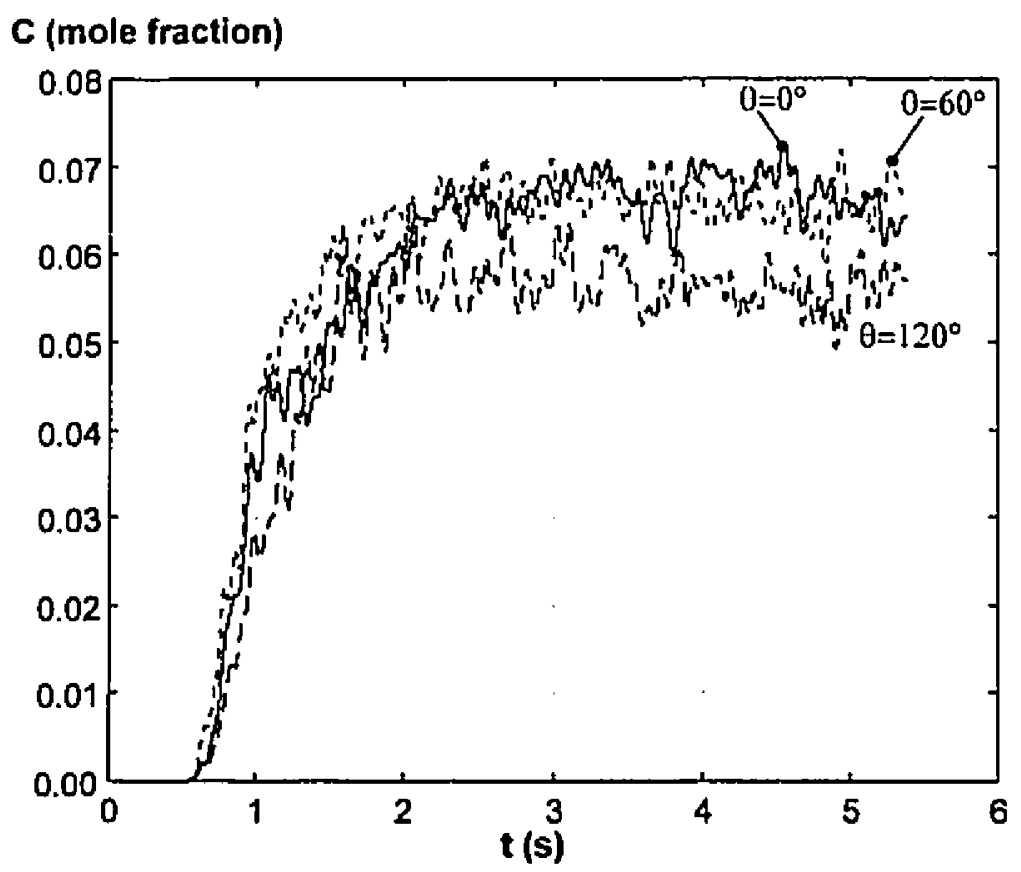

Figure B.6 Concentration vs time experiments at different angles - carrier gas: $\mathrm{He}, v_{\text {jet: }} 4.6 \mathrm{~m} / \mathrm{s}, \mathrm{L}=35.6 \mathrm{~cm}, \mathrm{Re}=210$.

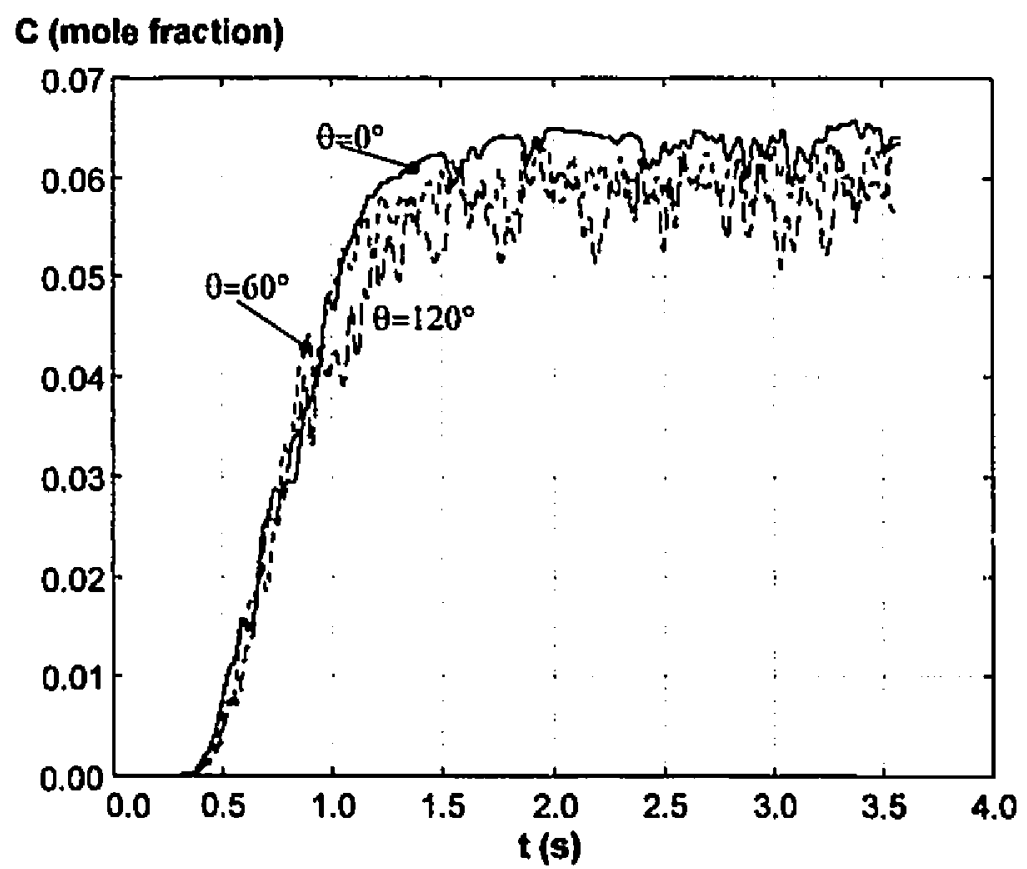

Figure B.7 Concentration vs time experiments at different angles - carrier gas: $\mathrm{He}, v_{\mathrm{jet}}: 12.5 \mathrm{~m} / \mathrm{s}, \mathrm{L}=35.6 \mathrm{~cm}, \mathrm{Re}=240$. 


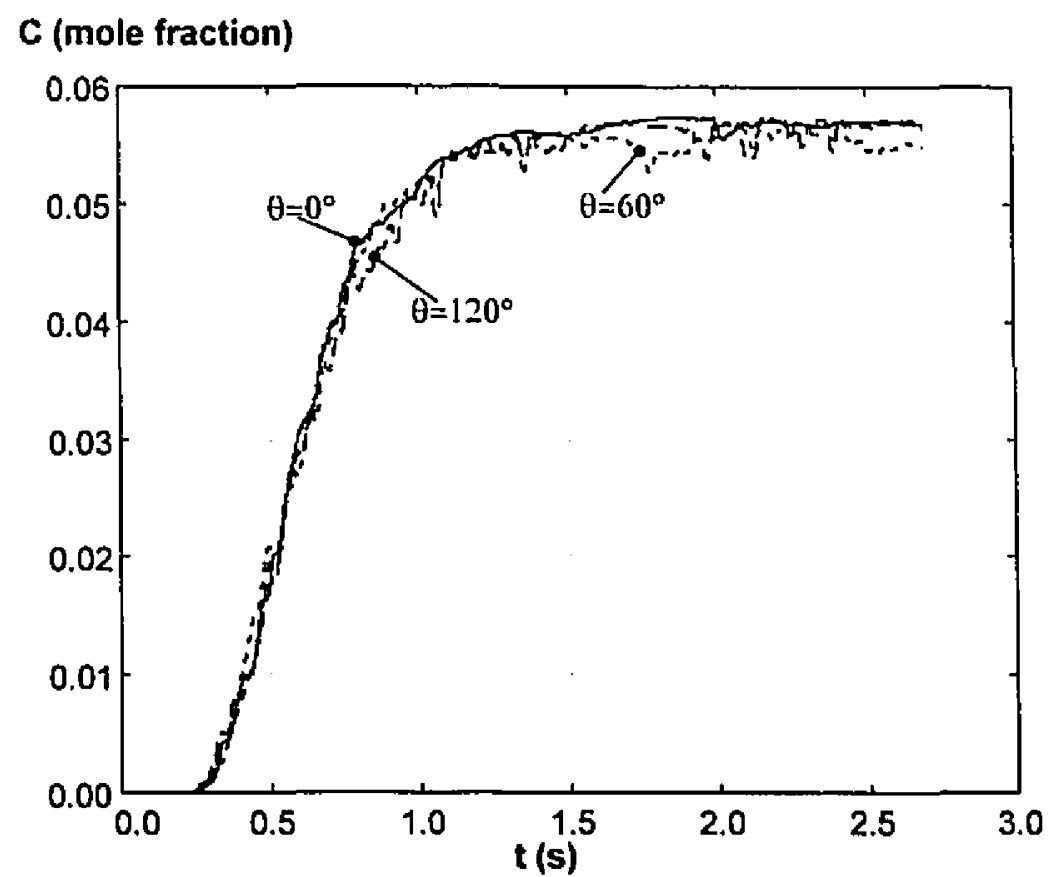

Figure B.8 Concentration vs time experiments at different angles - carrier gas: $\mathrm{He}, v_{\mathrm{jet}}: 37.5 \mathrm{~m} / \mathrm{s}, \mathrm{L}=35.6 \mathrm{~cm}, \mathrm{Re}=310$.

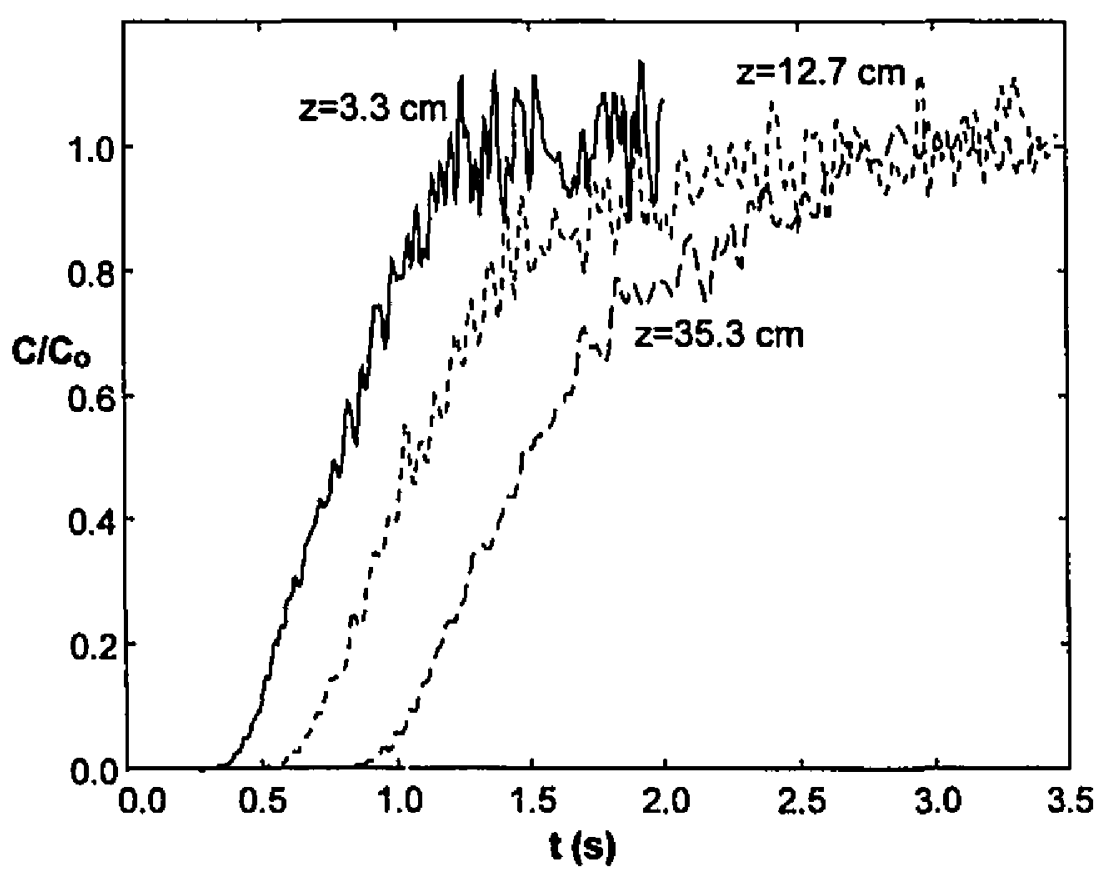

Figure B.9 Concentration vs time experiments at various axial locations carrier gas: $\mathrm{N}_{2}, v_{\mathrm{jet}}: 2.3 \mathrm{~m} / \mathrm{s}, \mathrm{Re}=1520$. 


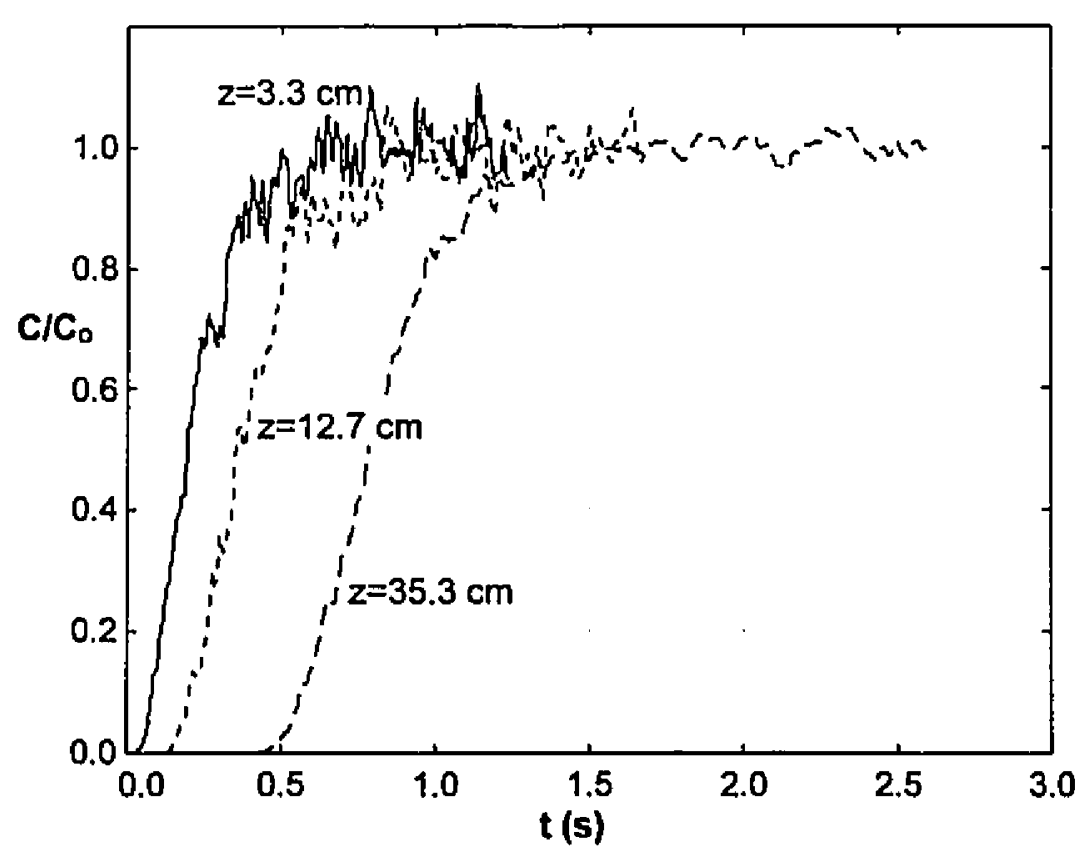

Figure B.10 Concentration vs time experiments at various axial locations carrier gas: $\mathrm{N}_{2}, v_{\mathrm{jet}}: 8.8 \mathrm{~m} / \mathrm{s}, \mathrm{Re}=1570$.

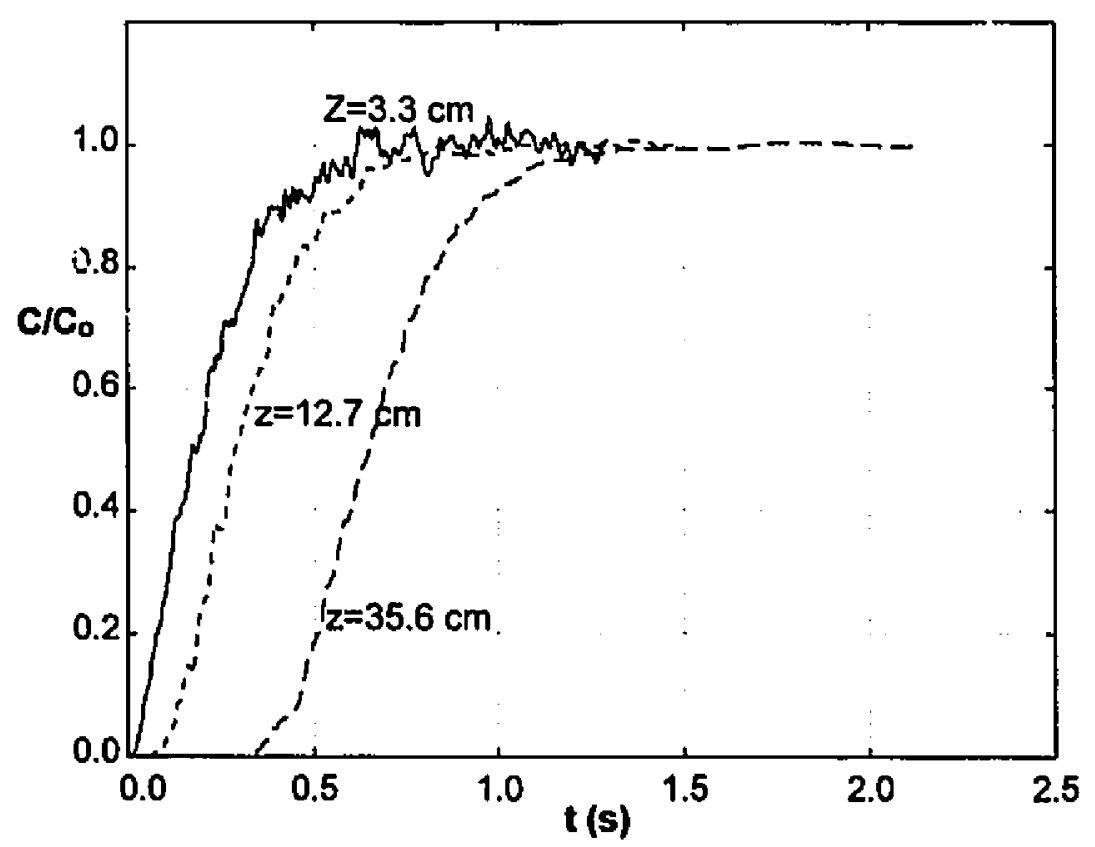

Figure B.11 Concentration vs time experiments at various axial locations varrier gas: $\mathrm{N}_{2}, \mathrm{v}_{\mathrm{jet}}: 21.9 \mathrm{~m} / \mathrm{s}, \mathrm{Re}=1840$. 


\section{Appendix C}

\section{Additional Residence Time Distribution Results}

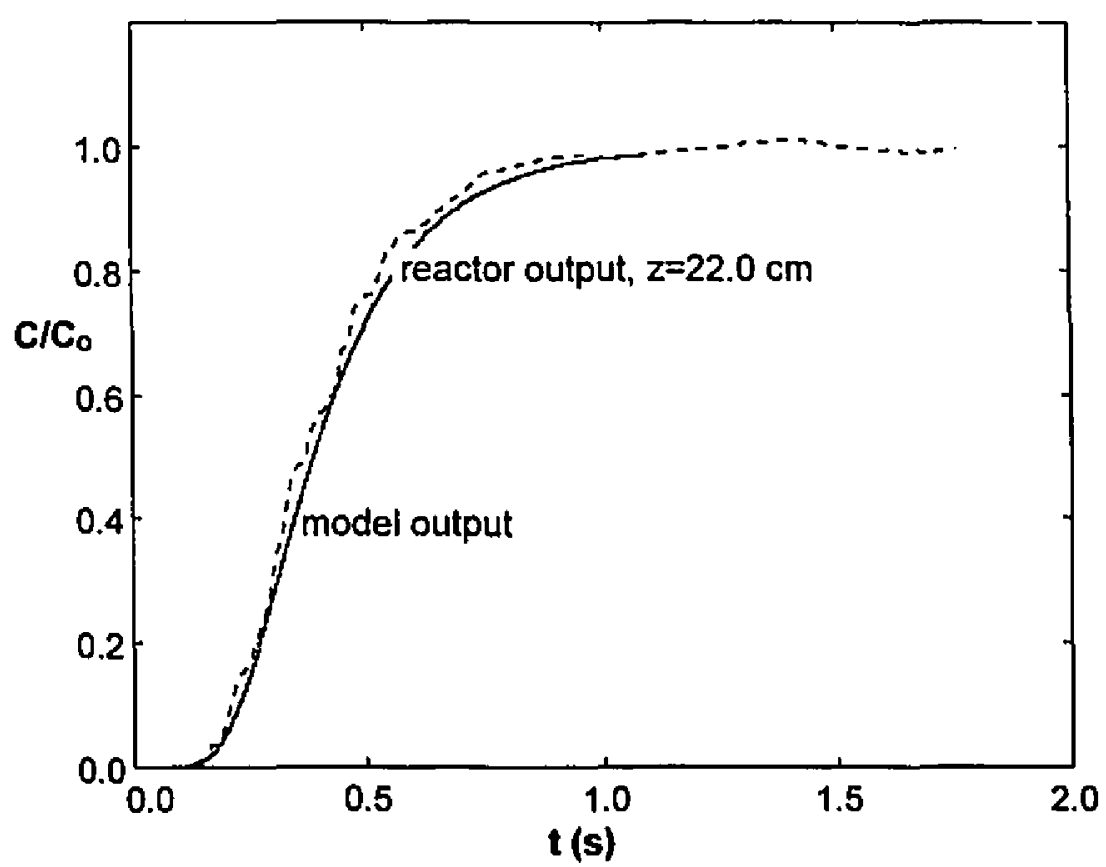

Figure C.1 Reactor output data with the differential equation axial dispersion model - carrier gas: $N_{2}, v_{\text {jet: }}: 38.2 \mathrm{~m} / \mathrm{s}, z_{\text {in }}=7.6 \mathrm{~cm}, z_{\text {oul }}=22.0 \mathrm{~cm}$, $D_{z}=0.0135 \mathrm{~m}^{2} / \mathrm{s}$. 


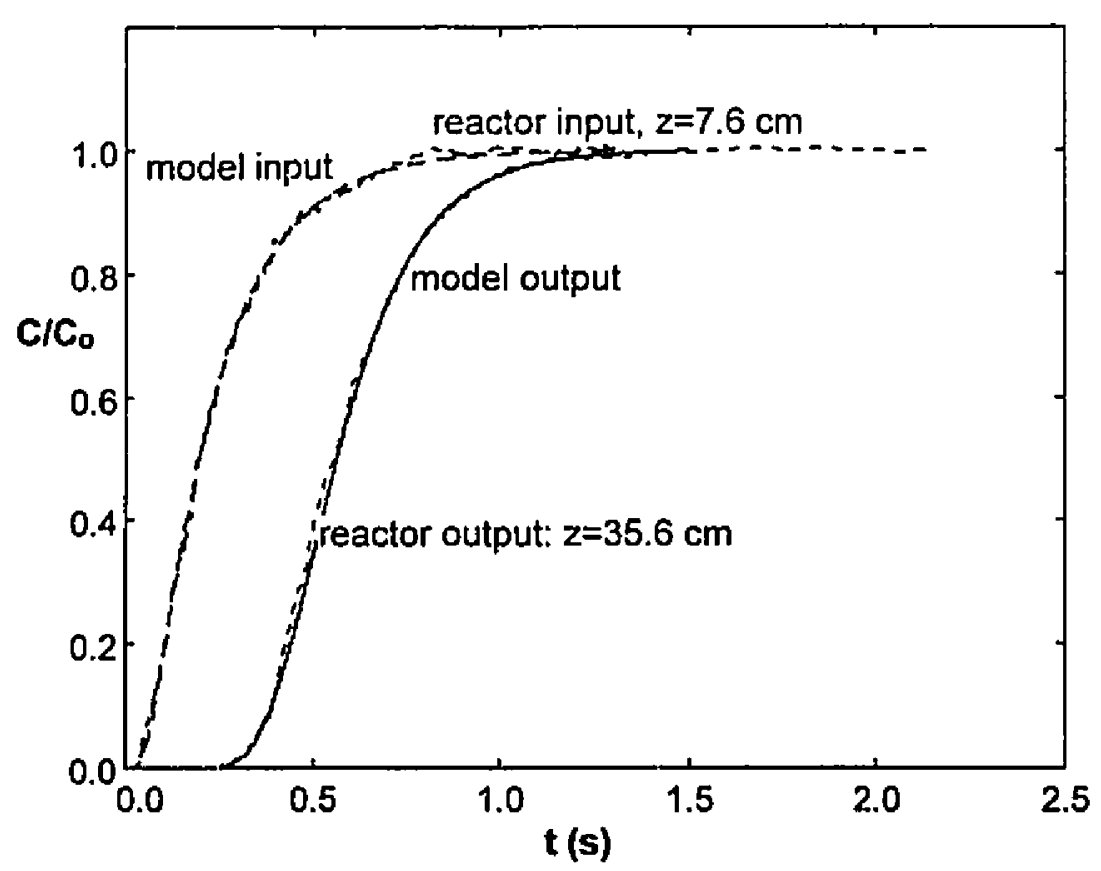

Figure C.2 Reactor in' lit and output data with the differential equation axial dispersion mudel - carrier gas: $N_{2}, v_{\text {jet }}: 38.2 \mathrm{~m} / \mathrm{s}, z_{\text {in }}=7.6 \mathrm{~cm}$, $\mathrm{z}_{\text {out }}=35.6 \mathrm{~cm}, \mathrm{D}_{2}=0.0090 \mathrm{~m}^{2} / \mathrm{s}$.

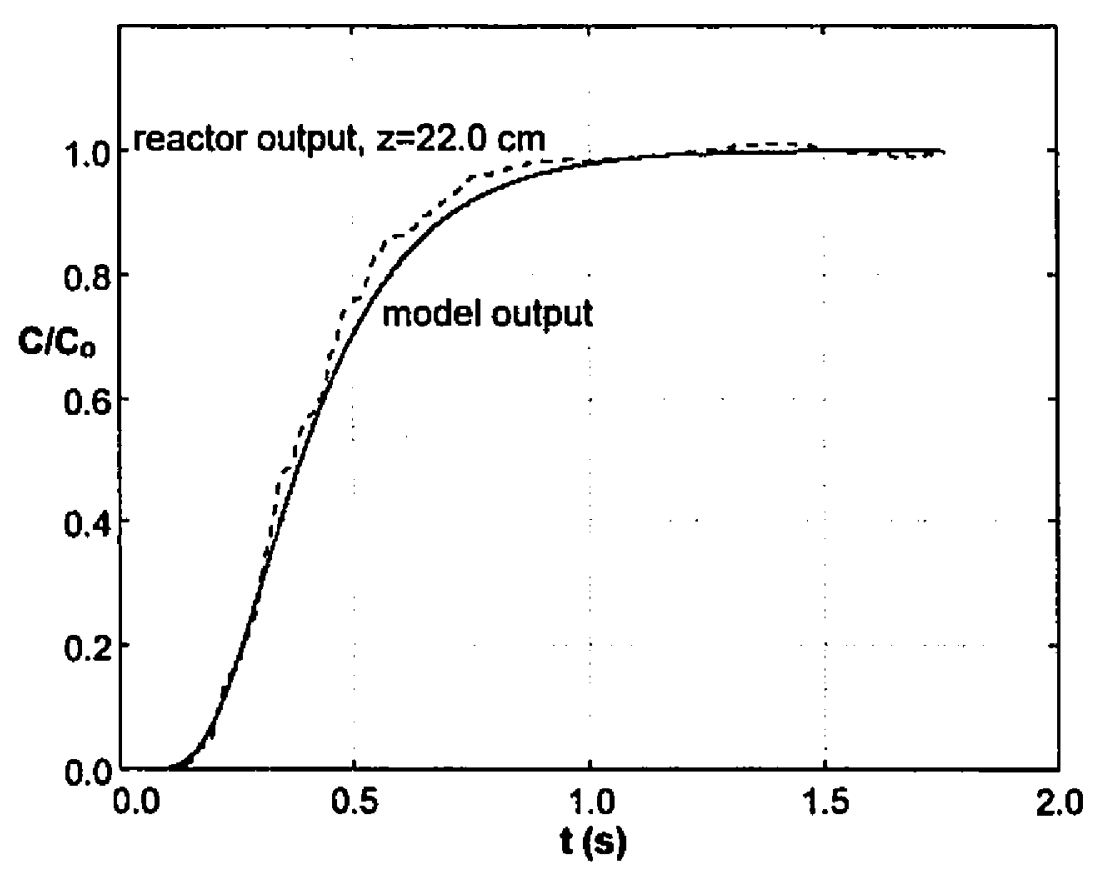

Figure C.3 Reactor output data with the statistical axial dispersion model carrier gas: $N_{2}, v_{j e t}: 38.2 \mathrm{~m} / \mathrm{s}, z_{\text {in }}=7.6 \mathrm{~cm}, z_{\text {out }}=22.0 \mathrm{~cm}, D_{2}=0.0250$ $\mathrm{m}^{2} / \mathrm{s}$. 


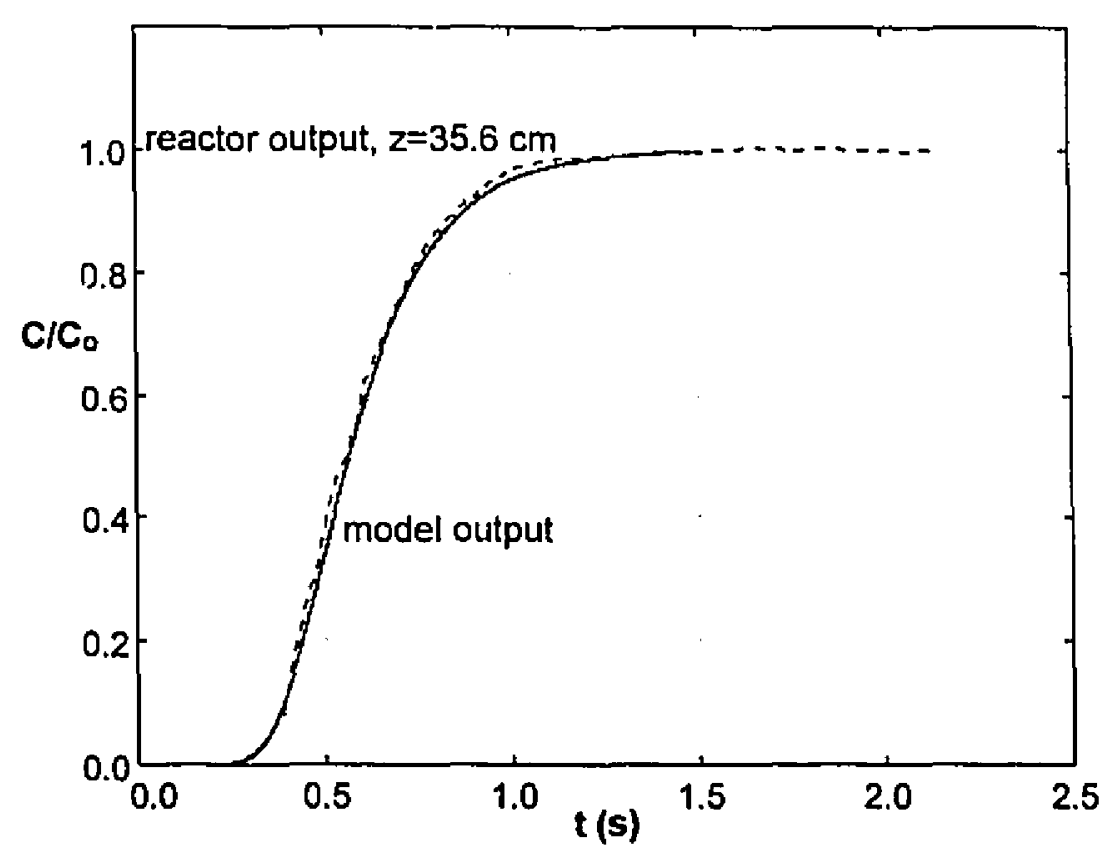

Figure C.4 Reactor output data with the statistical axial dispersion model carrier gas: $N_{2}, v_{\text {jet: }} 38.2 \mathrm{~m} / \mathrm{s}, z_{\text {in }}=7.6 \mathrm{~cm}, z_{\text {out }}=35.6 \mathrm{~cm}, D_{Z}=0.0083$ $\mathrm{m}^{2} / \mathrm{s}$.

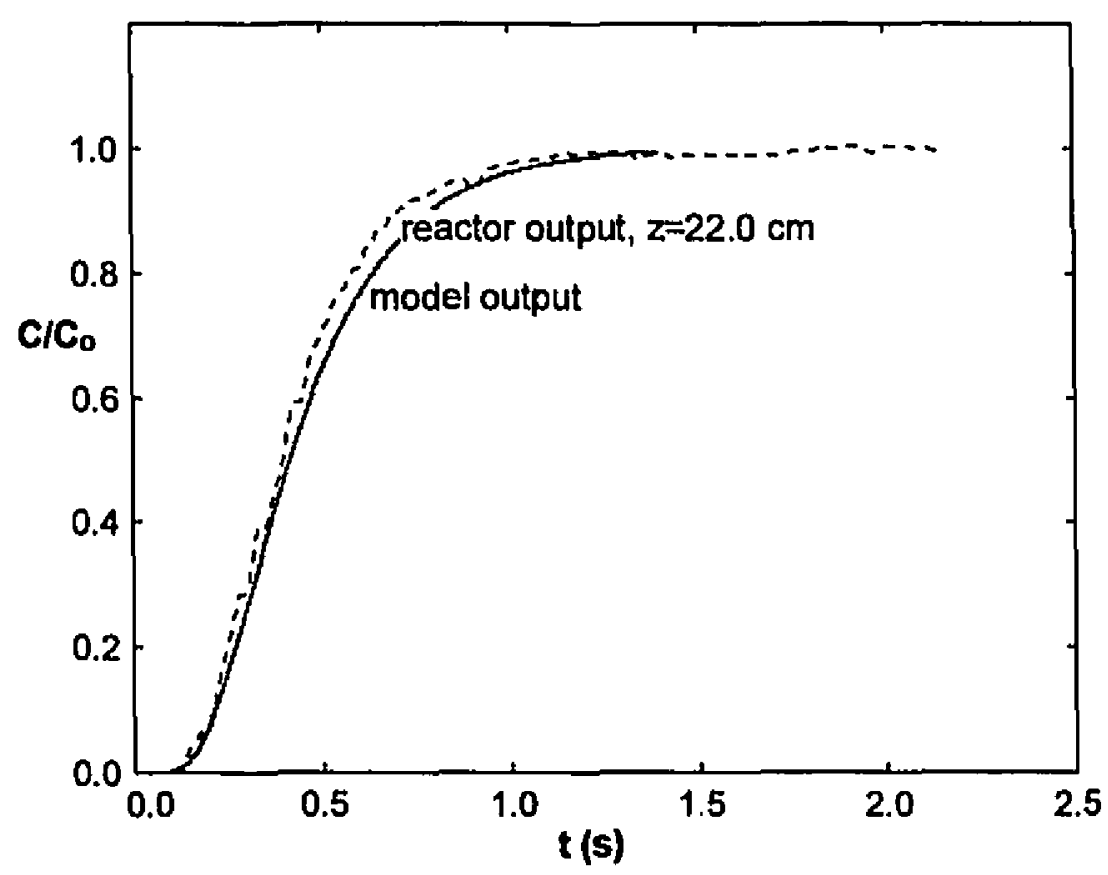

Figure C.5 Reactor output data with the differential equation axial dispersion model - carrier gas: He, $v_{\text {jel }}: 37.5 \mathrm{~m} / \mathrm{s}, z_{\text {in }}=7.6 \mathrm{~cm}, z_{\text {out }}=22.0 \mathrm{~cm}$, $D_{Z}=0.0360 \mathrm{~m}^{2} / \mathrm{s}$. 


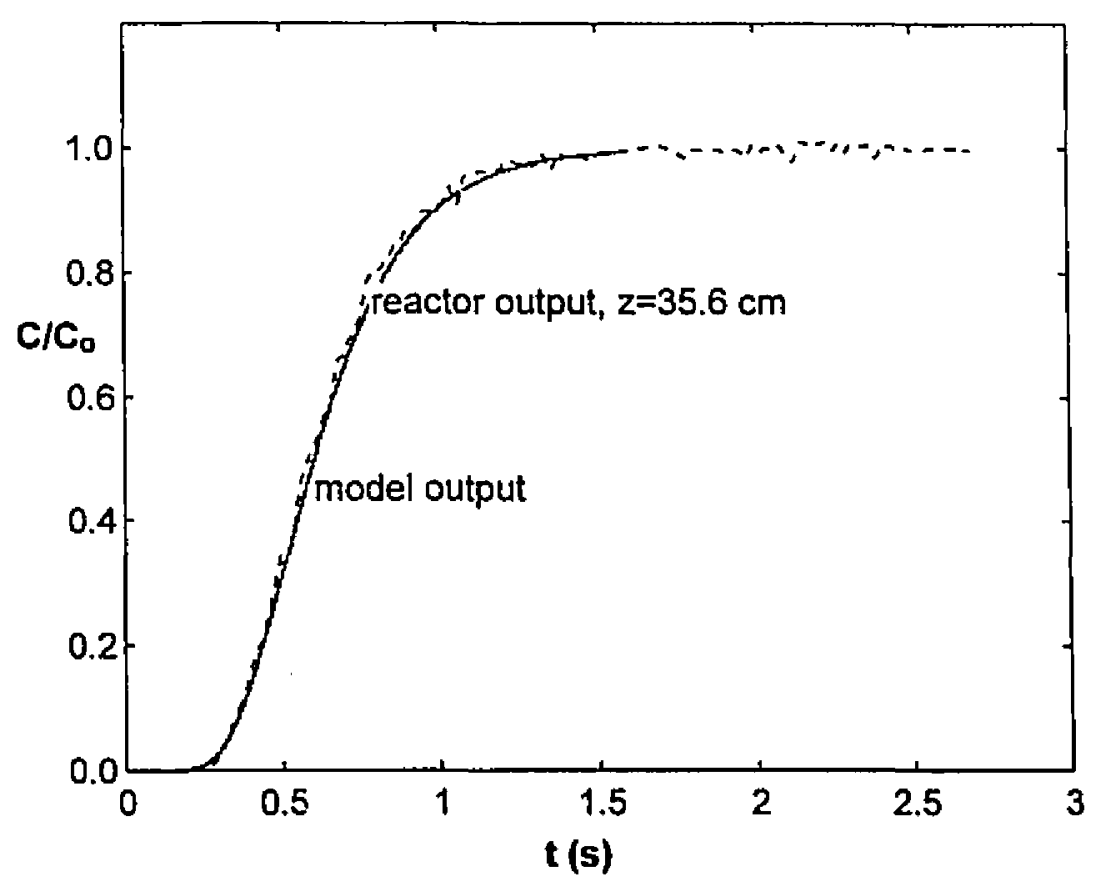

Figure C.6 Reactor output data with the differential equation axial dispersion model - carrier gas: $\mathrm{He}, v_{\mathrm{jet}}: 37.5 \mathrm{~m} / \mathrm{s}, \mathrm{z}_{\mathrm{in}}=7.6 \mathrm{~cm}, \mathrm{z}_{\text {out }}=35.6 \mathrm{~cm}$, $\mathrm{D}_{\mathrm{z}}=0.0210 \mathrm{~m}^{2} / \mathrm{s}$.

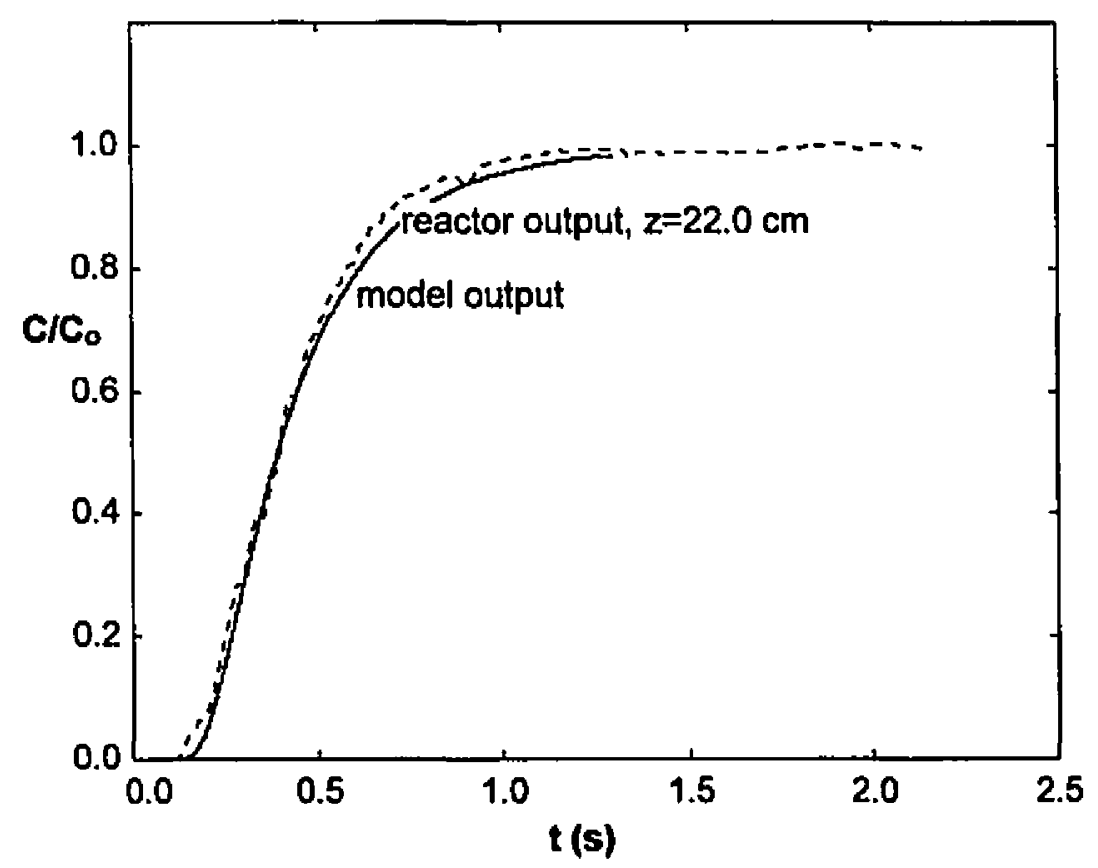

Figure C.7 Reactor output data with the plug flow + laminar flow model carrier gas: $\mathrm{He}, v_{\text {jet: }}: 37.5 \mathrm{~m} / \mathrm{s}, z_{\text {in }}=7.6 \mathrm{~cm}, z_{\text {out }}=22.0 \mathrm{~cm}, L_{L F R}=0.144$ $m, L_{P F R}=0 \mathrm{~m}$. 


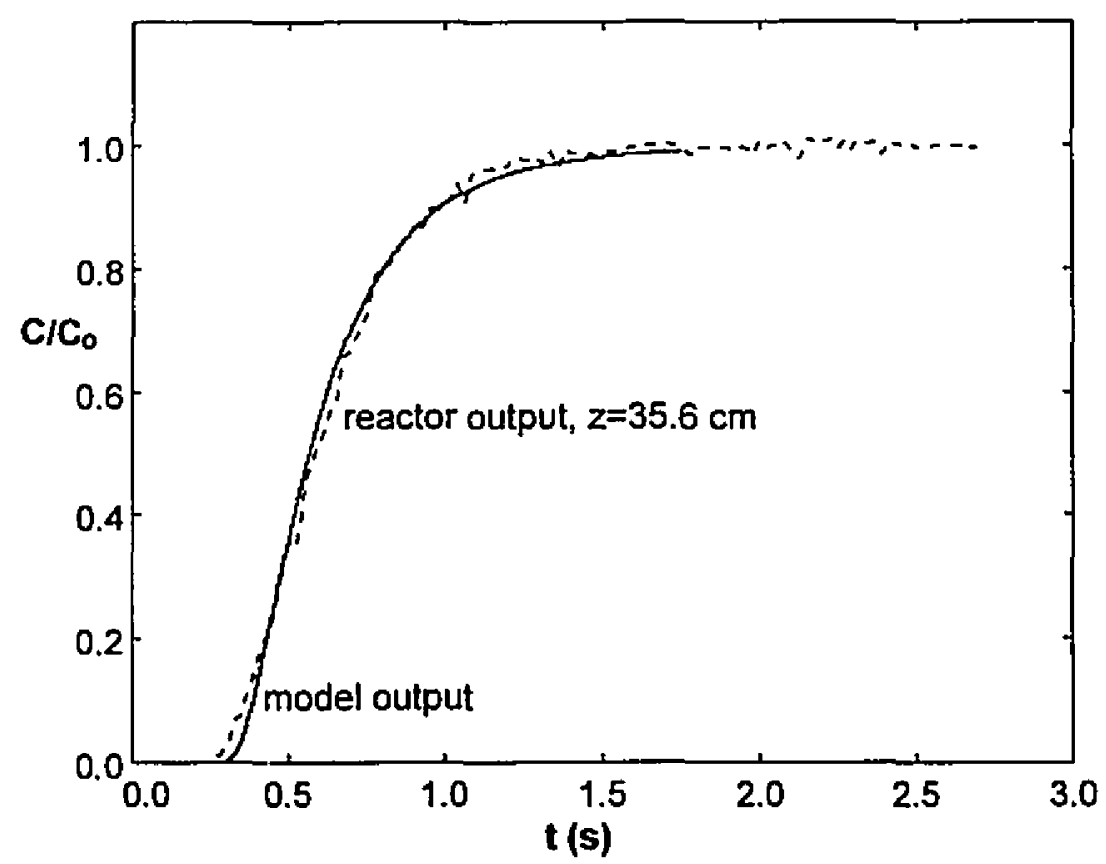

Figure C.8 Reactor output data with the plug flow + laminar flow model carrier gas: $\mathrm{He}, v_{\mathrm{jet}}: 37.5 \mathrm{~m} / \mathrm{s}, \mathrm{z}_{\mathrm{in}}=7.6 \mathrm{~cm}, \mathrm{z}_{\mathrm{out}}=35.6 \mathrm{~cm}, \mathrm{~L}_{\mathrm{LFR}}=0.180$ $\mathrm{m}$, LPFR $=0.100 \mathrm{~m}$. 